ANTÔNIO CARLOS BASTOS DE GODÓI

DETECÇÃO DE POTENCIAIS EVOCADOS P300 PARA ATIVAÇÃO DE UMA INTERFACE CÉREBRO-MÁQUINA 
ANTÔNIO CARLOS BASTOS DE GODÓI

\title{
DETECÇÃO DE POTENCIAIS EVOCADOS P300 PARA ATIVAÇÃO DE UMA INTERFACE CÉREBRO-MÁQUINA
}

\author{
Dissertação apresentada à Escola \\ Politécnica da Universidade de São \\ Paulo para obtenção do título de \\ Mestre em Engenharia
}


ANTÔNIO CARLOS BASTOS DE GODÓI

\title{
DETECÇÃO DE POTENCIAIS EVOCADOS P300 PARA ATIVAÇÃO DE UMA INTERFACE CÉREBRO-MÁQUINA
}

\author{
Dissertação apresentada à Escola \\ Politécnica da Universidade de São \\ Paulo para obtenção do título de \\ Mestre em Engenharia
}

Área de Concentração:

Sistemas Eletrônicos

Orientador: Prof. Dr. Francisco Javier Ramírez Fernández 


\section{FICHA CATALOGRÁFICA}

Godoi, Antonio Carlos Bastos de

Detecção de potenciais evocados P300 para ativação de uma interface cérebro-máquina / A.C.B. de Godoi. -- São Paulo, 2010. $112 \mathrm{p}$.

Dissertação (Mestrado) - Escola Politécnica da Universidade de São Paulo. Departamento de Engenharia de Sistemas Eletrônicos.

1.Interface homem-computador 2.Sinais biomédicos 3.Processamento de sinais biomédicos 4.Engenharia de reabilitação I.Universidade de São Paulo. Escola Politécnica. Departamento de Engenharia de Sistemas Eletrônicos II.t. 


\section{DEDICATÓRIA}

À memória do meu avô Antônio, cujas lembranças remetem à minha descoberta da acepção da palavra amor. 


\section{AGRADECIMENTOS}

Ao amigo e orientador, Professor-Doutor Francisco Javier Ramírez-Fernández, cujos conselhos e persistência foram indispensáveis para a conclusão desta dissertação.

Aos Professores-Doutores João Francisco Justo Filho e Gerson Ballester pelas sugestões de melhorias oferecidas durante o exame de qualificação.

À minha família pela contribuição inestimável nos momentos difíceis.

A todos os funcionários da Universidade de São Paulo, entidade pública que proporcionou os meios para que este trabalho fosse realizado. 


\section{RESUMO}

Interfaces cérebro-computador ou Interfaces cérebro-máquina (BCls/BMls do inglês Brain-computer interface/Brain-machine interface) são dispositivos que permitem ao usuário interagir com o ambiente ao seu redor sem que seja necessário ativar seus músculos esqueléticos. Estes dispositivos são de extrema valia para indivíduos portadores de deficiências motoras. Esta dissertação ambiciona revisar a literatura acerca de BMls e expor diferentes técnicas de pré-processamento, extração de características e classificação de sinais neurofisiológicos. Em particular, uma maior ênfase será dada à Máquina de vetor de suporte (SVM do inglês Support-Vector machine), método de classificação baseado no princípio da minimização do risco estrutural. Será apresentado um estudo de caso, que ilustra o funcionamento de uma BMI, a qual permite ao usuário escolher um dentre seis objetos mostrados em uma tela de computador. Esta capacidade da BMI é conseqüência da implementação, através da SVM de um sistema capaz de detectar o potencial evocado P300 nos sinais de eletroencefalograma (EEG). A simulação será realizada em Matlab usando, como sinais de entrada, amostras de EEG de quatro indivíduos saudáveis e quatro deficientes. A análise estatística mostrou que 0 bom desempenho obtido pela BMI $(80,73 \%$ de acerto em média) foi promovido pela aplicação da média coerente aos sinais, o que melhorou a relação sinal-ruído do EEG.

Palavras-chave: Interface cérebro-computador. BCI. Interface cérebro-máquina. BMI. P300. Máquina de vetor de suporte. SVM. Tecnologia assistiva. 


\begin{abstract}
Brain-computer interfaces (BCl's) or Brain-machine interfaces (BMl's) technology provide users with the ability to communicate and control their environment without employing normal output pathway of peripheral nerves and muscles. This technology can be especially valuable for highly paralyzed patients. This thesis reviews BMI research, techniques for preprocessing, feature extracting and classifying neurophysiological signals. In particular, emphasis will be given to Support-Vector Machine (SVM), a classification technique, which is based on structural risk minimization. Additionally, a case study will illustrate the working principles of a BMI which analyzes electroencephalographic signals in the time domain as means to decide which one of the six images shown on a computer screen the user chose. The images were selected according to a scenario where users can control six electrical appliances via a BMI system. This was done by exploiting the Support-Vector Machine ability to recognize a specific EEG pattern (the so-called P300). The study was conducted offline within the Matlab environment and used EEG datasets recorded from four disabled and four able-bodied subjects. A statistical survey of the results has shown that the good performance attained $(80,73 \%)$ was due to signal averaging method, which enhanced EEG signal-to-noise ratio.
\end{abstract}

Keywords: Brain-computer interface. BCl. Brain-machine interface. BMI. P300. Support-Vector Machine. SVM. Assistive technology. AT. 


\section{LISTA DE ABREVIATURAS E SIGLAS}

\begin{tabular}{ll} 
AAR & Adaptive Autoregressive \\
ANN & Artificial Neural Network \\
AR & Autoregressive \\
BCI & Brain-Computer Interface \\
BMI & Brain-Machine Interface \\
BOLD & Blood Oxygen Level Dependent \\
BSS & Separação Cega de Fontes \\
CBI & Computer-Brain Interface \\
CAR & Common Average Reference \\
CSP & Common Spatial Pattern \\
DFT & Transformada Discreta de Fourier \\
ECoG & Eletrocorticografia \\
EEG & Eletroencefalografia \\
EP & Error Potential \\
EP & Evoked Potential \\
EPFL & Ecole Polytechnique Fédérale de Lausanne \\
ERD & Event-related Desynchronization \\
ERF & Campos Evocados \\
ERP & Potenciais Evocados \\
ERS & Event-related Synchronization \\
FFT & Transformada Rápida de Fourier \\
FIR & Finite Impulse Response \\
fMRI & Imagens por Ressonância Magnética Funcional \\
HMM & Hidden Markov Model \\
ICA & Análise de Componentes Independentes \\
IIR & Infinite Impulse Response \\
kNN & k-Nearest Neighbors \\
LFP & Potenciais de Campos Locais \\
ME & Micro-eletrodos \\
\hline MEA & Cade Micro-eletrodos \\
\hline
\end{tabular}




$\begin{array}{ll}\text { MEG } & \text { Magnetoencefalografia } \\ \text { NIRS } & \text { Espectroscopia de Infravermelho Próximo } \\ \text { RBF } & \text { Radial Basis Function } \\ \text { RP } & \text { Readiness Potential } \\ \text { SCP } & \text { Potenciais Corticais Lentos } \\ \text { SL } & \text { Superfície Laplaciana } \\ \text { SSEP } & \text { Potencial Evocado Sustentado } \\ \text { SSVEP } & \text { Potencial Evocado Visual Sustentado } \\ \text { STFT } & \text { Short-Time Fourier Transform } \\ \text { SVM } & \text { Máquina de Vetor de Suporte }\end{array}$




\section{SUMÁRIO}

1 Introdução.

2 Interfaces Cérebro-máquina

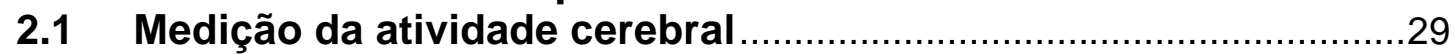

2.1.1 Eletroencefalograma (EEG) ………...................................29

2.1.2 Eletrocorticografia (ECoG) ....................................................

2.1.3 Cadeias de micro-eletrodos (MEA) (Micro Electrode Arrays) .......32

2.1.4 Magnetoencefalografia (MEG) .................................................32

2.1.5 Imagem por ressonância magnética funcional (fMRI) ...................32

2.1.6 Espectroscopia do infravermelho próximo (NIRS) .........................33

2.2 Sinais neurofisiológicos usados em BMIs ....................................33

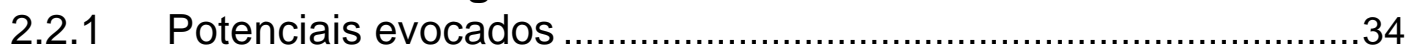

2.2.1.1 Potenciais evocados sustentados (SSEP) ...............................34

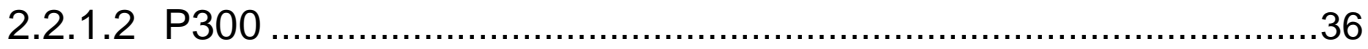

2.2.2 Potenciais espontâneos.............................................................37

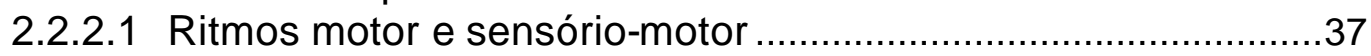

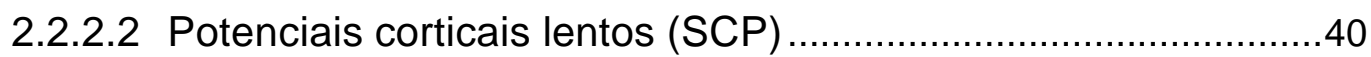

2.2.2.3 Tarefas cognitivas não-motoras .............................................. 41

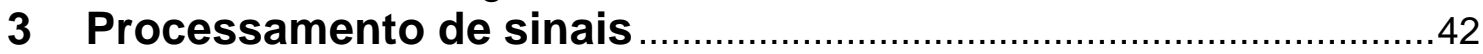

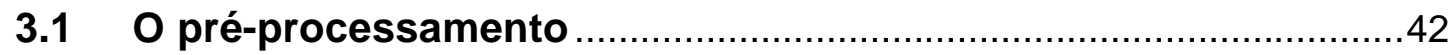

3.1.1 Filtros simples espaciais e temporais........................................

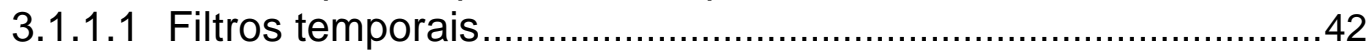

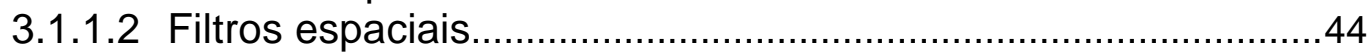

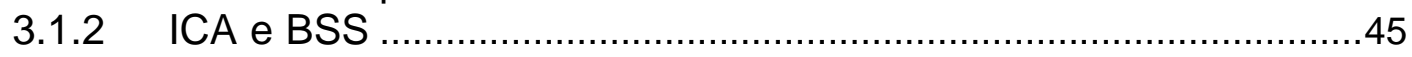

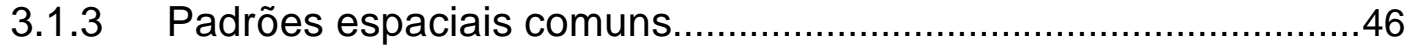

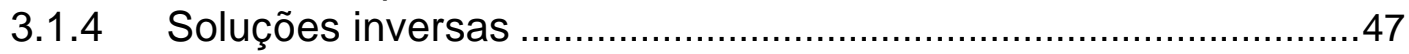

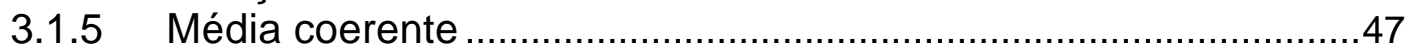

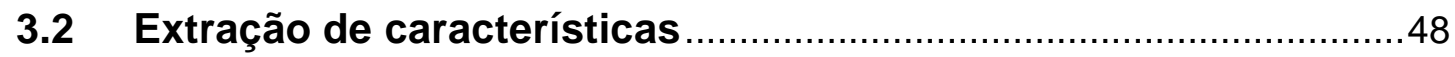

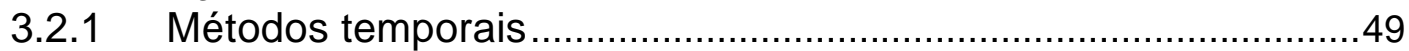

3.2.1.1 Método de amplitude do sinal................................................49

3.2.1.2 Parâmetros auto-regressivos.................................................50

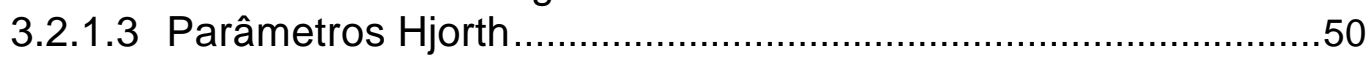

3.2.2 Métodos de freqüência ……......................................................51

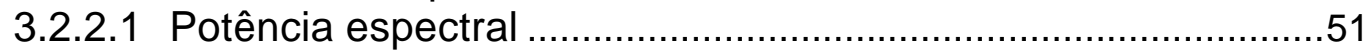

3.2.2.2 Densidade espectral de potência............................................52

3.2.3 Representações tempo-freqüencia ............................................52

3.2.3.1 Transformada janelada de Fourier..........................................52

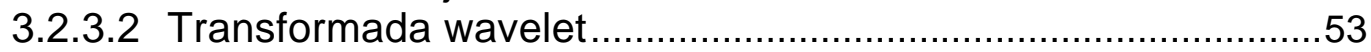

3.2.3.3 Outras representações tempo-freqüência..................................53

3.2.4 Outros métodos de extração de características.............................54

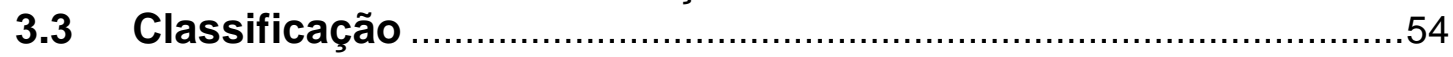

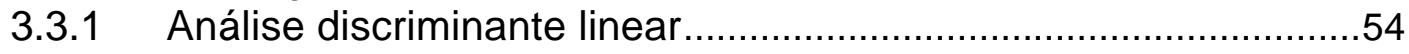

3.3.2 Máquinas de vetor de suporte......................................................55 
3.3.2.1 Hiperplano ótimo de separação para padrões linearmente separáveis

3.3.2.2 Hiperplano ótimo de separação para padrões não-separáveis 58

3.3.2.3 Construção de SVMs para reconhecimento de padrões...........59

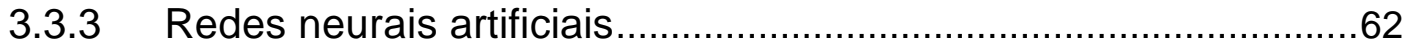

3.3.3.1 O percéptron multicamadas......................................................63

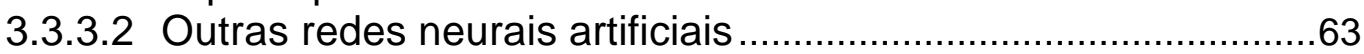

3.3.4 Classificadores Bayesianos não-lineares …………………..........64

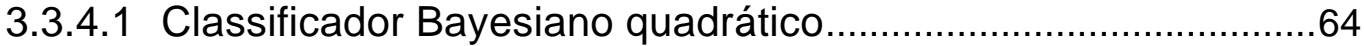

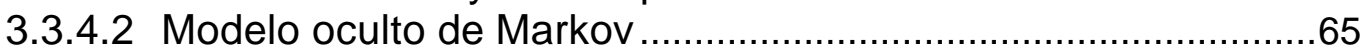

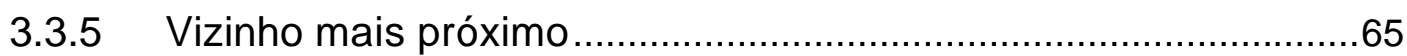

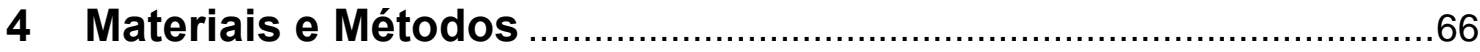

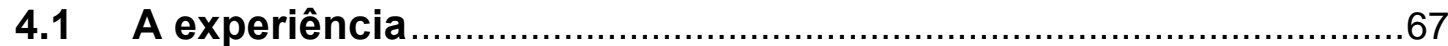

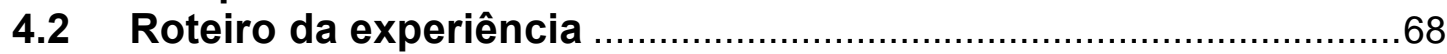

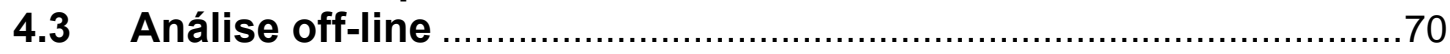

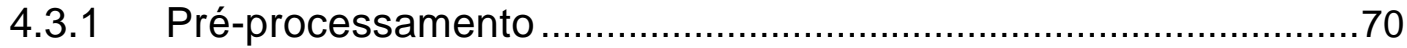

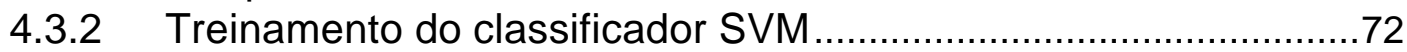

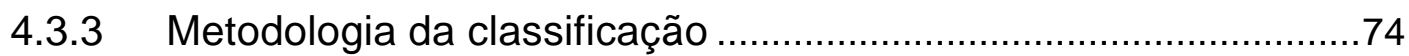

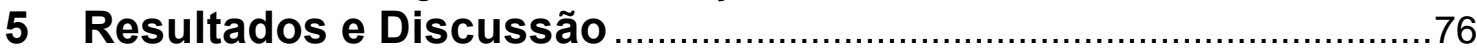

5.1 Obtenção das probabilidades de acerto.......................................76

5.2 Cálculo da taxa de transmissão de informação...............................76

5.3 Gráficos de desempenho .........................................................77

5.3.1 Gráficos de desempenho individual ............................................77

5.3.2 Gráficos de desempenhos médios .............................................79

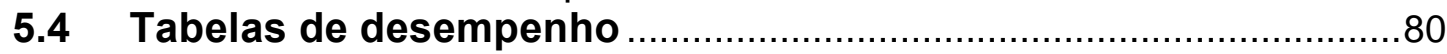

6 Conclusões e propostas para futuros trabalhos ...........................87

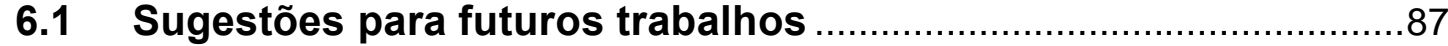

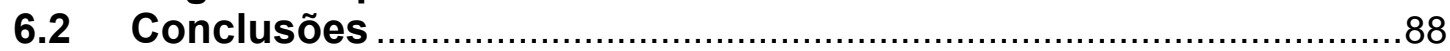

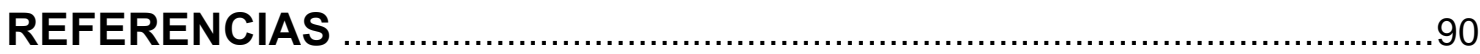

APÊNDICE A - Demonstração do efeito da média coerente.............109 


\section{Introdução}

Entre as habilidades mais importantes que diferencia os seres humanos das outras espécies está a capacidade de comunicar-se. A comunicação na espécie humana se caracteriza por ser a mais rica e complexa atividade de todas já conhecidas e exerce um papel de grande relevância nos relacionamentos interpessoais, na apropriação do conhecimento e no progresso da ciência.

Não podemos transmitir idéias, pensamentos e conceitos diretamente sem fazermos uso da escrita, fala, gesticulação ou sem empregar sinais ou expressões possíveis de serem interpretadas. Embora nem sempre seja devidamente reconhecida, a anatomia humana tem, entre as suas principais funções, servir de interface natural para permitir às pessoas a transmissão de informações. Enviamos mensagens geralmente de forma oral ou escrita, em que as mãos, boca e olhos agem como periféricos controlados pelo cérebro.

Apesar da comunicação entre as pessoas ter sido intensamente desenvolvida e estudada, a comunicação entre indivíduos e dispositivos eletrônicos, em especial, computadores encontra-se em estado embrionário.

Recursos computacionais sofisticados, como gráficos 3-D em tempo real, têm promovido o desenvolvimento de ambientes virtuais complexos, nos quais o usuário está sujeito a uma grande quantidade de informação. Nestes ambientes as formas convencionais de interação com a máquina mostram-se lentas e pouco eficientes. As estratégias de mitigação destes problemas abrangem a adoção de dispositivos que oferecem melhor visualização das imagens e interfaces capazes de reconhecer fala, escrita, expressões faciais, etc.

Com o aumento da compreensão do funcionamento cerebral e melhoria da tecnologia de aquisição não-invasiva de sinais neurológicos vislumbra-se a elaboração de interfaces mais eficientes, capazes de transmitir informação diretamente do cérebro para o computador: a $\mathrm{BCl}$ (do inglês Brain-Computer Interface) ou BMI (Brain-Machine Interface). Este novo artifício de comunicação requer o uso de algum dispositivo que traduza a atividade cerebral em sinais elétricos que irão alimentar uma entrada de computador. 
Esta dissertação explora diferentes técnicas de extração de características e reconhecimento de padrões em sinais elétricos resultantes de atividade cerebral, as quais podem ser usadas na construção de uma interface de comunicação cérebromáquina. São objetivos do presente trabalho:

- Contribuir para o aperfeiçoamento de interfaces cérebro-máquina;

- Descrever princípios de processamento de sinais com vistas ao desenvolvimento de BMIs;

- Ilustrar com um estudo de caso a concepção de uma interface cérebromáquina, que utiliza determinados paradigma e algoritmo de funcionamento.

Nesta dissertação será usada a conceituação de interface cérebro máquina definida por Wolpaw: "BCl é um sistema de comunicação, no qual mensagens ou comandos enviados pelo individuo não percorrem as vias convencionais do cérebro para os nervos periféricos e músculos." (WOLPAW et al., 2002, p. 769, tradução nossa)

Embora o sentido formal da palavra interface faça alusão a um tipo de comunicação bidirecional, a sigla $\mathrm{BCl}$ tem sido adotada na literatura com caráter de transmissão unidirecional de informação: do cérebro para o computador. O termo CBI (do inglês Computer-Brain Interface) é genericamente eleito para designar o tipo de comunicação em sentido oposto: do computador para o cérebro (KÖNIG; VERSCHURE, 2002). Do mesmo modo, muitas interfaces comumente usadas, como teclado e mouse, transmitem informações em apenas uma direção.

Pesquisas em neurociência cognitiva têm obtido êxito na melhoria da compreensão do cérebro e seu código neural, que são as regras que regulam como as informações são representadas pelos neurônios. Apesar de estarmos muito distantes de decifrar completamente o código neural, já se conhecem as relações entre importantes estados cognitivos e suas respectivas ativações neurais. Isto tem promovido o desenvolvimento, nos últimos anos, de BMls cada vez mais sofisticadas, que permitem desde a realização de tarefas simples como mover uma cadeira de rodas até controlar os próprios padrões de ativação cerebral.

A mídia tem tornado públicos alguns resultados extraordinários conseguidos através de BMls como, por exemplo, o mostrado por Kübler et al. (2005), em que quatro pacientes em estado avançado de esclerose lateral amiotrófica aprenderam a controlar uma BMI através da modulação voluntária de seus ritmos cerebrais; o 
mostrado por Velliste et al. (2008), no qual macacos (Macaca Mulatta) conseguiram, após treinamento, controlar um braço robótico multi-articulado (NICOLELIS, 2003); e, mais recentemente, a experiência de Monti et al. (2010) que revelou ser possível a cinco pacientes em estado vegetativo comunicarem-se com o mundo externo através do uso de uma BMI.

Para melhor discutir os aspectos mais relevantes de uma BMI usaremos a estrutura mostrada na figura 1.1, chamada de ciclo BCl (GERVEN et al., 2009). O ciclo $\mathrm{BCl}$ tem inicio no usuário, que realiza uma tarefa cognitiva e aguarda um possível estímulo. Os sensores registram a atividade cerebral que passa pelas fases de pré-processamento e extração de características. Em seguida, uma saída é computada. Esta saída, que pode ser contínua ou discreta, deve representar a escolha mental do indivíduo e pode, eventualmente, ativar um dispositivo remoto. $\mathrm{O}$ ciclo termina com o usuário percebendo o resultado da sua tarefa mental. Interagindo ao longo deste ciclo, homem e máquina podem adaptar-se, aumentando a eficiência do funcionamento da máquina.

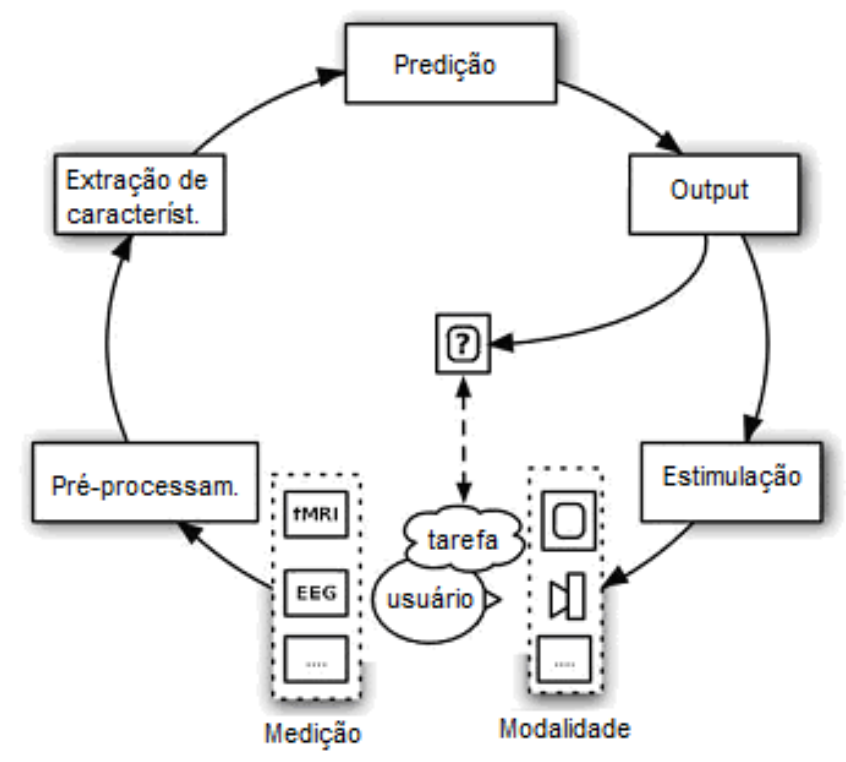

Figura 1.1 - Ciclo BCl (adaptado de GERVEN et al., (2009))

A interface cérebro-máquina ideal deve exigir esforço mental que não cause fadiga, gerar saídas com grande relação sinal-ruído, isto é, que possam ser facilmente reconhecidas, e requerer um nível não muito elevado de controle mental. 
Até onde chega nosso conhecimento, ainda não existe tão perfeita interface, capaz de atender a todos estes requisitos. Freqüentemente a operação de uma interface cérebro-máquina requer significativo esforço mental (CURRAN; STOKES, 2003). Além disso, apesar de certos estudos sugerirem que alguns indivíduos possam operar uma BMI com esforço reduzido (MINER; MCFARLAND; WOLPAW, 1998), eles inevitavelmente acabam tendo de empregar maior concentração nas ocasiões em que a tarefa deixa de ser automática. (CURRAN; STOKES, 2003)

Para transmitir caracteres ou símbolos é necessário que a BMI possa reconhecer as escolhas mentais do usuário. A primeira BMI concebida com este propósito serviu-se da capacidade do indivíduo modular voluntariamente seus padrões de atividade cerebral. Em um trabalho deste tipo Birbaumer et al. (1999) conseguiram que pacientes paralíticos, após longas sessões de treinamento, movimentassem um cursor na tela de um computador, por meio da alteração voluntária de potenciais corticais lentos. Em outro trabalho mais recente Pineda et al. (2003) conceberam um experimento de neuro-realimentação (neurofeedback), no qual os indivíduos eram treinados para controlar seus ritmos mu, e conseguiam mover um personagem virtual através da modulação da potência do seus respectivos sinais cerebrais.

Entretanto, os paradigmas de uso das BMls citados exigem longos treinamentos e, além disso, não são eficazes para todas as pessoas, conforme discutido por Birbaumer (2006a). Essas limitações motivaram a procura por outras abordagens, como a realização de tarefas cognitivas para controlar o funcionamento das BMI. Estas tarefas podem ser perceptivas, como de atenção seletiva, de movimentos ou percepções imaginários, ou de mais alto nível, tais como as que exigem a realização de cálculos matemáticos e outras operações sofisticadas. Nos paradigmas de atenção seletiva o indivíduo deve dirigir a sua concentração para um dos estímulos que são concebidos seqüencial ou simultaneamente. Os estímulos podem ser abstratos, como no caso do trabalho de Gerven e Jensen (2009), no qual, os indivíduos deveriam imaginar uma dentre quatro direções possíveis: cima, baixo, esquerda e direita. Farwell e Donchin (1988) usaram o paradigma de atenção seletiva concreta, em que, o sujeito deveria direcionar sua atenção a um determinado símbolo que iria piscar aleatoriamente na tela de um computador numa matriz $6 \times 6$ de símbolos. 
Dentre as tarefas imaginárias, a de movimento é atualmente a mais usual (CURRAN; STOKES, 2003). Outras tarefas imaginárias incluem as visuais (KEIRN; AUNON, 1990), de navegação mental (CABRERA; DREMSTRUP, 2008) e musicais (CABRERA; DREMSTRUP, 2008; CURRAN et al., 2003; DE KRUIF; SCHAEFER; DESAIN, 2007; SCHAEFER et al., 2008).

Tarefas cognitivas de alto nível, tais como associações de palavras e operações aritméticas geralmente são aplicadas em paradigmas nos quais estão presentes diferentes modalidades de tarefas mentais, como em Keirn e Auron (1990) e Sepulveda et al., (2007).

BMls que usam paradigmas síncronos são mais simples de fazer, contudo são menos intuitivas que aquelas que são dotadas de paradigmas assíncronos, pois estas não dependem de um estímulo externo e podem ser ativadas em qualquer momento.

A diversidade de tarefas mentais que se poderia aplicar a BMls ainda é desconhecida. Especula-se que o pensamento em palavras seria o paradigma de comunicação mais direto e que mais se aproxima de uma leitura cerebral imediata. Em sendo possível, uma segunda questão que se levanta refere-se ao nível de abstração que poderia ser reconhecido (como semântico, léxico, de timbre, etc ). Um estudo recente, em que se usou imagens de ressonância magnética funcional, sugeriu que há possibilidade disso ocorrer no futuro (FORMISANO, 2008).

Existem dois tipos de aquisição de sinais para BMls: invasivo e não-invasivo. A figura 1.2 apresenta diversos métodos e relaciona as suas resoluções temporais e espaciais. Duas das formas não-invasivas: Magnetoencefalografia (MEG) e Eletroencefalografia (EEG) medem a atividade média das correntes dendríticas em um grande conjunto de células nervosas. As suas resoluções temporais são elevadas, isto é, conseguem identificar variações em um curto intervalo de tempo, contudo suas resoluções especiais são ruins e não se consegue identificar com precisão os locais de ativação das fontes. A resolução espacial pobre deve-se à mistura de correntes elétricas geradas em diferentes áreas corticais, e que atravessam os tecidos cerebrais, os ossos e o couro cabeludo. Além disso, o EEG e - MEG são susceptíveis a artefatos provenientes dos músculos e movimentos oculares. 


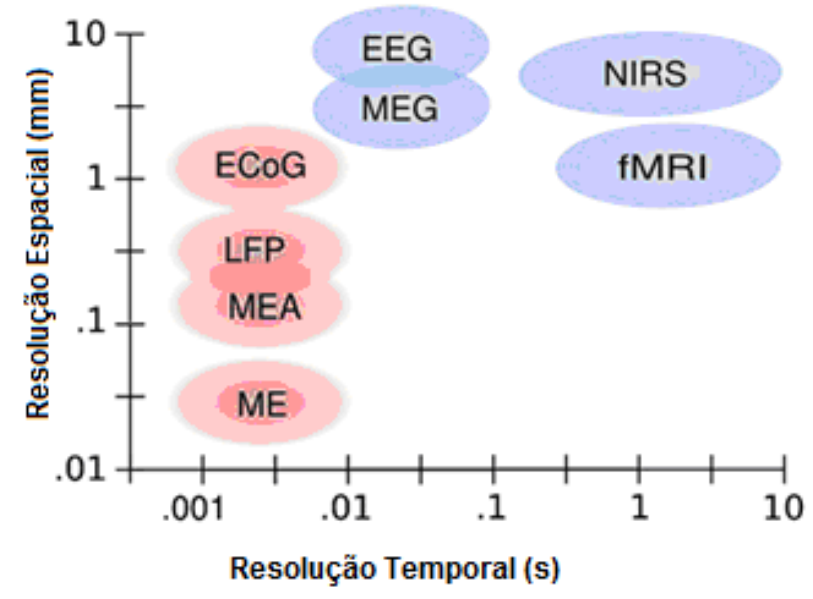

Figura 1.2 - Resoluções dos Métodos de Medida (adaptado de GERVEN et al., (2009))

Alguns trabalhos usaram imagens por ressonância magnética funcional (fMRI do inglês functional Magnetic Ressonance Imaging) para ativar BMIs (CARIA, 2007; HINTERBERGER, 2005; WEISKOPF, 2004). A fMRI detecta mudanças nas concentrações de hemoglobina, associadas às atividades neurais. A técnica da fMRI permite uma resolução espacial superior àquelas conseguidas por EEG e MEG, contudo padece de uma resolução temporal baixa, o que limita a banda de transmissão de informações de BMls que usam fMRI. A espectroscopia de infravermelho próximo (NIRS do inglês Near-infrared Spectroscopy) também é uma técnica de medição não-invasiva, que se baseia nas diferenças de ressonância das hemoglobinas oxigenadas e desoxigenadas para detectar atividade cerebral. A NIRS representa uma alternativa portátil e mais econômica à fMRI, e permite a utilização de BMIs mesmo com o usuário em movimento. O trabalho de Sitaram (2007) foi um dos primeiros a usar a técnica NIRS na aquisição de sinais para uma BMI. Contudo, o alcance da NIRS é limitado ao tecido cortical o que a torna uma técnica de menor resolução espacial que a fMRI, que pode detectar atividade em regiões cerebrais mais profundas. Além disso, a NIRS apresenta uma resolução temporal limitada e próxima a da fMRI.

Embora seu uso exija cautela (WOLPAW, 2007), as técnicas de medição invasiva apresentam resoluções espaciais e temporais muito superiores às demais. Este tipo de técnica requer a implantação de eletrodos sobre ou no neocórtex (CARMENA et al., 2003; NICOLELIS, 2003; SCHWARTZ, 2006). Foram experiências realizadas em macacos (FETZ, 1969) que em 1969 mostraram a 
viabilidade de se usar impulsos elétricos cerebrais em BMls. A eletrocorticografia (ECoG) é uma técnica invasiva e oferece altas definições temporal e espacial, produz uma boa relação sinal-ruído e tem ótima sensibilidade a sinais oscilatórios de altas freqüências (LEUTHARDT, 2004; MILLER et al., 2007; RAMSEY, 2006; SCHALK et al., 2008). A ECoG é muito usada, através da implantação de eletrodos em regiões subdurais, para localizar focos de epilepsia no cérebro. Como alternativas à ECoG a Microeletrônica possibilita a fabricação de micro-eletrodos (ME) e a cadeia de micro-eletrodos (MEA do inglês Micro-electrode Array), que consistem em muitos eletrodos (até várias centenas) implantados no cérebro. Estes eletrodos podem registrar a atividade de apenas um neurônio, de pequenos grupos de neurônios ou de potenciais de campos locais (LFPs do inglês Local Field Potentials). Esta técnica foi usada inicialmente em macacos (MUSALLAM et al., 2004; VELLISTE et al., 2008) e também teve sucesso posterior em experiências com seres humanos (HOCHBERG, 2006). Embora tenham obtido algum sucesso, as técnicas invasivas de BMls estão longe de se tornar habituais, pois além dos riscos inerentes à operação ainda existem dificuldades na manutenção dos contatos dos eletrodos, o que exige que um corpo de especialistas trabalhe diariamente no sistema.

Apesar das suas limitações, as técnicas de análise de EEGs vêm mostrandose bastante eficazes no desenvolvimento de ferramentas muito práticas e úteis para as pesquisas experimentais. Comparadas às demais técnicas de medição de atividades neurais, são simples, fáceis de preparar, baratas e exigem pouco conhecimento por parte do usuário. Além disso, os equipamentos necessários podem ser portáteis e funcionam em ambientes sujeitos a diversos tipos de ruído.

Avanços das técnicas de medição tornaram viável o uso de BMls e o aprimoramento destas tecnologias poderia difundir sua utilização. Poderiam contribuir para isso pesquisas envolvendo biocompatibilidade e tecnologias de transmissão sem fio para dispositivos implantáveis, como a realizada por Schwartz (2004). Outros aprimoramentos como: eletrodos menores, técnicas de medição de maiores resoluções temporal e espacial, além de dispositivos que apresentem maior relação sinal-ruído, poderiam melhorar os desempenhos das BMls.

Para garantir o correto funcionamento de uma BMI é essencial que o sistema seja capaz de reconhecer características do sinal cerebral associadas a determinados estados ou processos mentais, doravante denominados assinaturas. 
Como exemplo comum de assinatura pode-se citar os fusos do sono, que são ondas rítmicas e monomórficas, de 10 a $14 \mathrm{~Hz}$ e que surgem quando o indivíduo dorme. Para a maioria dos processos mentais, entretanto, não se conhecem assinaturas muito robustas. As assinaturas que se mostraram úteis para BMls podem ser classificadas em: respostas evocadas e respostas induzidas. As respostas evocadas são aquelas sincronizadas em tempo e fase com um evento. Assim, o cálculo da média de sinais repetidos fornece um sinal com ruídos atenuados. As respostas induzidas são sincronizadas em potência, dessa forma, as potências em bandas específicas devem ser primeiramente obtidas, antes de se calcular as médias (PFURTSCHELLER; LOPES DA SILVA, 1999). As respostas finais são denominadas Potenciais Evocados (ERP do inglês Event-related Potential) ou Campos Evocados (ERF do inglês Event-related Field) (GAZZANIGA, 2004).

Os potenciais corticais lentos (SCP do inglês Slow Cortical Potentials) (ROCKSTROH, 1989), que são potenciais evocados, foram uns dos primeiros tipos de sinais usados em BMIs (BIRBAUMER, 1999). Contudo, as BMls que adotam os SCPs exigem do usuário longos períodos de treinamento. Além disso, a modulação de SCPs é relativamente lenta, o que limita a velocidade de transmissão de informações da BMI. O potencial evocado mais utilizado em BMls é o P300 (FARWELL; DONCHIN, 1988; SELLERS; DONCHIN, 2006). O P300 surge como um pico no sinal de eletroencefalograma, após aproximadamente $300 \mathrm{~ms}$ da apresentação de um estímulo relevante. O potencial visual evocado P300 tem sido muito usado em BMIs, que permitem ao usuário escolher caracteres de um teclado numa tela de computador e assim poder digitar sem usar as mãos (FARWELL; DONCHIN, 1988). Outro tipo de potencial evocado é o potencial evocado sustentado (SSEP do inglês Steady-state-evoked Potential) (REGAN, 1977). O SSEP aparece como um padrão de ativação neural, ondulatório e periódico que se relaciona a um estímulo visual, auditivo ou somatosensorial. Este estímulo pode ser pseudoaleatório, periódico ou de amplo espectro, como aquele apresentado por Desain (2008). A potência e a fase do sinal mudam em função do alvo para o qual o indivíduo direciona a sua atenção, o que torna o SSEP adequado ao uso em BMIs (ALLISON et al., 2008; MIDDENDORF, 2000). Outros dois tipos de potencial evocado usado em BMls são: o potencial de erro (EP do inglês Error Potential), aplicado na detecção de erros de classificação (SCHALK, 2000) e o potencial de 
prontidão (RP do inglês Readiness Potential). O RP tem sido estudado com o propósito de melhorar a confiabilidade das BMIs (KRAULEDAT, 2004).

A dessincronização/sincronização relacionada ao evento (ERD/ERS do inglês Event-related Desynchronization/Synchronization) representa um exemplo de resposta induzida, que é provocada por mudanças do comportamento oscilatório de grupos de neurônios. Certas tarefas mentais provocam a dessincronização de ritmos oscilatórios cerebrais, o que acarreta atenuações das potências em bandas de freqüências específicas. De maneira análoga, a sincronização promove o aumento da potência em determinadas freqüências (PFURTSCHELLER, 2006). A sincronização e a dessincronização de ritmos mu e beta têm sido aplicas às tarefas de imaginação motora (PFURTSCHELLER, 2006; PFURTSCHELLER; LOPES DA SILVA, 1999; TORO et al., 1994), podendo ser medidas em regiões do córtex motor. A ERD foi também observada durante a realização de tarefas mentais, relacionadas à atenção dirigida (VAN GERVEN; JENSEN, 2009), cálculos matemáticos (CHOCHON, 1999), rotação de objetos (MILLÁN et al., 2004) e linguagem (PETERSEN et al., 1988).

Em um trabalho recente Guger et al. (2009) apresentaram uma BMI que reconhece o potencial evocado P300 e, exigindo apenas 5 minutos de treinamento, permitia que $89 \%$ dos usuários digitassem mentalmente em um teclado, atingindo um desempenho superior a 80\%. Além disso, a favor do P300 pesam o fato deste potencial ser bem compreendido do ponto de vista neurológico, mostrar-se robusto em diferentes pessoas e dispensar treinamento, pois surge automaticamente. Esta última vantagem é importante quando o objetivo é oferecer uma BMI a pacientes com dificuldades em adquirir controle voluntário sobre as próprias atividades cerebrais.

A concepção de novas tarefas para BMls resulta de mais descobertas sobre o código neural. Diversas questões importantes precisam ser respondidas, como:

- Quais regiões cerebrais são ativadas durante as diferentes tarefas?

- Qual é o papel funcional da sincronização rítmica?

- Como as diferentes regiões cerebrais se comunicam?

À medida que mais se aprende sobre estes assuntos, com maior precisão se poderá extrair as características relevantes para a determinação das tarefas mentais. 
Outra importante indagação relaciona-se às formas de interação entre as representações de múltiplas tarefas cognitivas. Seria a resposta à realização de dois movimentos simultâneos o somatório das respostas para cada um deles ou haveria uma interação não-linear que produziria uma assinatura completamente diferente? Consistiriam os sinais cerebrais referentes a uma palavra na sucessão de sinais associados a cada um dos fonemas? A melhoria na compreensão da natureza e das relações das representações neurais certamente contribuiria para o aperfeiçoamento das BMls.

O pré-processamento e a extração de características em uma BMI têm como propósito melhorar a relação sinal-ruído, de tal sorte a aumentar a probabilidade de se encontrar as características do sinal que levem à correta classificação do estado mental. A escolha dos algoritmos de extração de características e préprocessamento deve levar em conta não apenas as características do sinal, mas também o tipo de tecnologia de medição empregada.

Os tipos mais comuns de pré-processamento são: detecção de artefatos, filtragem espacial e filtragem espectral. A detecção de artefatos visa subtrair do sinal as interferências provenientes de fontes estranhas, tais como músculos e olhos. Em situações onde não é possível subtrair o artefato do sinal deve-se descartar a amostra. A filtragem espectral serve para eliminar ruídos, como o da linha. A filtragem espacial combina linearmente sinais de diversos eletrodos a fim de obter a atividade neural em uma determinada região cerebral. Ela é usada para intensificar ou eliminar sinais provenientes de determinada região. Um exemplo de filtragem espacial é a análise de componentes independentes (ICA do inglês Independent Component Analysis) (HYVÄRINEN, 2000), que separa as fontes cerebrais estatisticamente independentes. Entre os métodos de filtragem espacial estão a referenciação comum média (CAR do inglês Common Average Reference), o filtro de Laplace (HJORTH, 1975), e o padrão espacial comum (CSP do inglês Common Spatial Patterns) (KOLES, 1991), que é muito popular em pesquisas com BMls (LEMM et al., 2005; RAMOSER; MÜLLER; PFURTSCHELLER, 2000). Outro tipo de filtragem espacial, que fazia uso do método de projeção direta, foi apresentado por Baillet, Mosher e Leahy (2001).

A extração de características visa obter propriedades específicas do sinal, geralmente por meio de análise temporal ou espectral. A análise temporal é feita 
diretamente no sinal amostrado ou com a média dos sinais. A análise espectral considera a distribuição da potência em cada uma das bandas de freqüência do sinal. É possível também representar o sinal em tempo-freqüência, em que a variação da potência para determinada banda é mostrada ao longo do tempo. Houve tentativas de usar não apenas a potência, mas também a fase da onda (BRUNNER et al., 2006). Outros trabalhos foram ainda mais especulativos e usaram medidas de teoria de sistemas dinâmicos não-lineares (STAM, 2005; WOON; CICHOKI, 2007).

Em síntese, o pré-processamento e a extração de características são partes importantes do ciclo $\mathrm{BCl}$, uma vez que eles são os responsáveis por tornarem adequados os sinais à fase seguinte (de classificação).

A capacidade de reconhecer as intenções do usuário é um elemento crítico para o funcionamento de toda BMI. Esta propriedade da BMI pertence ao escopo do aprendizado de máquina. Quando a saída é contínua como, por exemplo, no trabalho de McFarland e Wolpaw (2005) trata-se de um problema de regressão, ao passo que se a saída for discreta o problema é de classificação. Diversos algoritmos de classificação foram propostos na literatura (BASHASHATI et al., 2007; LOTTE et al., 2007); alguns dos mais usados são: análise discriminante linear e máquina de vetor de suporte (DORNHEGE, 2007). Todavia, a eficiência da classificação não depende apenas do algoritmo, mas também de fatores como, o número de características extraídas, o montante de amostras de treinamento disponível e o tipo de paradigma experimental.

Geralmente, arquivos de neuroimagem possuem uma quantidade muito grande de informação, como milhares de voxels, e um número pequeno de amostras. Neste caso, é muito alto o risco do classificador se super-especializar, isto é, circunscrever a um conjunto bastante limitado os tipos que poderá reconhecer, o que implica em queda do desempenho quando diante de novas amostras. Pode-se lançar mão de diversos artifícios para amenizar este problema, tais como, usar classificadores lineares simples, eliminar os exemplos espúrios e reduzir o número de características observadas (MÜLLER, 2004). É importante salientar que estes métodos não apenas melhoram a capacidade de generalização, mas também auxiliam na interpretação dos parâmetros. Um assunto relacionado diz respeito à capacidade de generalização para novas sessões ou usuários (WONG, 2008). Este assunto, conhecido nos textos de aprendizado de máquina como transferência de 
aprendizado (RAINA; KOLLER, 2006) ou aprendizado multitarefa (CARUANA, 1993), tem recebido crescente atenção nas pesquisas com BMIs (VAN GERVEN et al., 2009).

Conciliar a dinâmica do sistema nervoso com a BMI é uma das grandes aspirações dos pesquisadores. O cérebro humano é uma entidade complexa muito poderosa e flexível, o que é evidenciado pela capacidade de readquirir habilidades motoras complexas, até mesmo após lesões significativas (MORITZ; PERLMUTER; FETZ, 2008). Para tirar proveito destas qualidades, a BMI deve ser capaz de adaptar-se constantemente. Assim, há um crescente interesse em desenvolver BMls que utilizam classificadores dinâmicos, tais como modelos ocultos de Markov e redes Bayesianas dinâmicas (OBERMEIER et al., 2001; SHENOY; RAO, 2005), que se adaptam constantemente e possibilitam a implementação de BMls assíncronas. Métodos Bayesianos também são usados em BMls adaptativas, isto é, que regulam o seu funcionamento baseadas em mudanças das características dos sinais, tais como as provocadas pela habituação (DORNHEGE, 2007; SYKACEK; ROBERTS; STOKES, 2004; VIDAURRE et al., 2006).

Em suma, a escolha do algoritmo não representa a maior dificuldade da classificação, uma vez que até mesmo classificadores simples podem apresentar um bom desempenho, mas outros fatores como a correta escolha das características e a capacidade de adaptação determinam a eficiência da BMI.

O componente de saída, que fecha o ciclo $\mathrm{BCl}$, realimenta o usuário com informações e gera estímulos que podem ativar dispositivos como, próteses motoras e cadeiras de rodas, ou comandar aplicativos de computador. A saída pode ser de diversos tipos, por exemplo, escrita em uma tela de computador (BIRBAUMER et al., 1999), auditiva (NIJBOER et al., 2007), de controle motor (DORNHEGE et al., 2007; NICOLELIS, 2001), gráfica (LEINS et al., 2007) ou tátil (CHATTERJEE, 2007). Freqüentemente combinam-se os sinais de realimentação (feedback) do usuário com o de controle de um dispositivo (BIRBAUMER; COHEN, 2007), de modo a permitir que o usuário consiga se adaptar. A saída mais comum é do tipo discreta (BASHASHATI et al., 2007; MASON et al., 2007), contudo também existem BMIs cujas saídas são contínuas, por exemplo, no trabalho de Wolpaw e McFarland (2004) medidas de potências de bandas de EEG servem para controlar um cursor 2D. 
Resultados promissores foram obtidos usando-se técnicas de medição invasivas, por exemplo, nos trabalhos em que macacos controlavam braços robóticos (NICOLELIS, 2001; NICOLELIS; CHAPIN, 2002) e, além disso, conseguiam alimentar-se (VELLISTE, 2008). Entretanto, como já foi dito, ainda estamos muito distantes de atingir velocidade e precisão semelhantes por meio de técnicas não-invasivas. Em função disso, estamos restritos a ampliar a dimensionalidade das BMls e aumentar os seus graus de liberdade.

As BMls típicas atingem taxas de transmissão de até 25 bits por minuto (WOLPAW et al., 2002). A taxa de transmissão é função da probabilidade de acerto e da velocidade da BMI. Pode ser expressa por $\mathrm{I}(\mathrm{C} ; \mathrm{Y}) / \mathrm{T}$, onde $\mathrm{I}(\mathrm{C} ; \mathrm{Y})$ representa a informação mútua entre a classe verdadeira $\mathrm{C}$ e a prevista $\mathrm{Y}$, e $\mathrm{T}$ representa a duração do evento em minutos (DORNHEGE et al., 2007). Para aumentar a taxa de transmissão, podem ser exploradas propriedades específicas da aplicação na construção de interfaces mais inteligentes (FELTON et al., 2007; KREPKI et al., 2007; PERELMOUTER; BIRBAUMER, 2000). Por exemplo, o teclado virtual poderia ser dotado da capacidade de antecipar as próximas escolhas mais prováveis de caracteres. Outra técnica é apresentada em um trabalho no qual o controle unidimensional de um cursor melhora significativamente em precisão e velocidade através da contínua adaptação dos parâmetros de ganho da BMI (MCFARLAND; WOLPAW, 2003). Em um trabalho recente Leeb et al. (2007) descrevem uma BMI que permitia ao usuário tetraplégico, apenas imaginando o movimento dos pés, caminhar em um ambiente virtual. Um trabalho de Vanacker et al. (2007) apresenta uma maneira de melhorar o desempenho uma BMI que controla uma cadeira de rodas, na qual o sistema inteligente conjectura e elimina determinados comandos que julga terem sido dados equivocadamente.

O estudo de sistemas que processam informações imprecisas e que pertence ao contexto de interações multimodais homem-máquina (DIX et al., 2004) pode oferecer diretrizes úteis para a concepção de BMls mais interativas.

Pessoas com diferentes tipos de paralisia têm se beneficiado de BMls que interpretam sinais de eletroencefalograma. Estas BMls baseiam-se em assinaturas como potenciais corticais lentos (BIRBAUMER et al., 1999), ERD/ERS (KÜBLER et al., 2005) ou P300 (PICCIONE et al., 2006). Embora os pacientes que mais poderiam se beneficiar com o uso de BMls fossem aqueles que sofrem da síndrome 
do encarceramento, é relativamente pequena a quantidade de BMls que se mostraram eficazes para essas pessoas. Observa-se que nem todas as BMls que são testadas e desenvolvidas para indivíduos saudáveis adaptam-se àqueles portadores de deficiência. De fato, estudos revelam que cerca de $45 \%$ dos portadores de esclerose lateral amiotrófica apresentam algum tipo de comprometimento cognitivo (ABE et al., 1997; RIPPON et al., 2006), assim como alterações nos padrões de EEG (MÜNTE et al., 1998). Uma possível causa pode ser o longo período de imobilidade, contudo talvez a doença acarrete danos de natureza ainda desconhecida (KÜBLER; BIRBAUMER, 2008).

Vinculada ao desenvolvimento de BMls está a tecnologia de monitoramento de estados mentais. Assim, a evolução dessas pode promover o aprimoramento de sistemas capazes de prever a ocorrência de atividades cerebrais anormais, como no caso da crise convulsiva (MORMANN et al., 2005), ou mesmo determinar o estado de inconsciência de um paciente submetido a anestesia (REZEK; ROBERTS; CONRADT, 2007).

Recentemente Hochberg et al. (2006) apresentaram os resultados de um trabalho, no qual, um paciente tetraplégico, em quem fora implantado um arranjo de micro-eletrodos intra-corticais era capaz de abrir emails, controlar a televisão e, movimentar mão e braço robóticos ao mesmo tempo em que conversava. Resultados como estes, embora animadores, não representam um cenário de curto prazo, pois problemas técnicos e questões de biocompatibilidade precisam ser solucionados primeiro.

Também é recente um trabalho no qual Leins et al. (2007) mostraram que a realimentação imediata (feedbacks online) de potenciais corticais lentos e das medidas de potência dos ritmos beta e theta produziram melhorias cognitivas e comportamentais duradouras em crianças com déficit de atenção e hiperatividade. Outro trabalho que oferece realimentação (feedback), mas implementado com técnicas de fMRI apresentou bons resultados em pacientes portadores de dor crônica e comportamento obsessivo-compulsivo (DECHARMS, 2008).

É notável o número de potenciais aplicações de BMls em pessoas saudáveis: desde a amplificação de emoções até novas formas de interação do homem com o computador. O uso de BMI em um jogo eletrônico, no qual o individuo navega por um labirinto já foi investigado em 1977 (VIDAL, 1977). Existem também aplicações de jogos de BMI voltadas ao tratamento médico, entretanto a maior parte das BMIs 
que implementam jogos se prestam a outros tipos de pesquisa ou apenas ao entretenimento. O trabalho de Krepki et al. (2007), por exemplo, apresenta BMls orientadas à recreação, as quais reconhecem imaginação motora e permitem ao usuário jogar Pacman, Pong e Tetris. Também existem BMls que proporcionam brincadeiras mais sofisticadas, como jogo de tiro em primeira pessoa (PINEDA et al., 2003) e navegação no Google Earth (SCHERER et al., 2007). Há inclusive jogos que exploram atividades mentais mais abrangentes, como o Brainball, que permite ao jogador controlar uma bola numa mesa através do seu estado de relaxamento (HJELM, 2003). Aplicativos como o Brainball demonstram a capacidade dos jogos de provocarem mudanças significativas no estado cognitivo do usuário. Atualmente diversas pequenas companhias comercializam BMls portáteis, acessíveis e com propósito de entretenimento.

Esta dissertação está dividida em seis capítulos e um apêndice. O primeiro capítulo, introdutório, menciona os aspectos gerais que correspondem à motivação, objetivos e justificativa do trabalho.

O segundo capítulo, intitulado Interfaces Cérebro-máquina, descreve pormenorizadamente algumas das modalidades de extração de sinais cerebrais citadas no primeiro capítulo. Este capítulo também traz uma relação de potenciais evocados e espontâneos, sinais neurofisiológicos empregados em BMls.

O terceiro capítulo apresenta algoritmos de processamento de sinais usados em BMls e aborda diferentes técnicas de pré-processamento, extração de características e classificação. Quanto à extração de características, são tratados métodos no domínio do tempo, freqüência e mistos (representações tempofreqüência). Dentre os algoritmos de classificação, será dado destaque à máquina de vetor de suporte em virtude de ser esta a técnica de reconhecimento de padrões utilizada na experiência do capítulo quatro.

O quarto capítulo, denominado Materiais e Métodos, é aquele em que a experiência em si é descrita. Este capítulo narra um experimento realizado pelo Multimedia Signal Processing Group da Ecole Polytechnique Fédérale de Lausanne (EPFL) na Suíça, que originou os sinais de EEG usados nesta dissertação. Neste 
capítulo procura-se discriminar os aspectos relevantes daquela experiência para que seja empregada em uma interface cérebro-máquina. Este capítulo revela detalhadamente a análise off-line, pré-processamento, e também apresenta as estratégias adotadas para o treinamento do classificador e reconhecimento dos padrões.

No quinto capítulo são exibidos, através de gráficos e tabelas, os resultados de desempenho do algoritmo reconhecedor de padrões. Neste capítulo discutem-se o desempenho e mérito do algoritmo, alicerçado na natureza dos sinais e em uma análise probabilística.

O capítulo seis delimita o final da dissertação e nele é feita uma análise conclusiva da pesquisa e desenvolvimento técnico-científico deste trabalho, além disso, são sugeridas propostas que visam aperfeiçoar os algoritmos utilizados, descritos no capítulo quatro.

O apêndice contém a demonstração matemática do efeito de melhora da relação sinal-ruído produzida pela técnica da média coerente. 


\section{Interfaces Cérebro-máquina}

O projeto de uma BMI é trabalhoso e requer conhecimentos multidisciplinares tais como da ciência da computação, processamento de sinais, neurociências e psicologia. Para conseguir um bom desempenho, a maioria das BMls exige uma fase preparatória offline, de treinamento e calibração. Segundo Mason e Birch (2003) a BMI, conforme ilustrado na figura 2.1, pode ser decomposta em seis partes:

- Medição das atividades cerebrais: consiste em diferentes técnicas de sensoriamento dos sinais que refletem o funcionamento cerebral do sujeito (WOLPAW et al., 2006). Nesta dissertação será enfatizado o eletroencefalograma;

- Pré-processamento: consiste na filtragem e eliminação de ruídos de modo a aumentar a relação sinal-ruído do sinal (BASHASHATI et al., 2007);

- Extração de características: nesta fase deseja-se encontrar uma descrição do sinal através de alguns parâmetros denominados características (BASHASHATI et al., 2007);

- Classificação: visa associar a uma classe uma determinada família de sinais com características semelhantes (LOTTE et al., 2007) que correspondem a um tipo de estado mental. A classificação também é denominada tradução de características por meio de algoritmos identificados como classificadores (MASON;BIRCH, 2003);

- Tradução em comandos: uma vez que o estado mental é determinado, associa-se a este a execução de um aplicativo, tal como um sintetizador de voz ou um robô (KÜBLER et al., 2006);

- Realimentação (Feedback): por fim, nesta fase o usuário é realimentado com informações referentes ao seu estado mental identificado. O feedback visa ajudar o usuário a controlar suas atividades cerebrais e, por conseguinte a BMI (WOLPAW et al., 2002). 


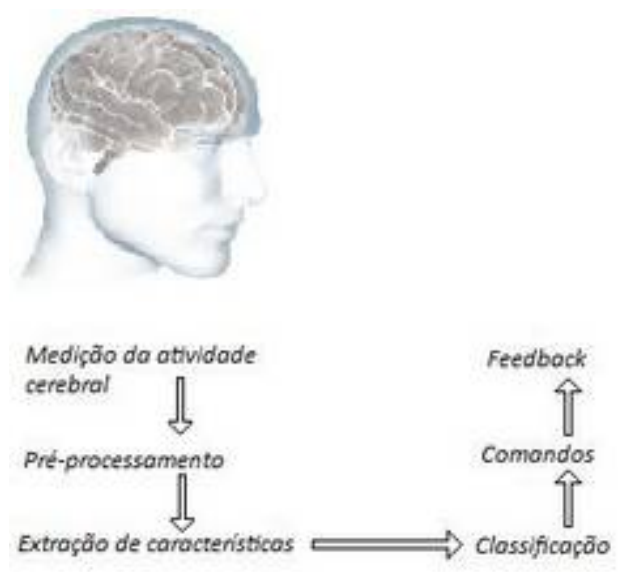

Figura 2.1 - Seis partes que compõem uma BMI

\subsection{Medição da atividade cerebral}

Existem várias técnicas de monitoração de sinais neurológicos descritas na literatura. Nas seis subseções seguintes serão apresentadas algumas delas, onde será dado maior destaque à eletroencefalografia.

\subsubsection{Eletroencefalograma (EEG)}

O eletroencefalograma (EEG) é uma das técnicas não-invasivas de aquisição de sinais cerebrais mais utilizadas. Desde que foi inventado por Hans Berger (1929) o EEG tem sido usado na investigação e diagnóstico de fenômenos neurológicos. O fato de esta técnica ser amplamente adotada deve-se, em grande parte, a sua natureza simples, de baixo custo e que exige pouco tempo de preparação. Os sinais de EEG são obtidos através de eletrodos com aproximadamente $5 \mathrm{~mm}$ de raio, colocados em posições padronizadas, como no sistema 10-20 mostrado na figura 2.2. Estes sinais são medidos com relação a eletrodos de referência e suas amplitudes são inferiores a $100 \mu \mathrm{V}$. 


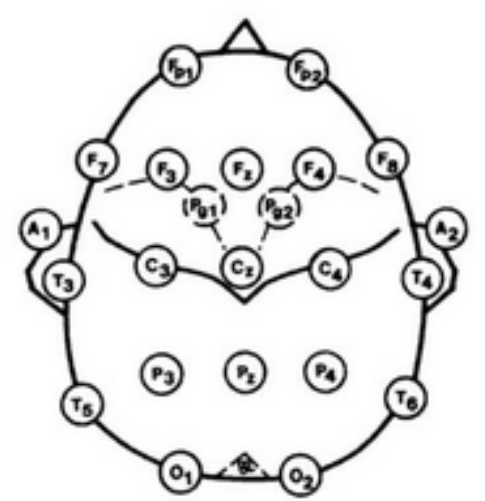

Figura 2.2 - Sistema Internacional 10-20 (adaptado de Niedermeyer (2004))

Segundo Martin (1991), os sinais provenientes do EEG refletem, em grande parte, o processamento de informação dos neurônios piramidais do córtex cerebral. Contudo, estes sinais geralmente estão contaminados por elementos espúrios de fontes fisiológicas e não-fisiológicas, tais como, movimentos voluntários, atividade cardíaca, piscar de olhos, ruído de linha, etc. Os elementos espúrios, doravante denominados artefatos, possuem eventualmente amplitudes maiores que as dos sinais que se desejam observar. Assim, devem ser feitas as remoções e filtragens desses artefatos antes de se analisar o sinal do EEG.

Os sinais de EEG são compostos por diferentes oscilações denominadas ritmos (NIEDERMEYER, 2004). Estes ritmos apresentam características espaciais e espectrais distintas. Conforme ilustrado na figura 2.3 existem 6 ritmos cerebrais clássicos:

- Ritmo Delta: É observado em adultos durante o sono. Possui amplitude relativamente grande e freqüência entre 1 e $4 \mathrm{~Hz}$;

- Ritmo Theta: Apresenta-se principalmente em crianças com sonolência. Sua freqüência é da ordem de 4 a $7 \mathrm{~Hz}$;

- Ritmo Alfa: Surge em regiões cerebrais posteriores (lobo occipital), com freqüência entre 8 e $12 \mathrm{~Hz}$, em indivíduos relaxados ou de olhos fechados;

- Ritmo Mu: Consiste em oscilações entre 8 e $13 \mathrm{~Hz}$, presentes no córtex motor e sensório-motor. A amplitude deste ritmo muda conforme o indivíduo realiza movimentos. Assim, este ritmo é também denominado ritmo sensório-motor (PFURTSCHELLER; NEUPER, 2001); 
- Ritmo Beta: É observado em indivíduos acordados e conscientes. Possui freqüência entre 13 e $30 \mathrm{~Hz}$. Este ritmo também é sensível a realização de movimentos (PFURTSCHELLER; NEUPER, 2001);

- Ritmo Gama: Está relacionado a diversas funções motoras e cognitivas. Possui freqüência maior que $30 \mathrm{~Hz}$.

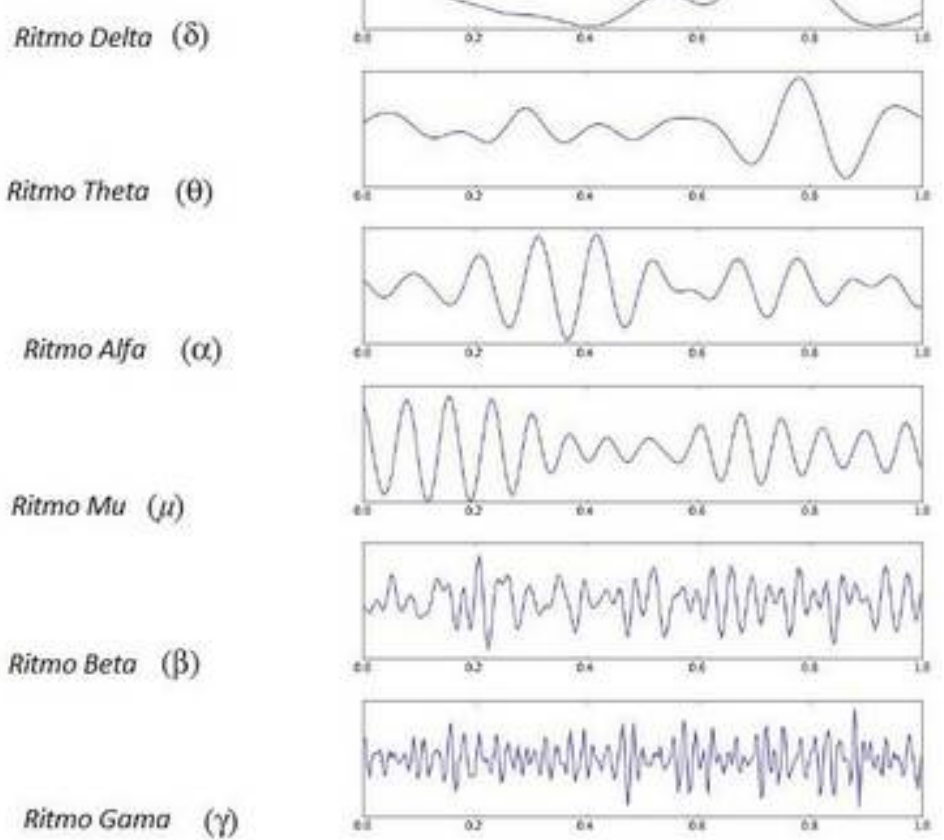

Figura 2.3 - Ritmos cerebrais obtidos por EEG (adaptado de Wikipedia.org)

\subsubsection{Eletrocorticografia (ECoG)}

A eletrocorticografia é uma técnica invasiva de aquisição de sinais elétricos cerebrais. Por meio de um procedimento cirúrgico um conjunto de eletrodos, tipicamente de dimensão 8x8, é implantado na superfície do córtex.

O ECoG apresenta menor distorção que o EEG. Além disso, os sinais de ECoG são menos afetados por artefatos que os de EEG. Sinais com freqüências de até $100 \mathrm{~Hz}$ podem ser facilmente observados através dessa técnica. Por estas razões, o ECoG tem sido cada vez mais usado em BMls. 


\subsubsection{Cadeias de micro-eletrodos (MEA) (Micro Electrode Arrays)}

As MEAs são técnicas de detecção de sinais elétricos de um ou vários neurônios. Assim como no caso do ECoG, os MEAS também exigem a realização de um procedimento cirúrgico para sejam inseridas eletrodos de agulhas no tecido cerebral. Tipicamente, um MEA mede $5 \times 5 \mathrm{~mm}$ e possui cerca de 100 eletrodos, os quais podem penetrar alguns milímetros no córtex (NICOLELIS et al., 2003). Comparada a outras técnicas as MEAs apresentam maiores resoluções espaciais e possibilitam até o monitoramento de apenas um neurônio. Contudo, a necessidade de cirurgia acrescenta o risco de infecção. Além disso, as MEAs só podem ser usadas por períodos de meses devido à morte das células nas vizinhanças dos eletrodos. Apesar dos problemas esta é uma técnica, juntamente com a EEG, das mais utilizadas em BMls.

\subsubsection{Magnetoencefalografia (MEG)}

A magnetoencefalografia (MEG) é uma técnica não-invasiva, cuja resolução é de aproximadamente $10^{-15}$ Tesla, capaz de detectar campos magnéticos causados por correntes intracelulares nos neurônios piramidais. Alguns estudos foram bem sucedidos no uso de MEG em BMIs (KAUHANEN et al., 2006) (LAL et al., 2005) e obtiveram desempenhos próximos àqueles conseguidos com EEG. Todavia, a aparelhagem exigida pela MEG é muito pesada, grande e de alto custo comparada ao EEG.

\subsubsection{Imagem por ressonância magnética funcional (fMRI)}

A técnica de imagem por ressonância magnética funcional é não-invasiva e mede o chamado sinal BOLD (do inglês Blood Oxygen Level Dependent). O sinal 
BOLD é função da oxigenação do sangue e depende da quantidade de hemoglobina oxigenada e desoxigenada, e também das respostas hemodinâmicas de ativação neuronal. A resolução temporal da fMRI é baixa, da ordem de 5 segundos, mas permite localizar estruturas de poucos milímetros em qualquer lugar do cérebro, não apenas no córtex. Porém, diferentemente do EEG, um trabalho de Logothetis (2008) sugere que o sinal BOLD, usado na fMRI, parece estar mais relacionado com a atividade elétrica que chega ao neurônio do que com potenciais de ação originados no próprio neurônio. O uso da fMRI é inviável em aplicações com BMls em razão da sua complexidade, alto custo e dificuldade de deslocamento.

\subsubsection{Espectroscopia do infravermelho próximo (NIRS)}

A NIRS (do inglês Near Infrared Spectroscopy) é um método não-invasivo de detecção da atividade hemodinâmica no córtex cerebral (similar ao sinal BOLD). $\mathrm{Na}$ medição dos sinais optodos dispostos no couro cabeludo do indivíduo emitem radiação no espectro do infravermelho próximo. A radiação é refletida na superfície cortical e medida por sensores. A intensidade do sinal, função da quantidade de hemoglobina oxigenada e desoxigenada no sangue, reflete a atividade cerebral. $A$ NIRS proporciona baixas resoluções espaciais e temporais.

\subsection{Sinais neurofisiológicos usados em BMls}

O correto funcionamento da BMI depende da capacidade da máquina de reconhecer estados cognitivos através da medição de sinais neurofisiológicos. Diversos tipos de padrões de sinais têm se mostrado adequados ao uso em BMls, isto é, eles são identificáveis por uma máquina e, eventualmente podem ser moduláveis pelo indivíduo. Podemos dividi-los em duas categorias (CURRAN; STOKES, 2003; WOLPAW et al., 2002): 
- Sinais evocados: Surgem involuntariamente quando o indivíduo observa determinado estímulo externo. Estes sinais são conhecidos como potenciais evocados (EP do inglês Evoked Potentials);

- Sinais espontâneos: São sinais controlados voluntariamente pelo indivíduo, que dispensam estimulação externa e acompanham o estado cognitivo do sujeito.

\subsubsection{Potenciais evocados}

Nesta categoria existem dois diferentes tipos de sinais: Potenciais evocados sustentados (SSEP do inglês Steady State Evoked Potentials) e P300 (CURRAN; STOKES, 2003; WOLPAW et al., 2002). Estes dois tipos serão apresentados nas duas subseções seguintes. A principal vantagem dos potenciais evocados em relação aos potenciais espontâneos reside no fato de ser desnecessário o treinamento do usuário, uma vez que os sinais aparecem automaticamente em resposta a um estímulo. Contudo, em virtude de serem evocados estes sinais exigem estimulação externa, o que pode eventualmente ser desconfortável e cansativo para o usuário.

\subsubsection{Potenciais evocados sustentados (SSEP)}

Os potenciais evocados sustentados aparecem quando o indivíduo percebe um estímulo periódico, tal como uma imagem piscando ou um som modulado em amplitude. Os SSEP definem-se pelo aumento da potência do sinal do EEG na freqüência de oscilação da excitação ou nas suas harmônicas ou sub-harmônicas (GOUY-PAILLER et al., 2007; LALOR et al., 2005; MÜLLER-PUTZ et al., 2006). Diversos tipos de SSEPs são usados em BMIs, sendo o Potencial evocado visual sustentado (SSVEP do inglês Steady State Visual Evoked Potentials) o mais comum (LALOR et al., 2005; MCMILLAN et al., 1995; SOLIS-ESCALANTE; GENTILETTI; 
YANEZ-SUAREZ, 2007; TOUYAMA; HIROSE, 2007). Também existem trabalhos nos quais as BMIs utilizam SSEPs somatosensoriais (MÜLLER-PUTZ et al., 2006) e SSEPs auditivos (GOUY-PAILLER et al., 2007). A figura 2.4 mostra um exemplo de gráfico de SSVEP, onde é possível ver picos de potência em 17 e $20 \mathrm{~Hz}$, além de suas sub-harmônicas. O SSEP surge em áreas cerebrais correspondentes ao sentido que está sendo estimulado. No caso do SSVEP a área ativada é a visual.

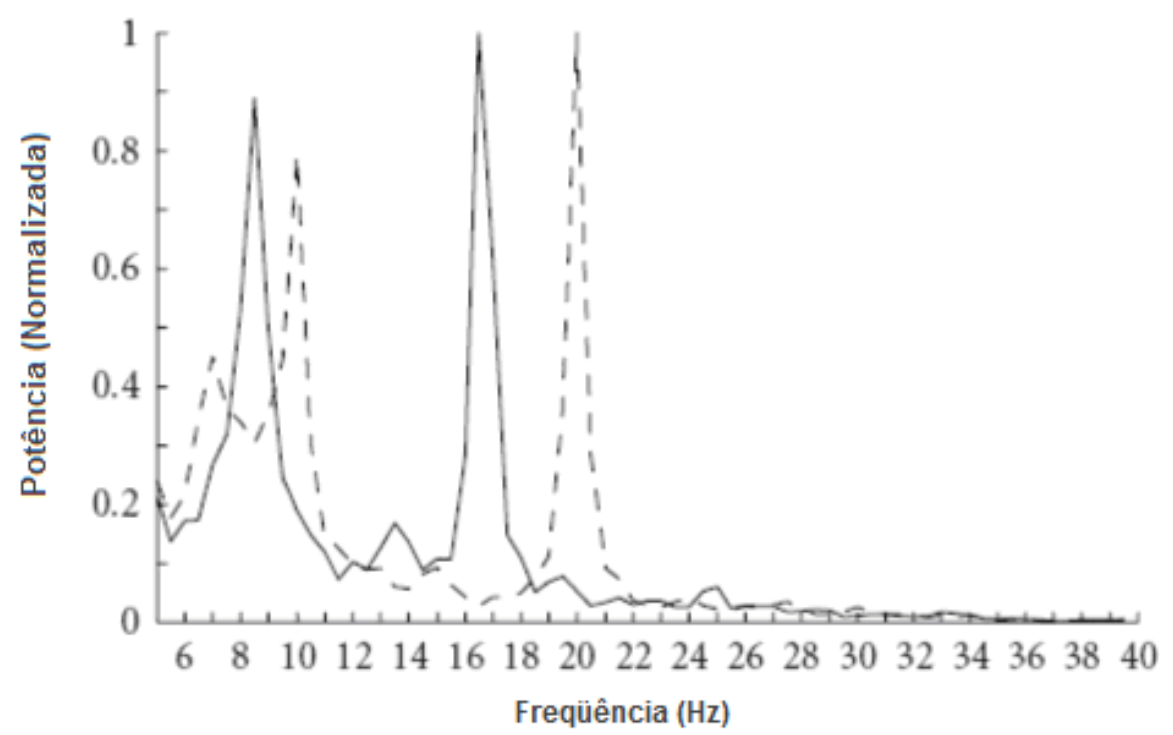

Figura 2.4 - Potência do sinal em função da freqüência (adaptado de LALOR et al., (2005))

A principal vantagem deste tipo de sinal é poder ser utilizado em BMls sem exigir treinamento prévio. Estimulações de diferentes freqüências deverão provocar SSEPs de diferentes freqüências, que corresponderão aos respectivos estímulos. É possível usar um grande número de estímulos para conseguir uma grande quantidade de estados mentais. No trabalho de Gao et al. (2003), por exemplo, foram usados 48 diferentes estímulos. Essas vantagens justificam o crescente interesse no uso de SSEP, particularmente o SSVEP, em aplicações BMIs (CHENG et al., 2002; GAO et al., 2003; MIDDENDORF et al., 2000; MULLER-PUTZ; PFURTSCHELLER, 2008; NIELSEN; CABRERA; NASCIMENTO, 2006; PARINI et al., 2009; TREJO; ROSIPAL; MATTHEWS, 2006; ZHANG et al., 2010). 


\subsubsection{P300}

O P300 consiste em uma forma de onda positiva que surge no EEG cerca de $300 \mathrm{~ms}$ após a ocorrência de um estímulo raro e relevante (FARWELL; DONCHIN, 1988). Ela é tipicamente gerada através do chamado paradigma odd-ball, no qual o indivíduo deve prestar atenção a uma seqüência aleatória de estímulos que possuem diferentes probabilidades de ocorrência. Caso o estímulo de baixa probabilidade de ocorrência seja relevante para o indivíduo a sua ocorrência irá deflagrar o surgimento do padrão P300 no EEG. Este potencial está presente sobretudo nas regiões parietais. A figura 2.5 mostra o P300 no canal Pz com ajuda da realização de médias para aumentar a relação sinal-ruído.

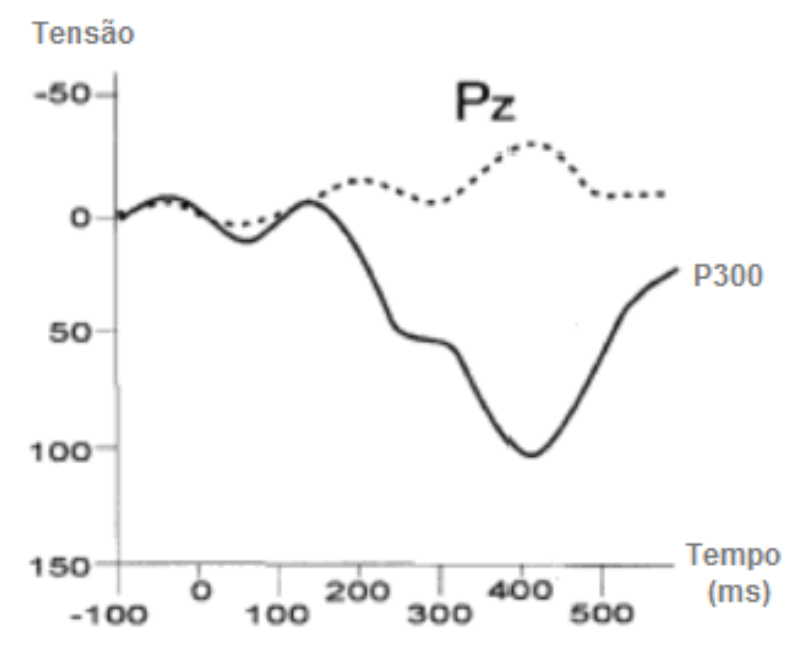

Figura 2.5 - Sinal P300 típico (adaptado de WOLPAW et al., (2002))

Geralmente, a BMI que faz uso do P300 somente executa uma aplicação caso o sinal esteja presente ou ausente. Da mesma forma que a BMI que emprega SSVEP, diversos objetos ou botões são apresentados em uma tela de computador. As imagens são intensificadas aleatoriamente, e o usuário é instruído a contar o número de vezes que uma determinada imagem foi intensificada durante um intervalo de tempo. Este procedimento tem como fim tornar a intensificação da imagem um evento raro e relevante de modo a deflagrar o sinal P300. Assim, ao detectar o P300 o sistema infere que a imagem escolhida era aquela que piscou a cerca de $300 \mathrm{~ms}$ atrás. As BMls baseadas em potenciais evocados, como o P300, não requerem treinamento por parte do usuário, por outro lado estas BMls exigem 
que o indivíduo preste atenção a um estímulo repetitivo, o que pode ser muito cansativo. O P300 é mais empregado em BMls que oferecem um tipo de teclado virtual (FARWELL; DONCHIN, 1988; KRUSIENSKI et al., 2006; PICCIONE et al., 2006; RIVET; SOULOUMIAC, 2007; SELLERS; DONCHIN, 2006).

\subsubsection{Potenciais espontâneos}

Dentre os sinais espontâneos, o mais usado é o ritmo sensório-motor. Além deste, outros sinais neurofisiológicos, como potenciais corticais lentos e sinais cognitivos não-motores, também são utilizados.

\subsubsection{Ritmos motor e sensório-motor}

São ritmos cerebrais relacionados a ações motoras como, por exemplo, o movimento das mãos. Tais ritmos, que geralmente se encontram nas freqüências $\mu(\sim 8-13 \mathrm{~Hz})$ e $\beta(\sim 13-30 \mathrm{~Hz})$ sobre o córtex motor, têm as suas amplitudes controladas voluntariamente pelo usuário. São conhecidas duas estratégias de controle de ritmo sensório-motor em BMls:

- Condicionamento operante: O usuário aprende a modular voluntariamente a amplitude dos seus ritmos sensório-motores através de um longo treinamento denominado condicionamento operante (VAUGHAN et al., 2006; WOLPAW et al., 1991; WOLPAW, 2007; WOLPAW; MCFARLAND, 2004);

- Imaginação de movimentos: Consiste em imaginar movimentos dos próprios membros (por exemplo: pés e mãos) (PFURTSCHELLER et al., 2003; PFURTSCHELLER et al., 2006; PFURTSCHELLER; NEUPER, 2001). O sinal produzido pela imaginação do movimento possui características temporais, espaciais e de freqüência bem determinadas, de modo que podem ser corretamente identificadas pela máquina (PFURTSCHELLER et al., 1997; PFURTSCHELLER et al., 1998; PFURTSCHELLER et al., 2006). 
Um exemplo de condicionamento operante é dado no trabalho de Wolpaw et al. (2002), no qual o indivíduo controla a posição de um cursor para cima e para baixo através da modulação do ritmo mu (8 a $12 \mathrm{~Hz})$. O gráfico com a variação da amplitude do ritmo mu é mostrada na figura 2.6.

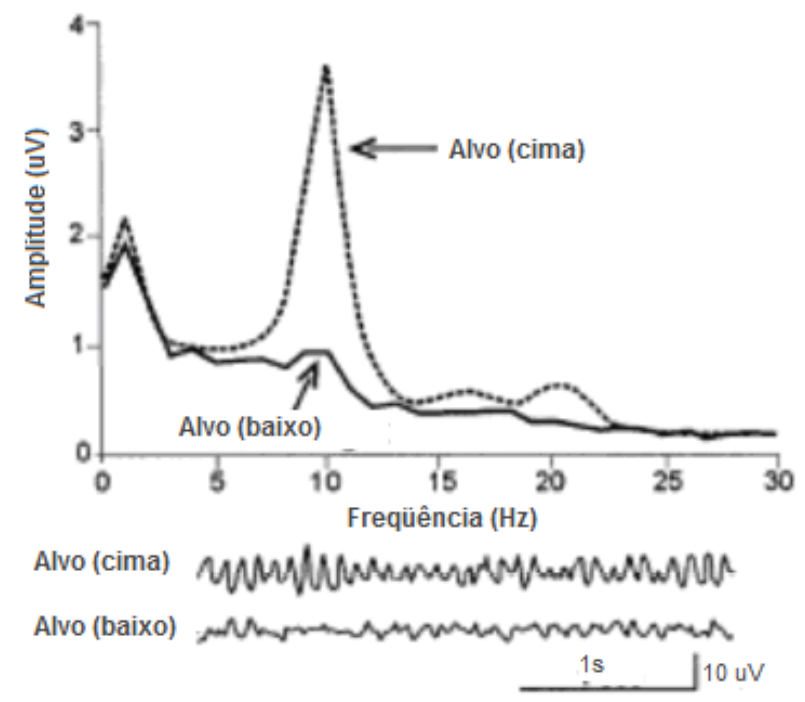

Figura 2.6 - Variação de amplitude do ritmo mu nos extremos do cursor (adaptado de WOLPAW et al., (2002))

No caso da estratégia de condicionamento operante o feedback é essencial, uma vez que ele permite ao usuário aprender a modular seus ritmos cerebrais de modo a comandar a BMI. Geralmente, para BMls que adotam o condicionamento operante, as potências dos ritmos $\mu$ e $\beta$ em diferentes eletrodos são combinadas linearmente para se obter um sinal de controle para movimentar cursores em uma, duas ou três dimensões (WOLPAW, 2007; WOLPAW; MCFARLAND, 2004). A principal desvantagem do método é o demasiadamente longo período de treinamento exigido para se usar a BMI. O treinamento pode ser estender por semanas ou até mesmo meses (WOLPAW et al., 1991; WOLPAW; MCFARLAND, 2004). Todavia, uma vez concluído o treinamento a BMI pode atingir bons desempenhos em termos de taxa de transmissão de informação.

Um exemplo de imaginação de movimentos é apresentado no trabalho de Pfurtscheller et al. (2000), no qual o fato do usuário imaginar um movimento com a mão esquerda ativa as regiões sensório-motoras primárias do hemisfério direito e promove a atenuação da potência dos ritmos (ERD do inglês Event Related Desynchronisation), conforme ilustrado nas figuras 2.7 e 2.8. O fenômeno ocorre de 
maneira simétrica, isto é, no hemisfério esquerdo quando o indivíduo imagina a realização de um movimento com a mão direita. As BMls que identificam a realização de movimentos costumam associar um comando a uma determinada imaginação de tarefa motora, como por exemplo, o movimento da língua, do pé direito, etc. (GUGER et al., 1999; PFURTSCHELLER et al., 2003; SCHERER et al., 2004). O uso eficiente de BMls de imaginação de movimentos geralmente requer do usuário poucas sessões de treinamento (PFURTSCHELLER; GRAIMANN; NEUPER, 2006). Todavia, técnicas sofisticadas de processamento de sinais e aprendizado de máquina permitem reduzir ou até mesmo eliminar a necessidade de treinamento (BLANKERTZ et al., 2006; BLANKERTZ et al., 2007).

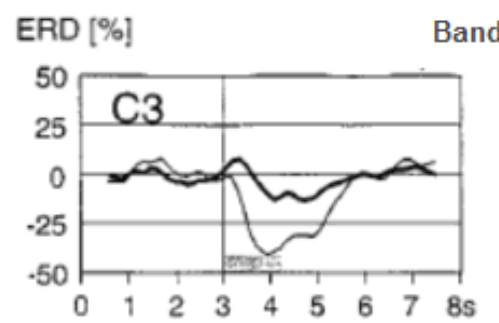

Banda Alfa

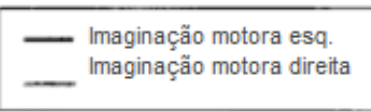

Figura 2.7 - ERD que decorre da imaginação de movimento das mãos esquerda e direita (adaptado de PFURTSCHELLER et al., (2000))
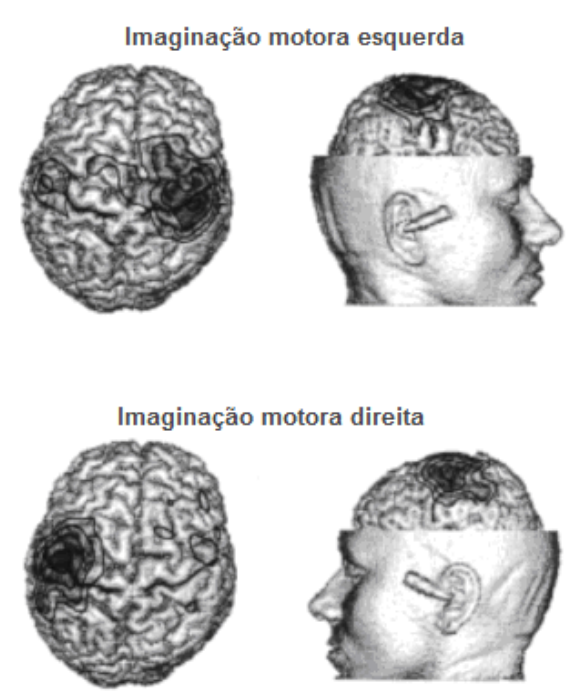

Figura 2.8 - Localização espacial do ERD provocados pelas imaginações de movimentos das mãos esquerda e direita (adaptado de PFURTSCHELLER et al., (2000)). 


\subsubsection{Potenciais corticais lentos (SCP)}

Os potenciais corticais lentos (SCP do inglês Slow Cortical Potentials) consistem em alterações lentas da atividade cortical, as quais duram de algumas centenas de milissegundos a vários segundos (BIRBAUMER et al., 2000) (KLEBER; BIRBAUMER, 2005). É possível, através do condicionamento operante, aprender a aumentar e diminuir estes potenciais. A figura 2.9 mostra o gráfico de uma experiência (WOLPAW et al., 2002) em que o indivíduo varia os potenciais corticais lentos entre dois extremos.

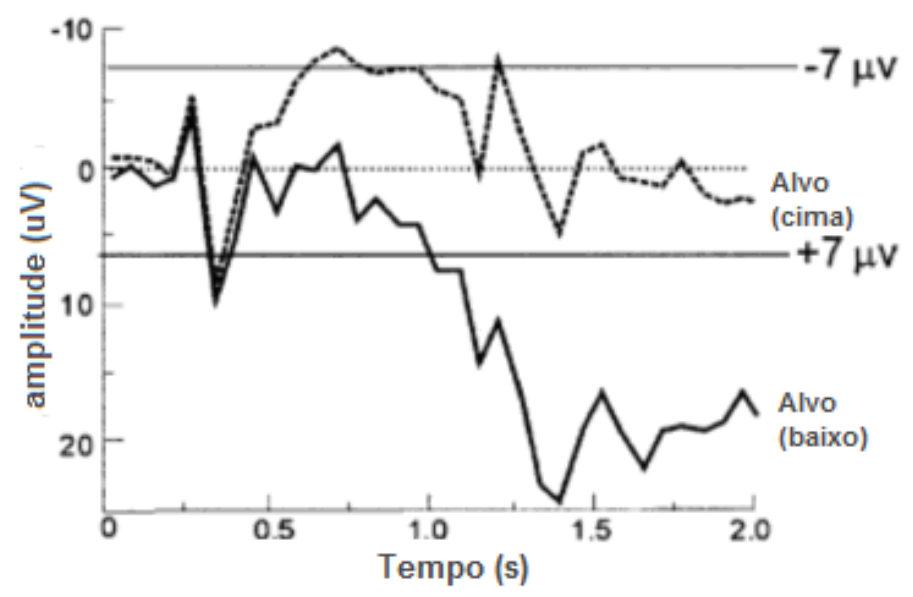

Figura 2.9 - Modulação voluntária dos potenciais corticais lentos (adaptado de WOLPAW et al., (2002))

Os potenciais corticais lentos podem ser usados em BMls, nas quais o indivíduo é instruído a aumentar ou diminuir o SCP de modo a escolher uma entre duas opções (BIRBAUMER et al., 2000). Como o controle do SCP é conseguido através de condicionamento operante, o aprendizado exige longo tempo de treinamento. Este tempo é maior, até mesmo, que o exigido no caso dos ritmos motores (BIRBAUMER, 2006b). Contudo o sinal do SCP parece ser mais estável que os ritmos motores (BIRBAUMER, 2006b). 


\subsubsection{Tarefas cognitivas não-motoras}

É possível usar também diversas outras tarefas cognitivas não-motoras para se controlar a BMI. Estas tarefas são, por exemplo, cálculos mentais, rotações imaginárias de objetos, contagem, imaginação de palavras ou músicas, etc. Cada uma destas tarefas gera um padrão bem determinado e que pode ser identificado por uma BMI. 


\section{Processamento de sinais}

\subsection{O pré-processamento}

O passo seguinte à aquisição dos sinais elétricos é o pré-processamento, que deve ser realizado para reduzir os ruídos e, assim tornar a informação relevante presente no sinal mais fácil de ser identificada. Os sinais de EEG estão freqüentemente contaminados por ruídos e artefatos, como movimentos musculares, piscar de olhos, etc. Os movimentos musculares produzem artefatos que se sobressaem por suas amplitudes muito mais altas que as dos sinais de EEG. Por isto, é difícil eliminar estes artefatos sem retirar informação relevante do sinal. Em síntese, o objetivo principal do pré-processamento é aumentar a relação sinal-ruído dos sinais de entrada da BMI.

O pré-processamento pode ser conseguido empregando-se filtros temporais ou espaciais simples, ou filtros mais sofisticados como Análise das Componentes Independentes e Padrões Espaciais Comuns. As subseções seguintes apresentam técnicas de pré-processamento de sinais.

\subsubsection{Filtros simples espaciais e temporais}

Grande parte das BMls utiliza as filtragens espaciais e temporais para melhorar a relação sinal-ruído da entrada.

\subsubsection{Filtros temporais}

Filtros temporais, como passa-banda ou passa-baixa, são freqüentemente utilizados para limitar a análise do sinal à faixa de freqüências onde acreditamos que o sinal neurofisiológico se encontra. Assim, por exemplo, no caso de BMls que 
utilizam ritmos sensórios-motores costuma-se usar filtros passa-banda entre 8 e 30 $\mathrm{Hz}$, visto que nestas freqüências estão situados os ritmos $\mu$ e $\beta$. Este filtro passabanda também é capaz de remover outros ruídos indesejáveis como o de linha (50 ou $60 \mathrm{~Hz}$ no Brasil). Logo, os filtros temporais possibilitam a redução da influência de freqüências fora das regiões de interesse. Costuma-se usar neste tipo de filtragem a Transformada Discreta de Fourier (DFT do inglês Discrete Fourier Transform), o filtro de Resposta Finita ao Impulso (FIR do inglês Finite Impulse Response) ou o filtro de Resposta Infinita ao Impulso (IIR do inglês Infinite Impulse Response).

DFT: A Transformada Discreta de Fourier possibilita a visualização do sinal no domínio da freqüência, isto é, apresenta o sinal como o somatório de oscilações em diferentes freqüências. Assim, podemos definir a DFT $S(f)$ de um sinal discreto $\mathrm{s}(\mathrm{n})$ com $\mathrm{N}$ amostras por:

$$
S(f)=\sum_{n=0}^{N-1} s(n) \cdot e^{\frac{-2 \cdot i \cdot \pi \cdot f \cdot n}{N}}
$$

Assim, a filtragem usando a DFT consiste em igualar a zero todos os coeficientes de $S(f)$ que não correspondem às freqüências que se deseja eliminar e, então realizar a inversa da DFT e transformar o sinal no domínio do tempo, através da equação:

$$
s(n)=\frac{1}{N} \cdot \sum_{k=0}^{N-1} S(k) \cdot e^{\frac{2 \cdot i \cdot \pi \cdot n \cdot k}{N}}
$$

Quando da realização filtragem por meio da DFT, deve-se fazer o janelamento antes da aplicação da DFT (SMITH, 1997). A filtragem DFT pode ser usada em aplicações online, isto é, em tempo real graças ao advento do algoritmo conhecido como Transformada Rápida de Fourier (FFT do inglês Fast Fourier Transform) (SMITH, 1997). A filtragem DFT foi usada, por exemplo, na classificação de intenção de movimento em algumas BMIs (BLANKERTZ; CURIO; MÜLLER, 2002; KREPKI et al., 2007).

FIR: A filtragem FIR é linear, faz uso das $M$ últimas amostras do sinal $s(n)$ e é dada por $y(n)$ :

$$
y(n)=\sum_{k=0}^{M} a_{k} \cdot s(n-k)
$$


onde, $a_{k}$ são os coeficientes do filtro, cujos valores dependem do tipo de filtragem desejada (SMITH, 1997). Os filtros FIR têm apresentado bons desempenhos no domínio da freqüência. No trabalho de Dornhege et al. (2006) ele é usado em que uma BMI que reconhece imaginação de movimentos. Também é aplicado em outra BMI que reconhece potenciais evocados sustentados (GOUY-PAILLER et al., 2007).

IIR: Os filtros de resposta infinita ao impulso, assim como os FIRs, são filtros lineares. Contudo, os IIRs são filtros recorrentes, isto é, usam as saídas das P últimas filtragens, além das $M$ últimas amostras. A resposta é, então, dada por:

$$
y(n)=\sum_{k=0}^{M} a_{k} \cdot s(n-k)+\sum_{k=1}^{P} b_{k} \cdot y(n-k)
$$

Deste modo, pode-se dizer que os filtros IIR realizam uma filtragem com um número muito menor de coeficientes que os filtros FIR. Contudo, o desempenho dos filtros IIR no domínio da freqüência é um pouco menor (SMITH, 1997). Entre os filtros IIR empregados no pré-processamento de EEG para BMI podemos citar o Butterworth, Tchebychev e os elípticos (DORNHEGE et al., 2004; MARTINEZ; BAKARDJIAN; CICHOCKI, 2007; SMITH, 1997).

\subsubsection{Filtros espaciais}

Do mesmo modo que os filtros temporais, diversos filtros espaciais simples são usados para separar as informações espaciais relevantes presentes nos sinais. Isto é conseguido através da escolha e ponderação acerca da contribuição de cada um dos eletrodos, ou seja, de cada uma das regiões cerebrais (MCFARLAND et al., 1997). A maneira mais simples de realizar uma filtragem espacial é através da seleção dos eletrodos sabidamente importantes, isto é, que carregam a informação neurofisiológica de interesse, e da eliminação dos demais eletrodos, os quais

provavelmente transportam ruídos e informações irrelevantes para a BMI. Por exemplo, no caso de uma BMI que usa imaginação de movimentos e cujos sinais de interesse vêm das regiões do córtex motor e sensório-motor (PFURTSCHELLER; NEUPER, 2001), pode-se enfatizar as os eletrodos C3 e C4, que se referem ao córtex motor esquerdo e direito respectivamente. Do mesmo modo, para o caso de 
uma BMI baseada em SSVEP, pode-se dar ênfase aos eletrodos $\mathrm{O} 1$ e O2, localizados nas regiões visuais (LALOR et al., 2005).

Outros filtros simples são: o CAR (Common Average Reference) e a Superfície Laplaciana (SL) (MCFARLAND et al., 1997). O filtro CAR é obtido através da eq.(3.4):

$$
\tilde{V} i=V i-\frac{1}{N_{e}} \cdot \sum_{j=0}^{N e} V j
$$

onde $\tilde{V}$ e $V_{i}$ são os potenciais do i-ésimo eletrodo, antes e depois da filtragem respectivamente. $\mathrm{N}_{\mathrm{e}}$ é o número de eletrodos utilizados. Assim, o filtro CAR rereferencia cada eletrodo em relação ao potencial médio.

A Superfície Laplaciana é dada por:

$$
\tilde{V} i=V i-\frac{1}{4} \cdot \sum_{j \in \Omega_{i}^{4}} V j
$$

onde $\Omega_{\mathrm{i}}{ }^{4}$ é o conjunto dos 4 eletrodos vizinhos do eletrodo $i$.

\subsubsection{ICA e BSS}

A Separação Cega de Fontes (BSS do inglês Blind Source Separation) consiste em uma família de métodos usados para separar diversas fontes misturadas, como em problemas do tipo "cocktail party" (JUTTEN; HERAULT, 1991; STONE, 2005). O "cocktail party" consiste em um ambiente com dois ou mais interlocutores conversando. Neste ambiente existe a mesma quantidade de microfones espalhados capturando os sons emitidos pelos interlocutores. $O$ sinal capturado por cada microfone é uma mistura de vozes de todos os indivíduos que estão conversando no ambiente. Neste contexto, deseja-se obter, a partir dos sinais capturados por cada microfone, o sinal individual emitido por cada um dos locutores.

A Análise dos Componentes Independentes (ICA do inglês Independent Component Analysis) é provavelmente o mais conhecido dos métodos de BSS (HYVÄRINEN; OJA, 2000).

O problema do "cocktail party" pode ser representado matematicamente pela eq.(3.7): 


$$
m=A \cdot s
$$

onde, $m$ é a matriz de medidas, com cada microfone em uma linha e cada amostra temporal em uma coluna; $s$ é a matriz das fontes, com uma fonte para cada linha e uma amostra temporal por coluna. A matriz $A$ é desconhecida e representa a mistura linear. A BSS consiste em determinar uma estimativa ś de $s$ sem conhecer a matriz A. Assim, temos:

$$
\dot{s}=W \cdot m
$$

onde, $W$ é a matriz de separação. Tipicamente temos $W=A^{-1}$. A dificuldade reside em descobrir os coeficientes da matriz $A$, dada que ela é desconhecida. Na estratégia adotada pela ICA assume-se que as fontes $s$ (também conhecidas por componentes) são estatisticamente independentes (HYVÄRINEN; OJA, 2000). A ICA tem se mostrado capaz de resolver muitos problemas, inclusive com sinais de EEG (DELORME; MAKEIG, 2004) e em aplicações BMI. De fato, os sinais de EEG resultam da soma de sinais provenientes de regiões cerebrais distintas. Assim, a ICA pode separar os sinais advindos de várias áreas cerebrais, que apresentam diferentes ritmos ou que contenham artefatos indesejados. Por meio da separação das fontes é possível preservar apenas as componentes de interesse e eliminar as que representam artefatos ou ruídos. A ICA tem conseguido melhorar a relação sinal-ruído e conseqüentemente o desempenho de várias BMIs (QIN; CICHOCKI, 2005).

\subsubsection{Padrões espaciais comuns}

Os Padrões Espaciais Comuns (CSP do inglês Common Spatial Patterns) são métodos de filtragem espacial, que estão sendo cada vez mais usados em BMls e têm apresentado muita eficiência (BLANKERTZ et al., 2007; POPESCU et al., 2007; RAMOSER; MULLER-GERKING; PFURTSCHELLER, 2000; WU;GAO;GAO, 2005). Estes métodos baseiam-se na decomposição do sinal de EEG em padrões espaciais (RAMOSER; MULLER-GERKING; PFURTSCHELLER, 2000). Tais padrões são escolhidos, de modo a maximizar as diferenças entre as classes envolvidas. Tipicamente, poucos padrões ou direções no espaço são suficientes para realizar a 
tarefa de discriminação. Estes padrões podem ser vistos como filtros espaciais que separam as principais características dos sinais.

\subsubsection{Soluções inversas}

Outras soluções interessantes, contudo muito menos freqüentes na literatura são as soluções inversas, as quais almejam determinar a atividade cerebral através apenas dos sinais elétricos de EEG (BAILLET;MOSHER;LEAHY, 2001; MICHEL, C.M. et al., 2004). Os sinais adquiridos no couro cabeludo podem ser modelados por um conjunto de potenciais elétricos provenientes de dipolos espalhados por todo o volume do cérebro. Diferentes técnicas visam projetar os elétricos dos eletrodos nos

dipolos e determinar o mapa de ativação cerebral, isto é, encontrar as posições, direções e amplitudes de cada dipolo.

Do ponto de vista da BMI, as soluções inversas fornecem informações relevantes sobre a atividade elétrica em cada área do cérebro e que têm dado resultados promissores (LOTTE; LÉCUYER; ARNALDI, 2007; NOIRHOMME; KITNEY; MACQ, 2008). Nas BMIs as soluções inversas são geralmente utilizadas de duas diferentes formas:

- Como algoritmo de pré-processamento que precede a extração de características (NOIRHOMME; KITNEY; MACQ, 2008);

- Como técnica de extração de características. Neste caso as posições estimadas dos dipolos ou as densidades de correntes elétricas são usadas para se determinar as tarefas mentais realizadas (CONGEDO; LOTTE; LÉCUYER, 2006).

\subsubsection{Média coerente}

A média coerente tem sido usada como método padrão na detecção de uma resposta evocada a partir de vários trechos de sinais de EEG, $x(t)$, sincronizados com o início do evento. Assume-se que a resposta evocada, $s(t)$, é determinística e 
o ruído, $r(t)$, aleatório de média igual a zero. Considera-se que o sinal $x(t)$ é igual à soma do sinal de ruído, $r(t)$, e da resposta evocada, $s(t)$.

Considerando o valor do ruído igual a zero implica que o valor médio do sinal é a própria resposta evocada. Com isto, pode-se estimar o potencial evocado como

a média aritmética de um número inteiro $N$ de trechos do sinal de EEG. É possível demonstrar (ver Apêndice A) que a relação sinal-ruído aumenta com $\sqrt{N}$.

\subsection{Extração de características}

O conjunto de sinais cerebrais adquiridos por meio do EEG alimenta o sistema com uma grande quantidade de informação, proveniente de até 256 eletrodos e com freqüências de amostragem entre 100 e $1000 \mathrm{~Hz}$. O uso mais eficiente da informação requer a separação dos dados mais relevantes, isto é, que transmitem as características dos fenômenos observados. Tais características poderiam ser, por exemplo, as potências dos sinais de EEG em diferentes freqüências. A extração de características pode ser definida como a operação que associa um conjunto de sinais a um vetor denominado vetor de características.

As etapas de identificação e extração de características dos sinais são de extrema importância para o bom desempenho da BMI. De fato, a eficácia do classificador exigirá que as características extraídas sejam adequadas, isto é, sejam capazes de transmitir corretamente o estado mental do indivíduo. Embora algumas vezes seja possível inserir os sinais brutos, isto é, sem extração de características, diretamente no algoritmo de classificação, não é recomendável fazê-lo posto que a escolha e a extração das características certas aumentam o desempenho do algoritmo de classificação. De acordo com alguns pesquisadores, as escolhas dos algoritmos de pré-processamento e extração de características parecem causar maior impacto no desempenho final que a escolha de um bom classificador (HAMMON; DE SA, 2007; PFURTSCHELLER; FLOTZINGER; KALCHER, 1993).

Diversas técnicas de extração de características para BMI têm sido propostas na literatura, as quais podem ser divididas em três grupos:

- Métodos que exploram a informação temporal presente no sinal; 
- Métodos que utilizam a informação relacionada com a freqüência;

- Métodos híbridos, baseados em representações de tempo e freqüência.

Poder-se-ia acrescentar uma quarta categoria, de métodos que exploram informação espacial. Contudo esta categoria seria útil apenas nos problemas de soluções inversas, os quais já foram descritos na seção anterior.

\subsubsection{Métodos temporais}

Os métodos temporais analisam as variações dos sinais no tempo. Tais métodos são particularmente adequados a descrição de sinais neurofisiológicos dotados de assinaturas temporais muito específicas, como o P300 e o ERD. Entre estes métodos, podemos destacar os parâmetros Hjorth, auto-regressivos e de amplitude.

\subsubsection{Método de amplitude do sinal}

A amplitude é o parâmetro mais simples de informação temporal que pode ser obtido do sinal de EEG. Este método simplesmente concatena as amplitudes dos sinais, pré-processados ou não, de diversos eletrodos em um vetor de características. Neste método, geralmente a quantidade de dados é reduzida através de filtragem espacial ou da diminuição da taxa de amostragem. Este tipo de extração de característica é dos mais usados na classificação de P300 (RIVET; SOULOUMIAC, 2007). 


\subsubsection{Parâmetros auto-regressivos}

Os métodos auto-regressivos (AR do inglês Autoregressive) assumem que o sinal $X(t)$, medido no instante $t$, pode ser modelado por uma soma ponderada de valores do sinal em instantes prévios, aos quais podemos acrescentar um termo $E_{t}$ (geralmente um ruído branco Gaussiano):

$$
X(t)=a_{1} \cdot X(t-1)+a_{2} \cdot X(t-2)+\ldots+a_{p} \cdot X(t-p)+E_{t}
$$

onde, p é a ordem do modelo e os pesos $a_{i}$ são os parâmetros auto-regressivos, usados geralmente como entradas para o algoritmo de classificação da BMI (GARRETT et al., 2003). Também foram usadas em BMls algumas variantes da AR tais como, os parâmetros auto-regressivos multivariados (ANDERSON; STOLZ; SHAMSUNDER, 1998), parâmetros exógenos auto-regressivos (BURKE et al., 2005) e parâmetros adaptativos auto-regressivos (AAR do inglês Adaptive Autoregressive) (HUAN; PALANIAPPAN, 2004). No caso do AAR os pesos $a_{i}$ podem variar com o tempo.

\subsubsection{Parâmetros Hjorth}

Os parâmetros Hjorth descrevem o comportamento de $X(t)$ no tempo usando três variáveis: atividade, mobilidade e complexidade (OBERMEIER et al., 2001).

O parâmetro atividade refere-se a variância $\sigma^{2}$ do sinal de EEG. No domínio da freqüência, a atividade pode ser interpretada como a área abaixo da curva do espectro de potência. As variáveis são dadas por:

$$
\begin{gathered}
\text { Atividade }(X(t))=\operatorname{VAR}(X(t)) \\
\text { Mobilidade }(X(t))=\sqrt{\frac{\text { Atividade }\left(\frac{\partial X(t)}{\partial t}\right)}{\text { Atividade }(X(t))}}
\end{gathered}
$$




$$
\text { Complexidade }=\frac{\text { Mobilidade }\left(\frac{\partial X(t)}{\partial t}\right)}{\text { Mobilidade }(X(t))}
$$

Tais parâmetros são geralmente usados em aplicações BMI de imaginação de movimentos (OBERMEIER et al., 2001).

\subsubsection{Métodos de freqüência}

Os sinais de EEG são compostos por um conjunto de ritmos de freqüências diferentes. A realização de uma tarefa cognitiva altera as amplitudes destes ritmos. Além disso, sinais como potenciais evocados sustentados são caracterizados por oscilações de EEG sincronizadas com as oscilações do estímulo. Deste modo, a análise do sinal no domínio da freqüência também se mostra adequada ao processamento de EEG. Existem duas abordagens diferentes para análise no domínio da freqüência: potência espectral e densidade de potência espectral.

\subsubsection{Potência espectral}

O cálculo da potência espectral numa janela de tempo consiste em uma filtragem com filtro passa-banda para uma dada freqüência seguida do cálculo da média de seus valores ao quadrado (PFURTSCHELLER; NEUPER, 2001). As características de potência de banda são geralmente calculadas para diversas freqüências, escolhidas de acordo com o estado mental que se deseja reconhecer. 


\subsubsection{Densidade espectral de potência}

A densidade espectral de potência, muitas vezes denominada espectro, informa a distribuição de potência em diferentes freqüências. A densidade espectral de potência pode ser dada pelo quadrado da transformada de Fourier do sinal (LALOR et al., 2005). O espectro é provavelmente a característica mais usada em BMls.

\subsubsection{Representações tempo-freqüencia}

Os métodos de extração de características mostrados até agora são os mais usados em BMls, entretanto alguns sinais neurofisiológicos apresentam características específicas nos domínios do tempo e freqüência. Para estes casos outras representações como a transformadas de wavelet e a transformada janelada de Fourier. Estas transformadas são mais adequadas aos sinais não estacionários, cujas freqüências variam ao longo do tempo.

\subsubsection{Transformada janelada de Fourier}

A transformada janelada de Fourier ou STFT (do inglês Short-Time Fourier Transform) consiste na multiplicação do sinal de entrada por uma função janela $w$, que é não-nula em apenas uma região limitada do tempo, seguida pela transformada deste sinal janelado. No caso do tempo discreto, a STFT $X(n, w)$ do sinal $x(n)$ é dada por:

$$
X(n, w)=\sum_{n=-\infty}^{+\infty} x(n) \cdot w(n) \cdot e^{-j w n}
$$

A representação tempo-freqüência é obtida calculando-se a transformada de Fourier por uma janela deslizante. Este método teve sucesso em diversas 
aplicações BMIs (COYLE; PRASAD; MCGINNITY, 2005; HERMAN; PRASAD; MCGINNITY, 2005). A desvantagem deste método reside no uso de uma janela de tamanho constante, o que torna as resoluções temporais e espectrais idênticas para todas as freqüências.

\subsubsection{Transformada wavelet}

A transformada wavelet apresenta como maior vantagem em relação à STFT a capacidade de adaptar a sua resolução temporal à freqüência do sinal, assim, é possível obter uma resolução temporal maior para freqüências mais altas. A transformada wavelet decompõe um sinal em um conjunto de funções $\phi_{a, b}$, denominadas wavelets. Cada função $\phi_{a, b}$ é uma versão transladada e em escala da wavelet mãe $\phi$ dada por:

$$
\phi_{a, b}=\frac{1}{\sqrt{a}} \cdot \phi\left(\frac{t-b}{a}\right)
$$

A transformada wavelet $W_{x}(s, u)$ do sinal $x$ é dada por:

$$
W_{x}(s, u)=\int_{-\infty}^{+\infty} x(t) \cdot \phi_{u, s}(t) \cdot d t
$$

onde, $s$ e $u$ são os fatores de escala e de translação respectivamente. A transformada wavelet permite analisar 0 sinal por diferentes escalas simultaneamente. Esta característica torna a transformada adequada à análise de sinais de EEG (SAMAR et al., 1999).

\subsubsection{Outras representações tempo-freqüência}

Além das transformadas STFT e wavelet outras representações tempofreqüência foram usadas em aplicações BMls. Tais representações baseavam-se em diferentes funções. Entre estes métodos, destacam-se a distribuição Wigner-Ville (GARCIA; EBRAHIMI. VESIN, 2003) e a representação Gaussiana adaptativa (MIDDENDORF et al., 2000). 
3.2.4 Outros métodos de extração de características

Além dos já citados, foram adotados, em menor escala, alguns outros métodos de extração de características em projetos de BMls. Entre estes métodos, vale a pena citar o que media a sincronização de fase ou coerência entre os eletrodos (GYSELS; CELKA, 2004), o que usava a dimensão fractal dos sinais (BOOSTANI et al., 2007), ou o espectro multifractal (BRODU, 2008). Por fim, alguns trabalhos mostraram ser interessante usar diversas técnicas de extração de características juntas (BOOSTANI et al., 2007; GYSELS; CELKA, 2004).

\subsection{Classificação}

A terceira etapa de identificação dos sinais neurofisiológicos de uma BMI refere-se à tradução das características extraídas em comandos. Esta etapa pode ser concretizada por meio de algoritmos de regressão ou classificação. Os algoritmos de classificação são os mais utilizados na literatura, assim, esta subseção será dedicada à descrição destes algoritmos.

O objetivo da classificação é associar automaticamente um vetor de características a uma determinada classe. Esta classe deve identificar a modalidade de tarefa cognitiva realizada pelo usuário. Os algoritmos de classificação, denominados classificadores, aprendem a associar o tipo ao vetor de características após serem apresentados a um conjunto de vetores de características de treinamento, os quais foram previamente rotulados com as suas respectivas classes.

\subsubsection{Análise discriminante linear}

A análise discriminante linear é uma técnica estatística de classificação de objetos em grupos. A análise é baseada em combinações lineares das variáveis 
independentes, as quais refletem uma pontuação para o determinado objeto. Esta pontuação está relacionada à probabilidade do objeto pertencer a um dado grupo.

A análise discriminante linear exige que duas condições sejam respeitadas: as variáveis independentes devem ter uma distribuição multinormal e a matriz de variâncias-covariâncias das variáveis independentes devem ser idênticas em cada grupo. O objetivo da análise discriminante linear é encontrar uma combinação linear das variáveis independentes tal que seja minimizada a probabilidade de se classificar erroneamente 0 objeto. A análise discriminante linear apresentou elevados desempenhos em diversas aplicações com BMls, tendo sido usada com sucesso no reconhecimento de imaginação de movimentos (PFURTSCHELLER, 1999), P300 (BOSTANOV, 2004), multiclasses (GARRETT et al., 2003). A análise discriminante linear pode, contudo apresentar um desempenho insatisfatório no reconhecimento de amostras de sinais complexas e não-lineares.

Uma versão deste método, denominada análise discriminante linear regularizada, que possui um parâmetro de regularização $C$ que penaliza erros de classificação durante o treinamento, apresenta melhor desempenho de classificação (MÜLLER et al., 2004). Entretanto esta versão tem sido pouco usada em aplicações com BMls.

\subsubsection{Máquinas de vetor de suporte}

As máquinas de vetor de suporte (SVMs do inglês Support Vector Machines) são redes neurais artificiais cujos neurônios estão organizados em camadas, e a informação pode trafegar em um único sentido (HAYKIN, 1999).

As redes neurais artificiais são ferramentas matemáticas compostas por unidades simples de processamento (neurônios) fortemente interconectadas e que funcionam em paralelo. Estas redes têm a capacidade de armazenar conhecimento adquirido experimentalmente e usá-lo quando necessário (HAYKIN, 1999).

Existem diversas arquiteturas de redes, que diferem entre si na função de transferência dos neurônios, no modo como são feitas as interconexões e em diversas outras características. Alguns exemplos que podem ser citados são o 
percéptron multicamadas, as redes com função de base radial, os mapa autoorganizáveis e as SVMs (HAYKIN, 1999).

No presente trabalho, foram usadas SVMs com o objetivo de classificar padrões. Em função da sua estrutura mais complexa, as redes neurais artificiais de um modo geral estão aptas a lidar com problemas envolvendo não-linearidades (HAYKIN, 1999).

A teoria sobre SVM está, a seguir, dividida em três partes. Na primeira parte, é apresentado o conceito de hiperplano ótimo de separação entre classes. $\mathrm{Na}$ segunda parte, o conceito é generalizado para o caso de padrões não separáveis. Finalmente, é descrita a construção de SVMs para a tarefa de reconhecimento de padrões.

\subsubsection{Hiperplano ótimo de separação para padrões linearmente separáveis}

Inicialmente, defini-se um conjunto de $N$ vetores $x_{i}(i=1,2, \ldots, N)$ que consiste em amostras de treinamento. Cada vetor de dados $x_{i}$ está associado a uma resposta desejada $d_{i}$ que assume os valores +1 ou -1 , dependendo da classe à qual a respectiva amostra pertence. Um hiperplano capaz de separar as duas classes pode ser descrito por:

$$
w^{T} \cdot x+b=0
$$

em que $w$ é um vetor de pesos ajustáveis e $b$ é um viés. A partir deste plano, podem-se escrever as seguintes regras

$$
\begin{gathered}
w^{T} \cdot x_{i}+b \geq 0, d_{\mathrm{i}}=+1 \\
w^{T} \cdot x_{i}+b<0, d_{\mathrm{i}}=-1
\end{gathered}
$$

onde, $d_{\mathrm{i}}$ é a saída desejada associada ao vetor de entrada $x_{\mathrm{i}}$.

Em seguida, define-se a margem de separação $\rho$ como sendo a distância calculada entre o hiperplano definido pela eq. (3.16) e o vetor de dados $x_{i}$ mais próximo (HAYKIN, 1999). O hiperplano que maximiza o valor da margem de separação $\rho$ é chamado de "hiperplano ótimo". Sendo $w_{0}$ e $b_{0}$ os valores ótimos do 
vetor de pesos e do viés definidos acima respectivamente, o objetivo de uma SVM é calcular essas variáveis, de modo a encontrar o hiperplano ótimo de separação. Os vetores $x_{i}$ que se encontram mais próximos do hiperplano são chamados de vetores de suporte.

Para isso, define-se a função discriminante:

$$
g(x)=w_{0}^{T} x+b_{0}
$$

que fornece uma medida da distância algébrica de um vetor qualquer $x$ até 0 hiperplano ótimo (HAYKIN, 1999). Mais precisamente, pode-se demonstrar que a distância algébrica entre um vetor $x$ e o hiperplano ótimo pode ser calculada como:

$$
r=\frac{g(x)}{\left\|w_{0}\right\|}
$$

em que $\left\|w_{0}\right\|$ é a norma do vetor de pesos $w_{0}$.

Quando se calcula a função discriminante da eq. (3.19) para um vetor de suporte, obtém-se, por definição, um vetor unitário. O sinal pode ser positivo ou negativo, dependendo de em qual lado do hiperplano o vetor se encontra.

Assim, para um vetor de suporte, a margem de separação vale:

$$
\rho=|r|=\frac{1}{\left\|w_{0}\right\|}
$$

Da eq. (3.21), conclui-se que, para que a margem de separação $\rho$ seja maximizada, ou seja, para que se obtenha o hiperplano ótimo, deve-se minimizar a norma euclidiana do vetor de pesos $w$.

Desta forma, pode-se formular a minimização da função custo dada por:

$$
\phi(w)=\frac{1}{2} w^{T} w
$$

Para se atender às condições de contorno $w^{T} \cdot x_{i}+b \geq 0$ e $w^{T} \cdot x_{i}+b<0$, o problema de otimização é descrito na forma (HAYKIN, 1999): desejam-se encontrar os valores do vetor de pesos $w$ e do viés $b$ de modo que a inequação

$$
d_{i} \cdot\left(w^{T} x_{i}+b\right) \geq 1
$$

seja obedecida para todas as amostras de treinamento, isto é, $i=1,2, \ldots, N$.

Esse problema de otimização pode ser resolvido utilizando-se o método dos multiplicadores de Lagrange. Verifica-se que os valores ótimos $w_{0}$ e $b_{0}$ podem ser calculados por (HAYKIN, 1999): 


$$
\begin{aligned}
& w_{0}=\sum_{i=1}^{N} \alpha_{0, i} d_{i} x_{i} \\
& b_{0}=1-w_{0}^{T} x^{(S)}
\end{aligned}
$$

em que $\mathrm{x}^{(\mathrm{S})}$ é um vetor de suporte do lado positivo do hiperplano ótimo e $\alpha_{0, \mathrm{i}}$ são os valores ótimos dos multiplicadores de Lagrange que maximizam a função objetivo dada por:

$$
Q(\alpha)=\sum_{i=1}^{N} \alpha_{i}-\frac{1}{2} \sum_{i=1}^{N} \sum_{j=1}^{N} \alpha_{i} \alpha_{j} d_{i} d_{j} x_{i}^{T} x_{j}
$$

tais que

$$
\sum_{i=1}^{N} \alpha_{i} d_{i}=0
$$

em que $\alpha_{i} \geq 0$, para $i=1,2, \ldots, N$. Desta forma, todos os parâmetros podem ser calculados a partir somente das amostras de treinamento $x_{i}$ e das respostas desejadas $d_{i}$.

\subsubsection{Hiperplano ótimo de separação para padrões não- separáveis}

Existem situações em que os dados não obedecem todos à inequação. (3.23). Destacam-se dois casos. No primeiro caso, o dado que não obedece à inequação. (3.23) está localizado dentro da região de separação, mas do lado certo da superfície de decisão, de modo que a classificação é realizada corretamente. No segundo caso, o dado se encontra do lado errado da superfície de decisão, portanto, sua classificação é incorreta.

Em ambos os casos, pode-se modificar a inequação. (3.23) incluindo-se um conjunto de variáveis escalares não-negativas $\xi_{i}, i=1,2, \ldots, N$. Então a condição imposta pela inequação. (3.23) pode ser reescrita como (HAYKIN, 1999):

$$
d_{i} \cdot\left(w^{T} x_{i}+b\right) \geq 1-\xi_{i}
$$

A função de custo definida pela eq. (3.22) também é alterada, resultando em: 


$$
\phi(w)=\frac{1}{2} w^{T} w+C \sum_{i=1}^{N} \xi_{i}
$$

em que o parâmetro $C$, selecionado pelo usuário, controla a relação entre a complexidade da SVM e o número de pontos não-separáveis (HAYKIN, 1999).

Os valores ótimos $w_{0}$ e $b_{0}$ são calculados de forma semelhante ao caso linearmente separável, porém, deve-se fazer uma alteração nas restrições impostas na eq. (3.27), para o cálculo dos multiplicadores de Lagrange:

$$
\sum_{i=1}^{N} \alpha_{i} d_{i}=0
$$

em que $0 \leq \alpha_{\mathrm{i}} \leq \mathrm{C}$, para $i=1,2, \ldots, N$.

Portanto, no caso de padrões não-separáveis, o problema a ser resolvido é muito parecido com o caso de padrões linearmente separáveis, do ponto de vista computacional. A única diferença é a restrição $0 \leq \alpha_{i} \leq C$, imposta à eq. (3.30).

\subsubsection{Construção de SVMs para reconhecimento de padrões}

O funcionamento de uma SVM se baseia, essencialmente, em um par de processos consecutivos.

O primeiro consiste no mapeamento não-linear dos vetores de entrada em um espaço de grande dimensionalidade. Este espaço, conhecido como espaço de características fica oculto da entrada e da saída da rede e tem como objetivo tornar os dados de entrada linearmente separáveis. O teorema de Cover (HAYKIN, 1999) sobre a separação de padrões diz que um conjunto de padrões não linearmente separáveis pode ser mapeado em um novo espaço multidimensional no qual esses padrões sejam muito provavelmente separáveis. Contudo, o teorema não indica de que maneira a separação é ótima.

Por isso, há a necessidade do segundo processo, o qual consiste na construção do hiperplano ótimo discutido anteriormente. Neste caso, os vetores a serem separados são os vetores de entrada originais mapeados no espaço de características que, por sua vez, são linearmente separáveis, segundo o teorema de Cover. 
O primeiro processo, isto é, o mapeamento dos dados de entrada, é realizado por um conjunto de funções não-lineares $\varphi_{j}(\mathrm{x})$, para $j=1,2, \ldots, \mathrm{m}_{1}$. O número $\mathrm{m}_{1} \mathrm{de}$ funções é a dimensão do espaço de características. Então, define-se o hiperplano de separação pela equação (HAYKIN, 1999):

$$
\sum_{j=1}^{m_{1}} w_{j} \varphi_{j}(x)+b=0
$$

em que $w_{j}$ são os pesos que conectam o espaço de características ao espaço de saída e $b$ é um viés. A eq. (3.31) pode ser reescrita assim:

$$
\sum_{j=0}^{m_{1}} w_{j} \varphi_{j}(x)=0
$$

fazendo-se $\varphi_{0}(x)=1$, para todo $x$, e $w_{0}=b$. Agrupando-se as variáveis $w_{j}$ em um vetor $w$ de dimensão $m_{1}+1$ e, analogamente, agrupando-se as funções $\varphi_{j}(x)$ em outro vetor $\varphi(x)$ também de dimensão $m_{1}+1$, chega-se a

$$
w^{T} \varphi(x)=0
$$

que é a eq. (3.32) reescrita na forma de um produto vetorial.

De forma análoga ao que foi desenvolvido anteriormente, pode-se concluir que o vetor ótimo de pesos $w_{0}$ pode ser calculado segundo a equação:

$$
w_{0}=\sum_{i=1}^{N} \alpha_{0, i} d_{i} \varphi\left(x_{i}\right)
$$

em que $\alpha_{0, i}$ são os valores ótimos dos multiplicadores de Lagrange, $d_{i}$ são as respostas desejadas para cada um dos vetores de entrada $x_{i}$ e $\varphi\left(x_{i}\right)$ é a função definida anteriormente responsável pelo mapeamento dos vetores de entrada para o espaço das características. A eq. (3.34) é equivalente à eq. (3.24) e à eq. (3.25) e uma vez que o primeiro componente de $w_{0}$ é igual ao viés $b_{0}$.

Os multiplicadores de Lagrange $\alpha_{0, i}$ são calculados minimizando-se a função objetivo:

$$
Q(\alpha)=\sum_{i=1}^{N} \alpha_{i}-\frac{1}{2} \sum_{i=1}^{N} \sum_{j=1}^{N} \alpha_{i} \alpha_{j} d_{i} d_{j} \varphi^{T}\left(x_{i}\right) \varphi\left(x_{j}\right)
$$

sujeita às restrições impostas pela eq. (3.30). Dentre os multiplicadores de Lagrange $\alpha_{0, i}$, aqueles que possuírem valor diferente de zero definem quais dos vetores de treinamento $x_{i}$ serão os vetores de suporte. 
Por último, define-se o núcleo do produto interno como sendo o produto de funções (MARPLE, 1987)

$$
K\left(x_{i}, x_{j}\right)=\varphi^{T}\left(x_{i}\right) \varphi\left(x_{j}\right)
$$

o que permite reescrever a eq. (3.35) como

$$
Q(\alpha)=\sum_{i=1}^{N} \alpha_{i}-\frac{1}{2} \sum_{i=1}^{N} \sum_{j=1}^{N} \alpha_{i} \alpha_{j} d_{i} d_{j} K\left(x_{i}, x_{j}\right)
$$

Os núcleos de produto interno devem ser escolhidos de modo a satisfazer o teorema de Mercer (MARPLE, 1987), portanto, há alguns grupos de funções que são geralmente escolhidas. No presente trabalho adotou-se o núcleo Gaussiano, dado por:

$$
K\left(x_{i}, x_{j}\right)=e^{\frac{-\left\|x_{i}-x_{j}\right\|^{2}}{\sigma^{2}}}
$$

A função discriminante, apresentada na eq. (3.19) pode, agora, ser reescrita como:

$$
g(x)=\sum_{i=1}^{N s} \alpha_{0, i} d_{i} K\left(x_{i}, x\right)+b_{0}
$$

em que Ns é o número de vetores de suporte, $\alpha_{0, i}$ são os valores ótimos dos multiplicadores de Lagrange, $d_{i}$ são as respostas desejadas equivalentes a cada vetor de treinamento $x_{i}, b_{0}$ é o viés, $x$ é o vetor que se deseja classificar e $K\left(x_{i}, x\right)$ é o núcleo do produto interno. 


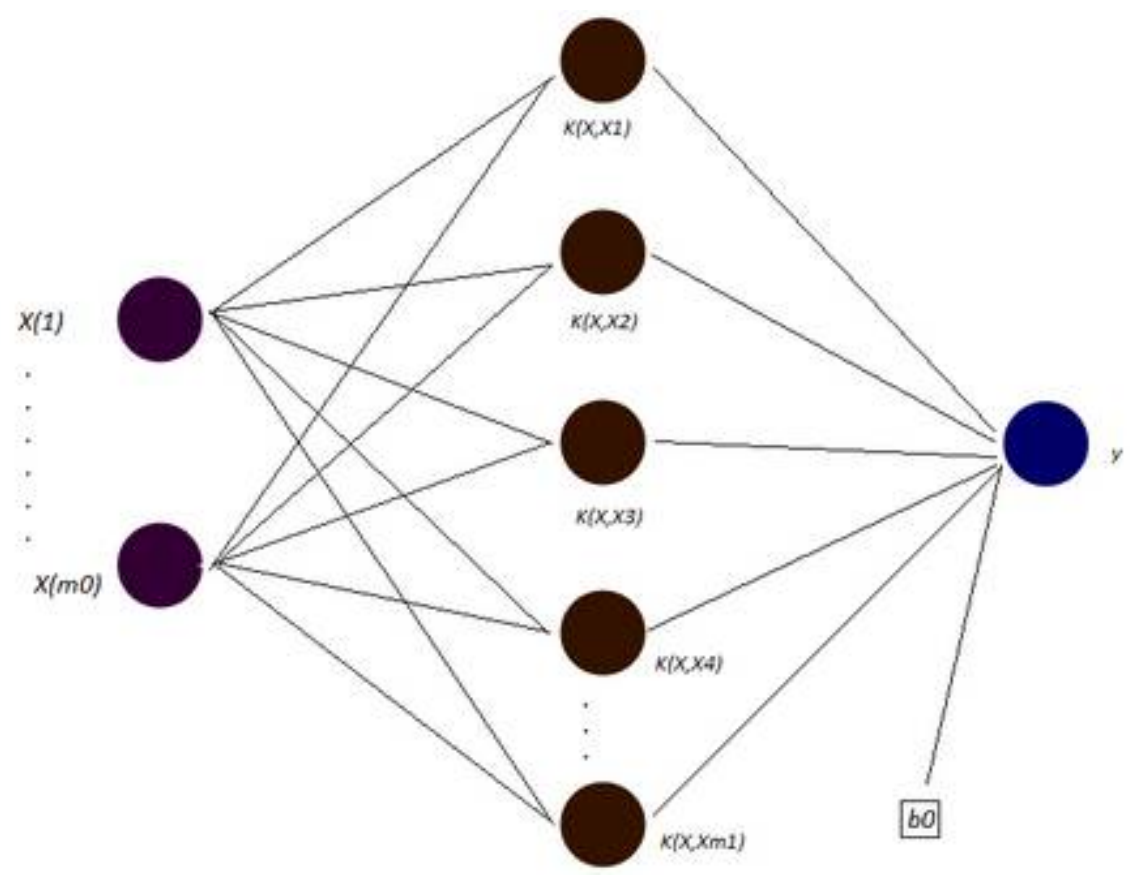

Figura 3.1 - Estrutura de uma SVM

Finalmente, a Figura 3.1 revela de forma esquemática a estrutura de uma SVM. A primeira camada, denominada camada de entrada, representa os elementos de entrada da rede, $X(I), I=1,2,3, \ldots, m_{0}$, ou seja, os elementos do vetor $X=[X(1) X(2)$ $X(3) \ldots X\left(m_{0}\right)$, que neste trabalho seriam os sinais de EEG.

A segunda camada, denominada camada oculta, possui $m_{1}$ neurônios. Um neurônio é um operador matemático que, neste caso, calcula o núcleo de produto interno entre o vetor de entrada $x$ e um dos $m_{1}$ vetores de suporte $x_{i}$.

$\mathrm{Na}$ última camada, as saídas dos neurônios da segunda camada são ponderadas e somadas, junto ao viés $b_{0}$, resultando na saída $\mathrm{g}(\mathrm{x})$ dada pela eq. (3.39).

\subsubsection{Redes neurais artificiais}

As redes neurais artificiais (ANN do inglês Artificial Neural Network) juntamente com os classificadores lineares são os algoritmos de classificação mais 
usados em projetos de BMls (ANDERSON; SIJERCIC, 1996). As ANNs são compostas por diversos neurônios, os quais permitem definir fronteiras de decisão não-lineares (BISHOP, 1996). Nesta subseção discorreremos brevemente sobre o percéptron multicamadas, que é a ANN mais utilizada em BMIs. Em seguida serão citadas algumas outras ANNs também usadas em BMIs.

\subsubsection{O percéptron multicamadas}

Este tipo de ANN é composto por diversas camadas de neurônios: uma camada de entrada, uma camada de saída e um número variável de camadas intermediárias (BISHOP, 1996). Cada uma das entradas dos neurônios é ligada à saída de um neurônio da camada antecedente. Os neurônios da última camada determinam a classe a qual pertence o vetor de características que alimenta a rede neural.

Redes neurais artificiais e, portanto, percéptrons multicamadas, são aproximadores universais. Assim, quando dotados de um número adequado de camadas e neurônios podem aproximar qualquer função contínua. Esta característica aliada à capacidade de reconhecer um número qualquer de classes torna as ANNs adequadas a uma grande quantidade de BMls. O percéptron multicamadas sem a camada intermediária é equivalente à análise discriminante linear. Por isso, podemos dizer que o percéptron também tem sido usado em BMIs.

\subsubsection{Outras redes neurais artificiais}

Outras arquiteturas de ANNs foram usadas em BMls. Entre elas, uma foi concebida com o propósito de ser utilizada em BMls: o classificador Gaussiano (MILLÁN et al., 2000; MILLÁN et al., 2004). Nesta rede cada neurônio é uma função discriminante Gaussiana. Segundo Millán (2000) o classificador Gaussiano apresenta desempenhos superiores aos dos percéptrons multicamadas em BMls. 
Além destas, as seguintes ANNs aparecem, em menor quantidade, na literatura:

- Learning Vector Quantization (KOHONEN, 1990; PFURTSCHELLER; FLOTZINGER; KALCHER, 1993);

- Fuzzy ARTMAP (CARPENTER et al., 1992);

- Finite Impulse Neural Network (HASELSTEINER; PFURTSCHELLER, 2000);

- RBF (HOYA et al., 2003);

- Bayesian Logistic Regression (PENNY et al., 2000);

- Adaptive Logic Network (KOSTOV; POLAK, 2000);

- Probability estimating Guarded Neural Classifier (FELZER; FREISIEBEN, 2003).

\subsubsection{Classificadores Bayesianos não-lineares}

Nesta subseção serão abordados dois tipos de classificadores Bayesianos: o quadrático e o modelo oculto de Markov. Ambos os classificadores produzem fronteiras de decisão não-lineares. Entretanto, estes classificadores não são tão usados como os classificadores lineares e as redes neurais artificiais.

\subsubsection{Classificador Bayesiano quadrático}

O propósito do classificador Bayesiano é associar o vetor de características à classe com maior probabilidade de possuí-lo. Este classificador admite que as características possuam distribuições normais, o que produz fronteiras de decisão quadráticas. Apesar deste classificador não ser muito usado em BMls, ele obteve bons resultados no reconhecimento de tarefas mentais e em imaginação de movimentos (BARRETO; FROTA; DE MEDEIROS, 2004; LEMM; SCHAFER; CURIO, 2004). 


\subsubsection{Modelo oculto de Markov}

O modelo oculto de Markov (HMM do inglês Hidden Markov Model) é um autômato finito probabilístico, que fornece a probabilidade de se observar uma determinada seqüência de vetores de características (RABINER, 1989). Cada estado do autômato finito corresponde à probabilidade de encontrar um dado vetor de características. Para as BMls, estas probabilidades são geralmente modelos de misturas gaussianas (OBERMEIER et al., 2001).

Modelos ocultos de Markov são algoritmos adequados à classificação de séries temporais (RABINER, 1989), deste modo têm sido aplicados como classificadores em projetos de BMls.

Apesar dos modelos ocultos de Markov não serem muito utilizados em BMls, há estudos que sugerem que eles podem apresentar bons desempenhos em BMls.

\subsubsection{Vizinho mais próximo}

Este é um dos métodos de classificação mais simples. Nele assumimos que duas instâncias próximas no espaço são oriundas da mesma classe. O algoritmo é simples: para cada amostra com classe desconhecida, procura-se a classe conhecida mais próxima no espaço de atributos, isto é, o vizinho mais próximo.

Uma variante deste é o método dos k-vizinhos mais próximos ( $\mathrm{kNN}$ do inglês $k$-Nearest Neighbors), que consiste em escolher a classe à qual pertencem os $\mathrm{k}$ vizinhos mais próximos. Podem ser escolhidas várias métricas de distância, como a euclidiana e a de Mahalanobis. 


\section{$4 \quad$ Materiais e Métodos}

Com o intuito de exemplificar o processamento de sinais de uma interface cérebro-máquina, é apresentada nesta seção uma experiência, na qual se põem em prática algoritmos de pré-processamento, extração de características e classificação, descritos na seção anterior. Por motivos de conveniência e limitação de recursos para realizar a experiência, a análise foi realizada sobre amostras de sinais de EEG adquiridas em 2007 pelo Multimedia Signal Processing Group da Ecole Polytechnique Fédérale de Lausanne (EPFL) na Suíça.

Participaram daquele experimento nove pessoas, sendo cinco portadores de deficiências motoras causadas por problemas neurológicos variados e quatro sem problemas neurológicos conhecidos. Nesta dissertação são considerados apenas quatro dos cinco indivíduos com problemas neurológicos, aqui denominados $\mathrm{S} 1, \mathrm{~S} 2$, S3 e S4. Sendo os indivíduos normais, estudantes de doutorado com idades entre $30 \pm 2,3$ anos, aqui chamados: S6, S7, S8 e S9.

Todos aqueles indivíduos portadores de algum tipo de deficiência (ver Tabela 4.1) usavam cadeira de rodas. Os indivíduos $S 1$ e $S 2$ eram capazes de realizar movimentos simples e lentos com os braços e mãos, contudo não podia mover outros membros. Os indivíduos S1 e S2 sofriam de disartria leve, mas eram capazes de se comunicar. O sujeito S3 podia realizar movimentos restritos com a sua mão esquerda, mas não era capaz de mover os braços ou outros membros. A comunicação oral com o sujeito S3 era inviável, contudo ele era capaz de responder sim/não piscando os olhos. A mulher S4 tinha reduzido controle sobre os movimentos das mãos e dos braços, era capaz de se comunicar oralmente, embora apresentasse disartria leve. 
Tabela 4.1 - Sujeitos com deficiência que participaram da experiência

\begin{tabular}{|c|c|c|c|c|}
\hline Sujeito & S1 & S2 & S3 & S4 \\
\hline Diagnóstico & Ataxia & $\begin{array}{l}\text { Esclerose } \\
\text { múltipla }\end{array}$ & $\begin{array}{c}\text { Estágio } \\
\text { avançado de } \\
\text { esclerose } \\
\text { lateral } \\
\text { amiotrófica }\end{array}$ & $\begin{array}{c}\text { Traumatismo } \\
\text { cerebral e } \\
\text { medular de } \\
\text { nível C4 }\end{array}$ \\
\hline Idade & 56 & 51 & 47 & 33 \\
\hline $\begin{array}{c}\text { Idade do início } \\
\text { da doença }\end{array}$ & 0 (neonatal) & 37 & 39 & 27 \\
\hline Sexo & Masculino & Masculino & Masculino & Feminino \\
\hline $\begin{array}{c}\text { Capacidade de } \\
\text { falar }\end{array}$ & Disartria leve & $\begin{array}{c}\text { Disartria } \\
\text { leve }\end{array}$ & Disartria grave & Disartria leve \\
\hline $\begin{array}{l}\text { Controle sobre } \\
\text { os membros }\end{array}$ & Pouco & Pouco & Muito pouco & Pouco \\
\hline $\begin{array}{l}\text { Controle da } \\
\text { respiração }\end{array}$ & Normal & Normal & Fraco & Normal \\
\hline $\begin{array}{c}\text { Movimento } \\
\text { voluntário dos } \\
\text { olhos }\end{array}$ & Normal & $\begin{array}{l}\text { Nistagmo } \\
\text { leve }\end{array}$ & Normal & Normal \\
\hline
\end{tabular}

\subsection{A experiência}
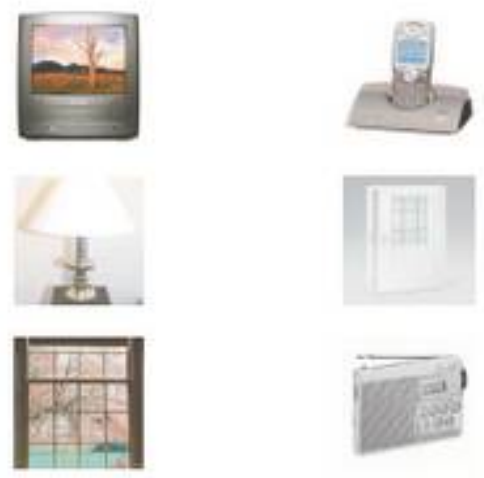

Figura 4.1 - Tela do laptop (adaptado de Ebrahimi (2007)) 
$\mathrm{Na}$ experiência uma tela de computador portátil (laptop) era usada para mostrar seis imagens relacionadas a uma televisão, um telefone, uma lâmpada, uma porta, uma janela e um rádio conforme a descrição contida na Figura 4.1. As imagens apareciam em uma seqüência aleatória, uma de cada vez. Conforme ilustra a figura 4.2 , cada imagem permanecia no monitor por $100 \mathrm{~ms}$, sendo que durante os $300 \mathrm{~ms}$ seguintes nenhuma imagem era mostrada, isto é, os intervalos interestímulos eram de 400ms.

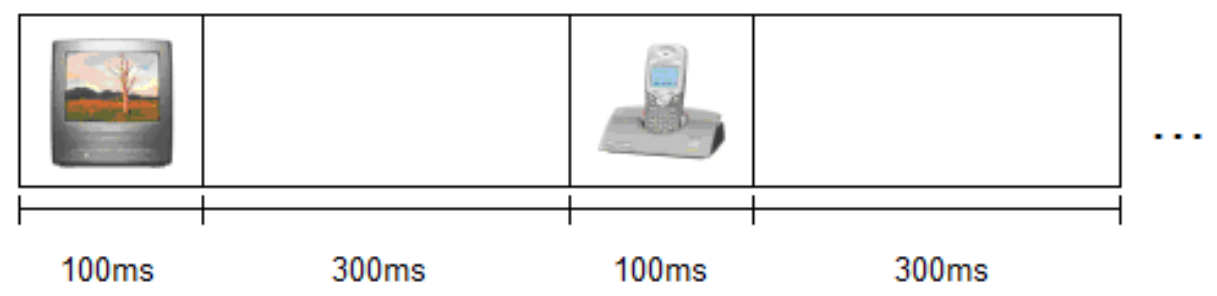

Figura 4.2 - Exemplo de seqüência aleatória de imagens apresentadas

Enquanto era realizado o experimento, os sinais de EEG de 32 eletrodos, localizados em posições do padrão internacional 10-20, do participante eram extraídos a uma freqüência de amostragem igual a $2048 \mathrm{~Hz}$ e enviados à entrada de um amplificador comercial Biosemi Active Two, usado para amplificação e conversão analógico-digital dos sinais.

\subsection{Roteiro da experiência}

Cada sujeito participou de quatro sessões. As duas primeiras ocorriam em um dia e as duas últimas em outro dia. O tempo entre a primeira e a última sessão era inferior a duas semanas. Conforme ilustrado na figura 4.3, cada sessão consistia em seis rodadas, uma para cada tipo de imagem. O seguinte protocolo era usado em cada rodada:

1- Era pedido aos indivíduos que contassem mentalmente o número de vezes em que uma dada imagem era mostrada;

2- $\quad$ As seis imagens eram mostradas e era emitido um aviso sonoro; 
3- Quatro segundos após o aviso, uma seqüência aleatória era apresentada no monitor. A seqüência era composta por blocos de seis, assim, em seis imagens cada uma aparecia uma vez, em doze imagens cada uma aparecia duas vezes, etc. O número de blocos era sorteado entre 20 e 25 . Em média 22,5 blocos de seis flashes eram mostrados em cada rodada. Deste modo, em média havia 22,5 alvos (P300) e 22,5 x 5 = 112,5 não-alvos (não P300);

4- Após cada rodada pedia-se aos sujeitos que dissessem o número de vezes em que a imagem alvo apareceu.

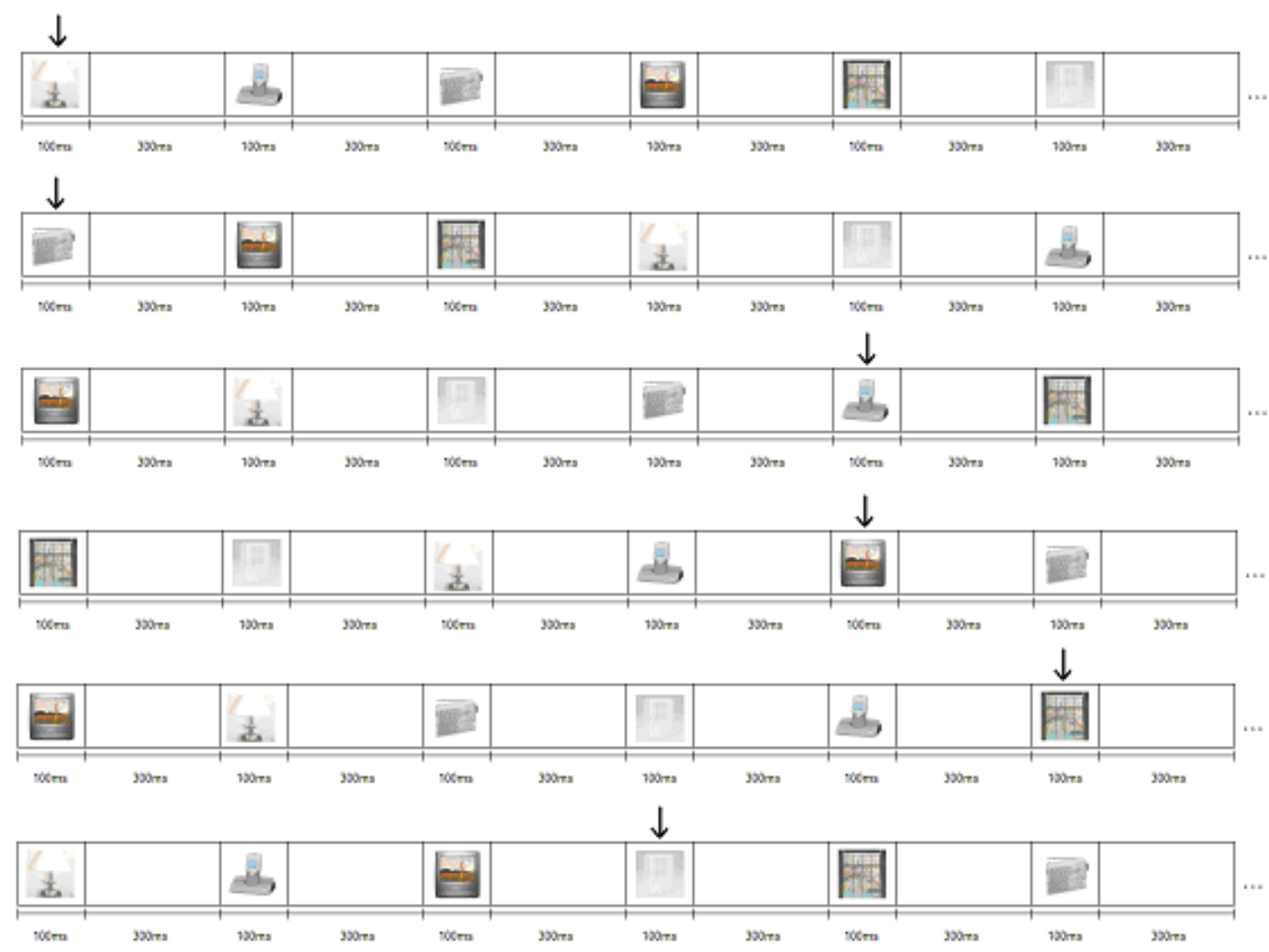

Figura 4.3 - Ilustração de sessão contendo seis rodadas, uma para cada tipo de imagem.

A duração de cada rodada era de aproximadamente um minuto e a duração de cada sessão, incluindo o tempo para colocar os eletrodos e os intervalos, era de aproximadamente 30 minutos. Uma sessão era composta por cerca de $6 \times 22,5 \times 6=$ 810 flashes. Em média, cada indivíduo via 3240 flashes ao longo das quatro sessões. 


\subsection{Análise off-line}

O processamento de sinais off-line, isto é, com os sinais de EEG já adquiridos consistiu em uma primeira fase de pré-processamento (seção 4.3.1), na qual os sinais foram preparados para serem usados como entradas dos algoritmos de classificação e, em uma fase seguinte, de classificação usando máquinas de vetores de suporte.

\subsubsection{Pré-processamento}

$\mathrm{Na}$ fase de pré-processamento e preparação dos dados seguiu-se 0 protocolo:

1 - Usou-se como potencial de referência o valor médio dos dois eletrodos mastóides;

2- Foi aplicado um filtro Butterworth passa-banda de sexta ordem com freqüências de corte iguais a $1 \mathrm{~Hz}$ e $12 \mathrm{~Hz}$. A função butter do Matalab foi aplicada para este fim;

3 - A freqüência de amostragem foi reduzida 64 vezes, e passou de 2048 para 32 $\mathrm{Hz}$;

4 - Foram extraídos todos os trechos de $1000 \mathrm{~ms}$ de duração, onde cada trecho tinha início no momento do flash;

5 - Para reduzir os efeitos de picos de grande amplitude, estranhos aos sinais que se desejava observar, tais como, movimentos musculares, piscar de olhos, etc. Para cada um dos eletrodos foi determinado $010^{\circ}$ e $090^{\circ}$ percentil. Valores de amplitude menores que $010^{\circ}$ ou maiores que $090^{\circ}$ foram substituídos pelo $10^{\circ}$ ou $90^{\circ}$ percentil respectivamente;

6 - Todos os sinais foram então normalizados e ficaram na escala comum entre 2 e +2 
7 - $\quad$ Foram escolhidos oito eletrodos (veja Figura 4.4): Fz, Cz, Oz, Pz, P3, P4, P7 e P8. Os demais foram eliminados;

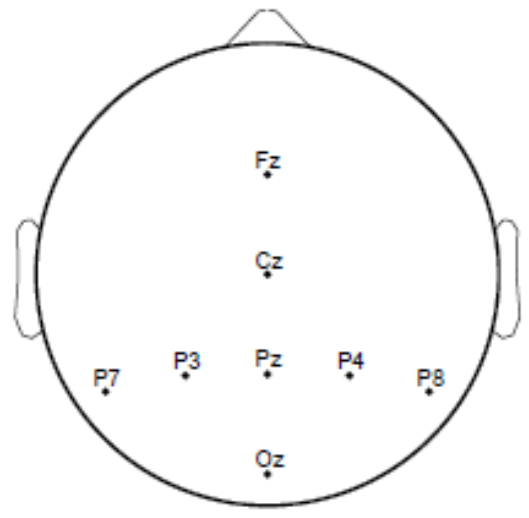

Figura 4.4 - Distribuição espacial dos eletrodos no escalpo

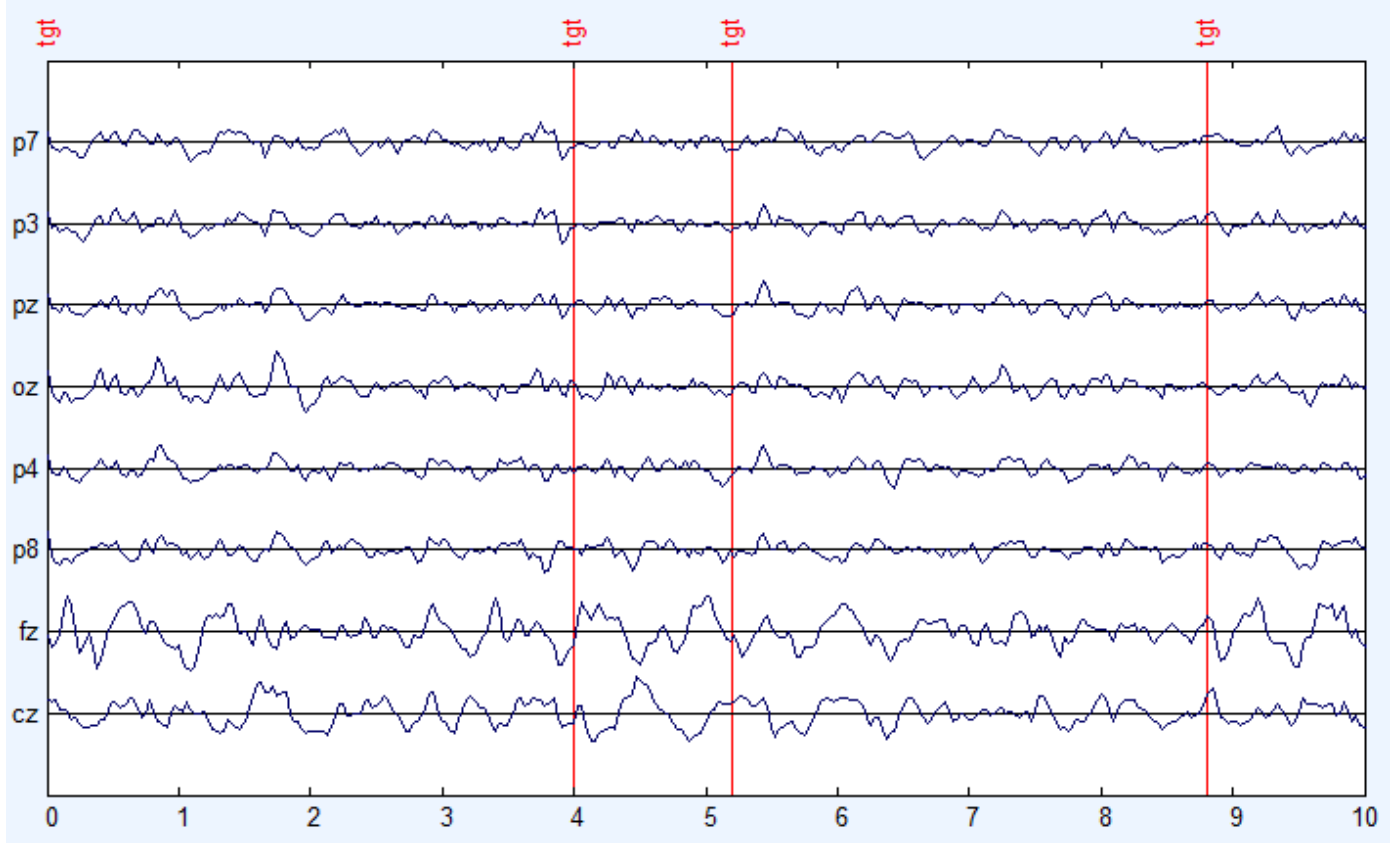

Figura 4.5 - EEG pré-processado da primeira rodada da sessão 1 do individuo S6, de 0 a 10 s (as linhas vermelhas representam os momentos em que a imagem referente àquela rodada foi mostrada).

A figura 4.5 ilustra os sinais após o pré-processamento, entre 0 e 10 s para a primeira rodada da sessão 1 do indivíduo S6. 


\subsubsection{Treinamento do classificador SVM}

Nesta dissertação optou-se por usar classificadores supervisionados do tipo máquina de vetor de suporte com núcleo linear. Para classificar os estímulos de cada indivíduo foram utilizadas oito SVMs, uma para cada eletrodo. Em cada rodada cinco objetos eram associados à saída -1 (falso), enquanto o objeto esperado, que disparava o P300, era associado à saída +1 (verdadeiro). As SVMs eram treinadas com amostras de dois tipos de objetos: um que continha o P300 (+1) e outro que não tinha o P300 (-1). O intervalo de interesse, isto é, o que efetivamente alimentava cada SVM, era aquele entre 150 e 350ms ocorridos após cada flash. Este intervalo foi escolhido em função da grande probabilidade de se encontrar nele o P300. Cada rodada oferecia então dois tipos de objetos: um verdadeiro (+1) e um falso $(-1)$. A figura 4.7 ilustra um bloco, contendo um alvo $(+1)$ e um objeto não-alvo (escolhido aleatoriamente). Conforme mostrado na figura 4.8 , no treinamento de cada SVM eram usados objetos de três sessões diferentes, cada uma com seis rodadas, o que totalizava 36 objetos diferentes: 18 com P300 (+1) e 18 sem P300 (-1).

Com a pretensão de melhorar a relação sinal-ruído das amostras usadas no treinamento foram feitas, para cada um dos objetos, médias coerentes usando os 20 primeiros blocos de cada rodada.

A figura 4.6 ilustra o efeito da média coerente (descrita na seção 3.1.5) usando-se 2, 5, 10, 15 e 20 blocos de alvos e não alvos. Os gráficos referem-se ao canal $\mathrm{Cz}$ em períodos entre 150 e 350ms após os flashes. Conforme esperado, na medida em que a média coerente é aplicada usando-se uma quantidade maior de blocos (da esquerda para a direita), observa-se a redução dos ruídos aleatórios presentes nos sinais e se torna mais evidente o potencial visual evocado P300, mostrado na parte de cima da figura. 

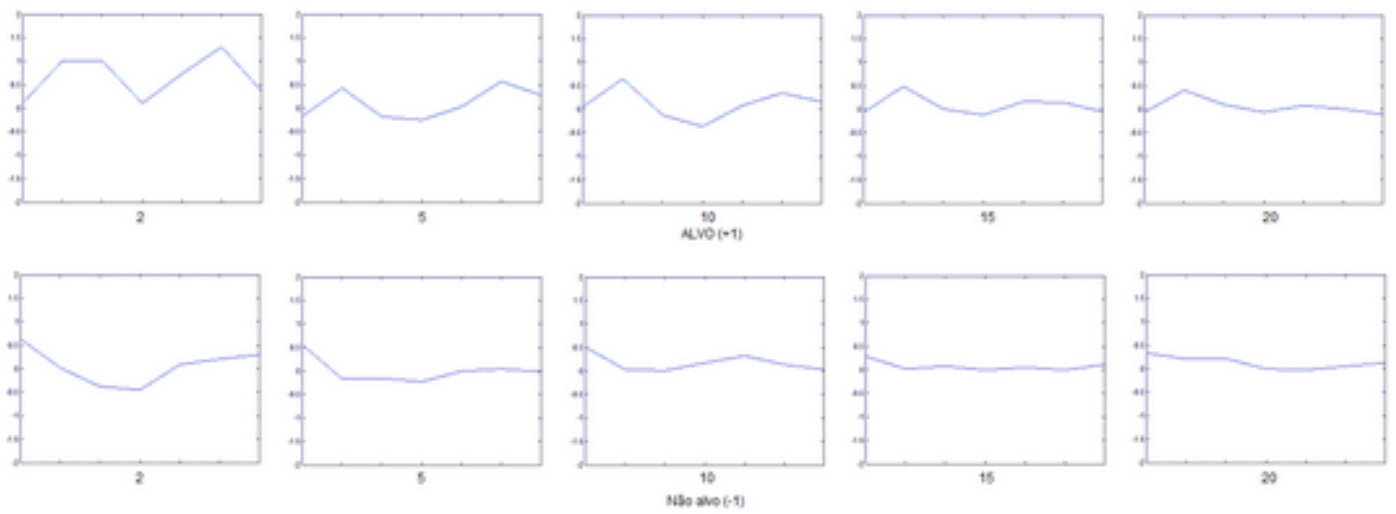

Figura 4.6 - Médias coerentes usando 2, 5, 10, 15 e 20 blocos para alvo (+1) (em cima) e não alvo (1) (em baixo).

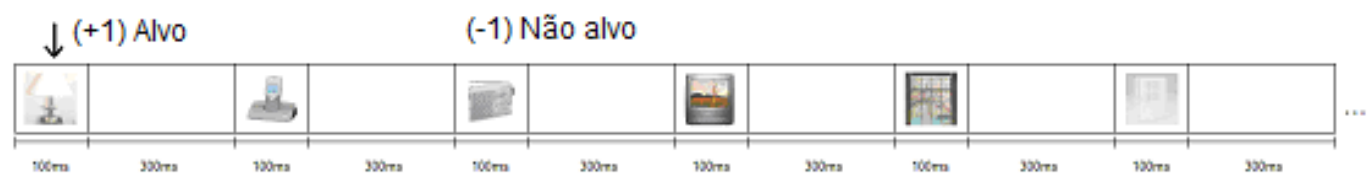

Figura 4.7 - Exemplo de um bloco, onde é associado +1 ao objeto alvo e -1 a um objeto não-alvo escolhido aleatoriamente dentre os cinco.

As SVMs foram criadas através da biblioteca LIBSVM (Chang;Lin, 2001), escrita em linguagem $\mathrm{C}$ e compilada para Matlab. Todas as fases de processamento de sinais foram realizadas com Matlab versão R14. 


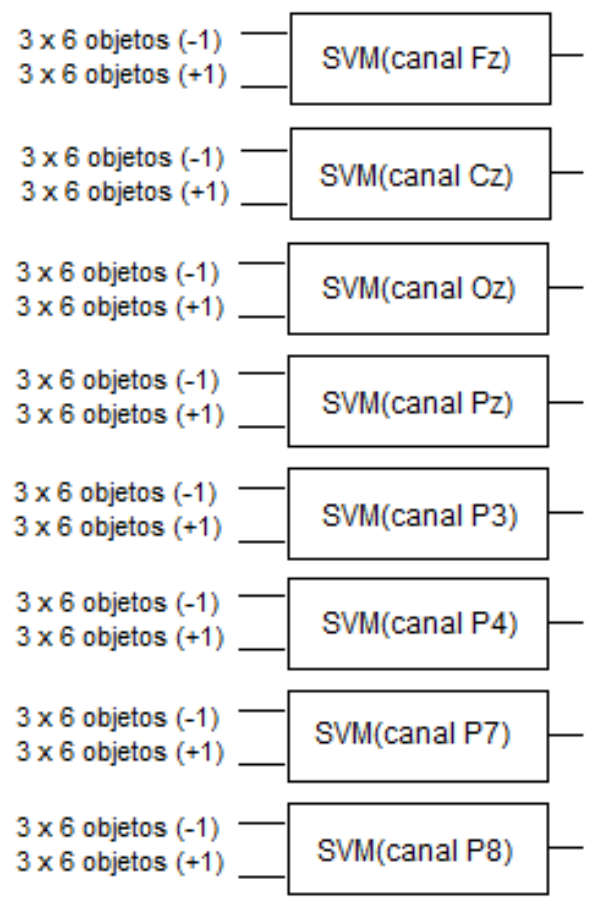

Figura 4.8 - Treinamento das 8 SVMs com objetos alvo (+1) e não-alvo (-1) de 3 sessões e 6 blocos cada.

\subsubsection{Metodologia da classificação}

Cada SVM era treinada independentemente das outras, assim cada SVM aprendia a reconhecer o potencial P300 de um dos oito canais. Reconhecer o potencial P300 quer dizer associar a amostra de sinal de EEG de certo eletrodo ao seu respectivo valor, que é (+1), caso esteja presente o potencial evocado P300 ou $(-1)$, caso contrário.

Depois de treinadas, as SVMs estarão aptas a classificar os as amostras de sinais de EEG. A classificação será feita da seguinte forma:

- Para um número inteiro de blocos entre 1 e 20 calculam-se, para cada um dos oito eletrodos, as médias coerentes referentes a cada um dos 6 objetos; Têm-se então seis amostras de sinais. Para: a televisão, o telefone, a lâmpada, a porta, a janela e o rádio; 
- As seis amostras, referentes aos diferentes tipos de objetos, serão as entradas de cada um dos seis módulos de decisão: $R_{1}, R_{2}, R_{3}, R_{4}, R_{5}$ e $R_{6}$. $O$ módulo de decisão, conforme ilustra a figura 4.9, consiste em um sistema que soma os resultados $(-1$ ou +1$)$ de um grupo de oito SVMs, uma para cada eletrodo. Assim, a saída do módulo de decisão é um número inteiro $R_{\mathrm{x}}$, tal que $-8 \leq \mathrm{R}_{\mathrm{x}} \leq+8$;

- Ao final, serão obtidos os resultados $R_{x}$ de cada um dos seis objetos. Se existir um valor $R_{x}$ maior que todos os outros cinco, então a este módulo de decisão $x$, e, portanto, ao objeto $x$ estará relacionado o potencial evocado P300.

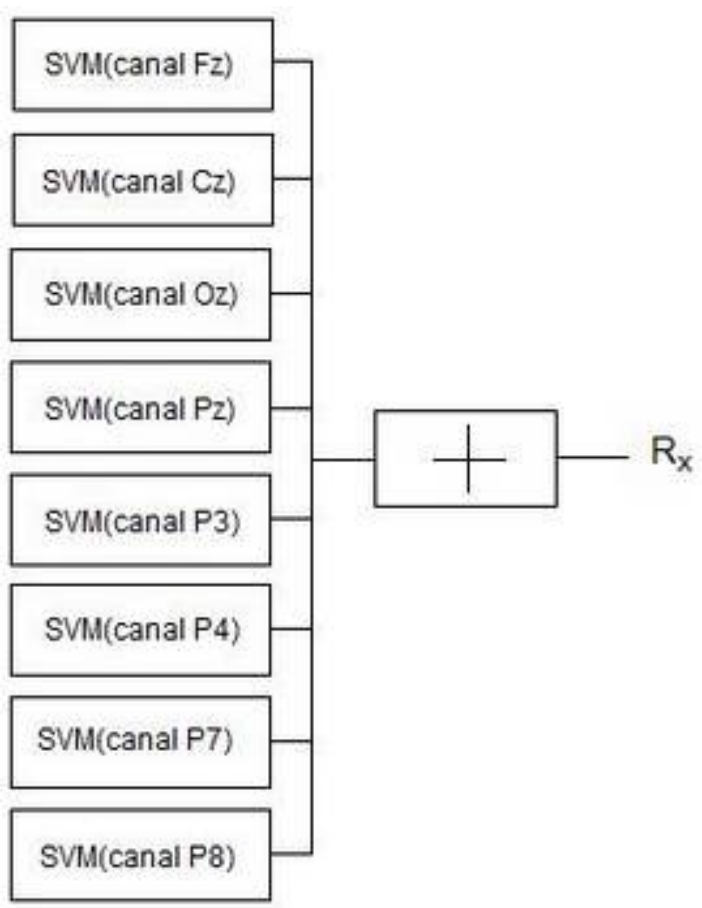

Figura 4.9 - Módulo de decisão $R_{x}$ 


\section{$5 \quad$ Resultados e Discussão}

Nesta seção serão apresentados os resultados obtidos de desempenho, isto é, a probabilidade de acerto do algoritmo classificador e a taxa de transmissão de informação (em bits/min) para cada um dos oito sujeitos. Além disso, serão discutidas as performances e diversos aspectos da experiência.

\subsection{Obtenção das probabilidades de acerto}

Foi aplicada a técnica de validação cruzada deixando um fora (leave-one-out cross-validation) para cada um dos indivíduos, o uso desta técnica tinha como propósito determinar o parâmetro de regularização $C$ (ver eq. 3.29) das SVMs, que promovia os melhores desempenhos dos classificadores. Os possíveis valores de $\mathrm{C}$ eram limitados ao intervalo de 1 a $10 \mathrm{com}$ passos de 0,5. Era considerado o classificador de melhor desempenho aquele que tivesse a maior probabilidade de classificar corretamente os objetos.

De maneira resumida, a técnica de validação cruzada deixando um fora propõe a escolha de uma amostra para avaliação e o uso das demais, no nosso caso três, para treinar os classificadores. Isto era repetido quatro vezes, uma vez para cada amostra, e então os desempenhos médios dos classificadores eram calculados. Esta técnica embora fosse computacionalmente custosa permitia aproveitar ao máximo os dados disponíveis.

\subsection{Cálculo da taxa de transmissão de informação}

Além da probabilidade de acerto, é também possível estimar o desempenho da BMI através da sua respectiva velocidade de transmissão de informação. De maneira simplificada, esta velocidade representa a quantidade de bits que pode ser 
transferida pelo usuário à BMI em um dado intervalo de tempo. Nesta dissertação a fórmula adotada no cálculo da velocidade de transmissão de informação foi aquela definida por Wolpaw et al. (2002):

$$
b(N, p, t)=\left(\log _{2}(N)+p \cdot \log _{2}(p)+(1-p) \cdot \log _{2}\left(\frac{1-p}{N-1}\right)\right) \cdot \frac{60}{t}
$$

onde, $N$ é o número de diferentes comandos que podem ser enviados, $p$ é a probabilidade do comando ser interpretado corretamente, e $t$ é o tempo em segundos necessário para enviar um comando. Deve-se observar que, de acordo com o teorema de codificação do canal ruidoso, a velocidade de transmissão representa a máxima taxa de envio de bits em um determinado canal de comunicação (MACKAY, 2003). Esta velocidade só pode ser alcançada caso sejam utilizados algoritmos ótimos de codificação e decodificação. Entretanto, esta forma de medição é muito empregada na literatura e seu uso aqui se justifica para efeito de comparação de desempenho com outros estudos.

\subsection{Gráficos de desempenho}

Abaixo são apresentados em gráficos, valores da probabilidade de acerto do classificador e a velocidade de transmissão de informação (em bits/min) em função do tempo (em segundos). Os eixos das abscissas referem-se ao número de blocos (de 1 a 20) usados no cálculo da média coerente da amostra de classificação. Para tornar mais evidente os desempenhos dos classificadores, os eixos das abscissas estão em unidades de tempo. Como cada bloco dura 2,4s, os gráficos mostram as performances dos classificadores entre 2,4 e $48 \mathrm{~s}$.

\subsubsection{Gráficos de desempenho individual}



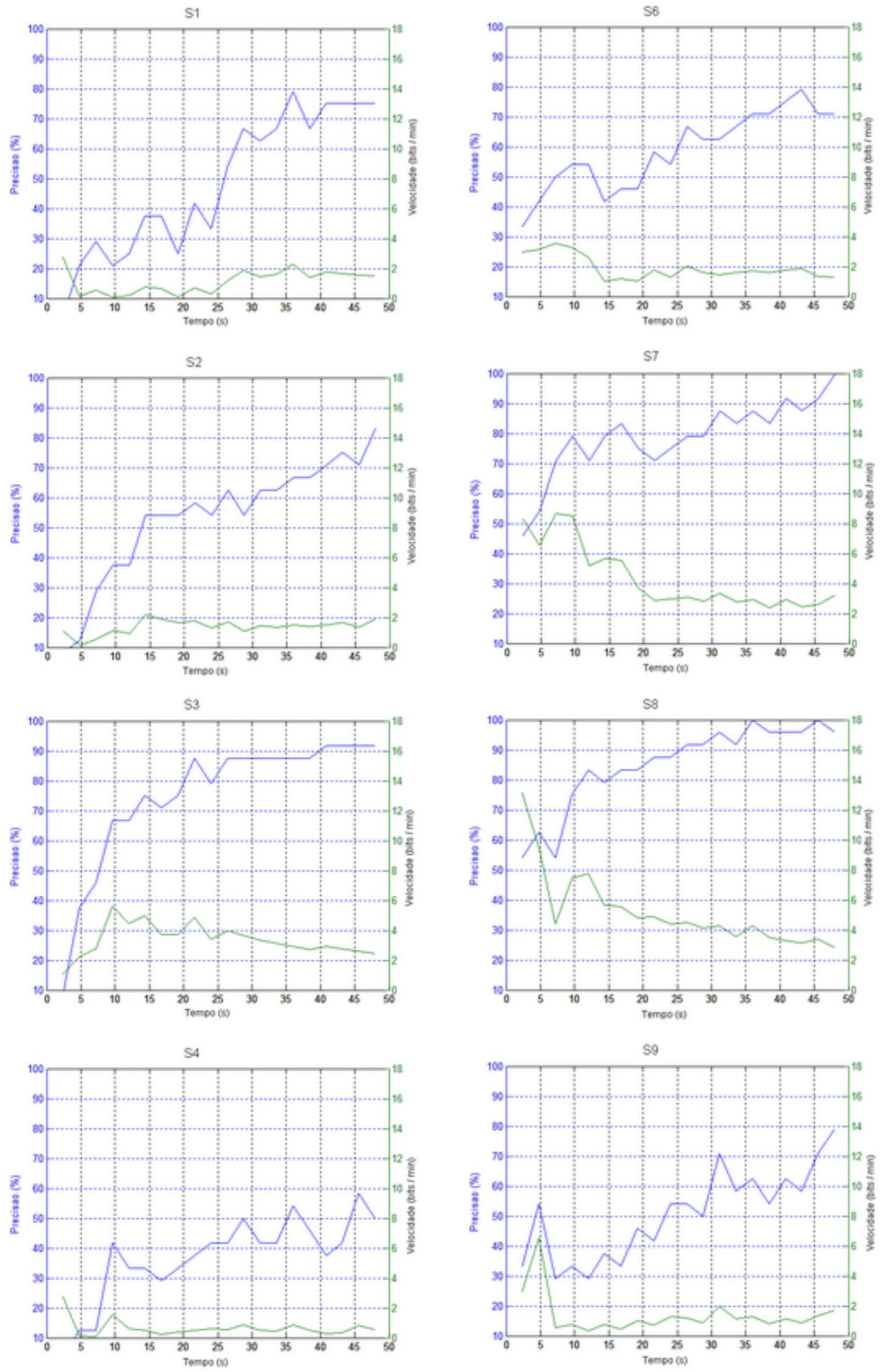

Figura 5.1 - Gráficos de probabilidade de acerto e de velocidades de transmissão de informações 


\subsubsection{Gráficos de desempenhos médios}

A figura 5.2 exibe o gráfico com o desempenho médio dos oito sujeitos.

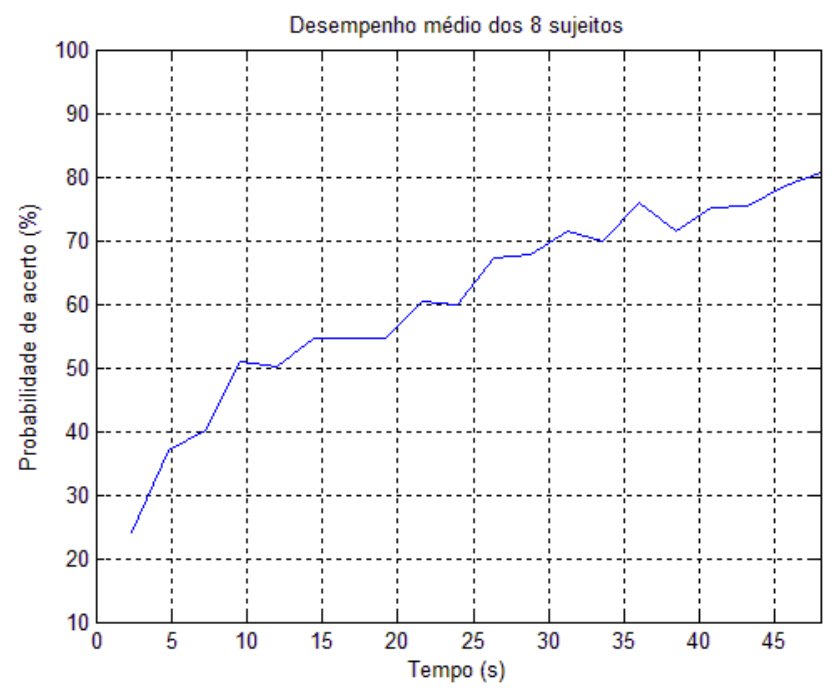

Figura 5.2 - Gráfico de desempenho médio dos indivíduos

A figura 5.3 mostra os desempenhos médios dos 4 indivíduos deficientes e 4 normais.

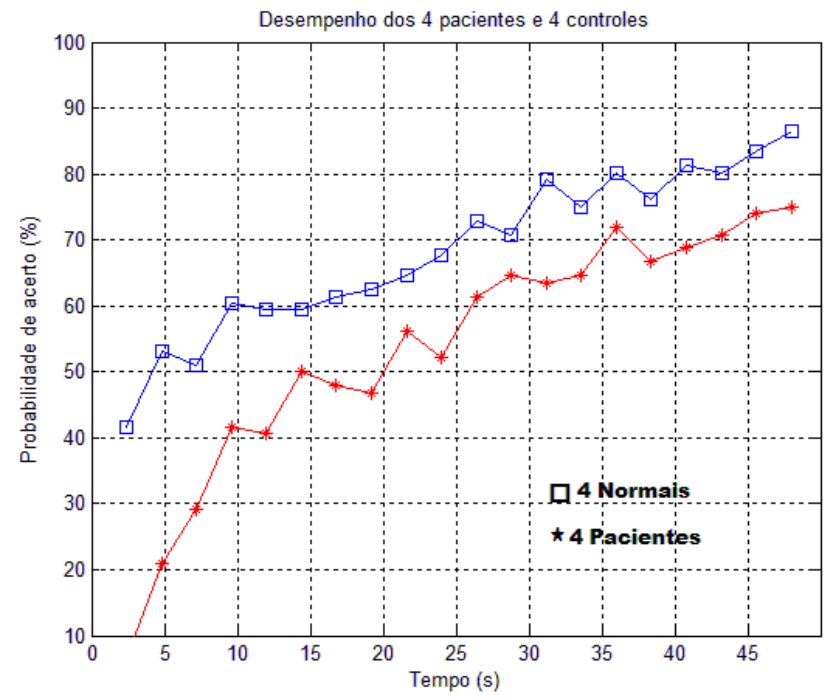

Figura 5.3 - Gráficos de desempenhos médios dos 4 pacientes e 4 controles 


\subsection{Tabelas de desempenho}

A tabela 5.1 apresenta, para cada um dos oito sujeitos, os valores máximos de probabilidade de correta classificação e o momento em que ocorre. Na tabela 5.2 são mostradas as probabilidades de acerto para cada sujeito após 48s (20 blocos).

A tabela 5.3 mostra as velocidades máximas de transmissão de informação (em bits/min) e os momentos em que ocorrem.

Tabela 5.1 - Valores das probabilidades máximas de acerto

\begin{tabular}{lcccccccc}
\hline Sujeito & S1 & S2 & S3 & S4 & S6 & S7 & S8 & S9 \\
\hline Probabilidade & 79,2 & 83,3 & 91,7 & 58,3 & 79,2 & 100 & 100 & 79,2 \\
máxima (\%) & & & & & & & & \\
\hline Momento da & 36 & 48 & 48 & 45,6 & 43,2 & 48 & 36 & 48 \\
ocorrência (s) & & & & & & & & \\
\hline
\end{tabular}

Tabela 5.2 - Probabilidades de acerto após 48s

\begin{tabular}{lcccccccc}
\hline Sujeito & S1 & S2 & S3 & S4 & S6 & S7 & S8 & S9 \\
\hline Probabilidade & 75 & 83,3 & 91,7 & 50 & 70,8 & 100 & 95,8 & 79,2 \\
(\%) após 48s & & & & & & & & \\
\hline
\end{tabular}

Tabela 5.3 - Velocidade de transmissão máxima

\begin{tabular}{lllllllll}
\hline Sujeito & S1 & S2 & S3 & S4 & S6 & S7 & S8 & S9 \\
\hline $\begin{array}{l}\text { Velocidade } \\
\text { max. de }\end{array}$ & 2,7 & 2,2 & 5,6 & 2,7 & 3,5 & 8,6 & 13,1 & 6,6 \\
transmissão & & & & & & & & \\
(bit/min) & & & & & & & & \\
\hline Momento & 2,4 & 14,4 & 9,6 & 2,4 & 7,2 & 7,2 & 2,4 & 4,8 \\
em que & & & & & & & & \\
ocorre (s) & & & & & & & & \\
\hline
\end{tabular}


A habilidade da BMI aqui descrita, de identificar as escolhas dos usuários que observam os objetos na tela de computador, provém da sua capacidade de distinguir os sinais de EEG que apresentam os potenciais evocados P300 daqueles que não apresentam.

A tarefa de discernir quais dentre as amostras de EEG possuem o P300 é bastante dificultada pelo fato dos sinais de EEG terem amplitudes, da ordem de $100 \mu \mathrm{V}$, muito superiores às dos potenciais evocados, que são tipicamente de 1 a $30 \mu \mathrm{V}$ (SANEl; CHAMBERS, 2007). Duas medidas práticas foram adotadas a fim de tornar o potencial evocado P300 mais perceptível: o uso de um filtro digital passabandas e o emprego da técnica conhecida como média coerente. O filtro digital passa-bandas usado tinha freqüências de corte de 1 e $12 \mathrm{~Hz}$ e a sua escolha baseou-se no fato do P300 ter uma longa latência ( aproximadamente $300 \mathrm{~ms}$ ), o que significa que as potências concentram-se em componentes espectrais de baixas freqüências, abaixo das ondas alfa (aproximadamente entre 8 e 13Hz). A aplicação da técnica da média coerente (ver seção 3.1.5) supõe que:

- O sinal de EEG pode ser concebido como a soma de: uma atividade cerebral de fundo com um potencial evocado;

- O potencial evocado apresenta características morfológicas, de amplitude e latência estáveis ao longo do tempo;

- A atividade cerebral de fundo é aleatória e não está relacionada aos potenciais evocados.

Entretanto, estas suposições não condizem totalmente com a natureza do EEG e dos potenciais evocados, os quais são constituídos de múltiplos componentes cujas amplitudes e latências variam em função de diversos fatores. Brazier (1964) foi um dos primeiros autores a destacar o fato de que as diferentes latências dos potenciais evocados alteram as formas e amplitudes das médias coerentes. As variações das latências sobressaem, em especial, nos potenciais evocados endógenos, como o P300, pois estes são menos dependentes do momento em que ocorre o evento e mais do processamento cerebral que o procede (KUTAS; MCCARTHY; DONCHIN, 1977). Além disso, a premissa de que a atividade cerebral de fundo é aleatória e não está relacionada aos potenciais evocados não é verdadeira. E as componentes espectrais da atividade cerebral de fundo variam, por exemplo, em função do estado de consciência do indivíduo. Há também evidências 
de que certas oscilações presentes na atividade cerebral de fundo relacionam-se ao processamento de informação (SPENCER; POLICH, 1999; TALLON-BAUDRY; BERTRAND, 1999).

Os oito gráficos da figura 5.1 refletem claramente um crescente aumento do desempenho em função do tempo do algoritmo de reconhecimento de padrões, o qual verifica a presença nos sinais de EEG do potencial evocado P300. Considerando que, ao longo do tempo, a estratégia de reconhecimento, isto é, o algoritmo de reconhecimento de padrões permanece inalterado é justo dizer que a melhora do desempenho advém da aplicação da média coerente a uma quantidade cada vez maior de amostras de estímulos. De fato, a realização da média coerente torna os potenciais evocados mais perceptíveis e facilmente identificáveis. E é possível demonstrar (ver Apêndice A), considerando as hipóteses simplificadoras citadas anteriormente, que a relação sinal-ruído entre o potencial evocado e o ruído (atividade cerebral de fundo) aumenta proporcionalmente a $\sqrt{N}$, onde $N$ é o número de estímulos usados no cálculo da média coerente. Este comportamento teórico está ilustrado pela figura 5.4, que mostra a relação sinal-ruído em função do número de estímulos $N$ (entre 1 e 20).

As imagens, que possuem intervalos entre si de $400 \mathrm{~ms}$, são apresentadas em grupos de seis e, portanto, de 2,4s de duração por grupo. As médias coerentes das seis imagens diferentes podem então ser recalculadas usando um novo grupo de seis imagens a cada 2,4s. Desta forma, o número de estímulos $N$, aplicado ao cálculo das médias coerentes das seis imagens, aumenta em uma unidade a cada $2,4 \mathrm{~s}$.

Multiplicando-se os valores do eixo das abscissas do gráfico da figura 5.4, que mostra a relação sinal-ruído pelo número de estímulos, por 2,4 obtêm-se o tempo (em segundos) necessário para se conseguir melhorar a relação sinal-ruído em um determinado valor. Assim, observa-se que a maior relação sinal-ruído (aproximadamente 4,5) ocorre para $N=20$, isto é, após 48s.

Contudo, deve-se acentuar que o aumento da relação sinal-ruído varia segundo as características dos sinais de EEG e será sempre menor que o valor teórico (ilustrado pela figura 5.4), o qual só pode ser alcançado sob as condições simplificadoras ideais descritas anteriormente. 


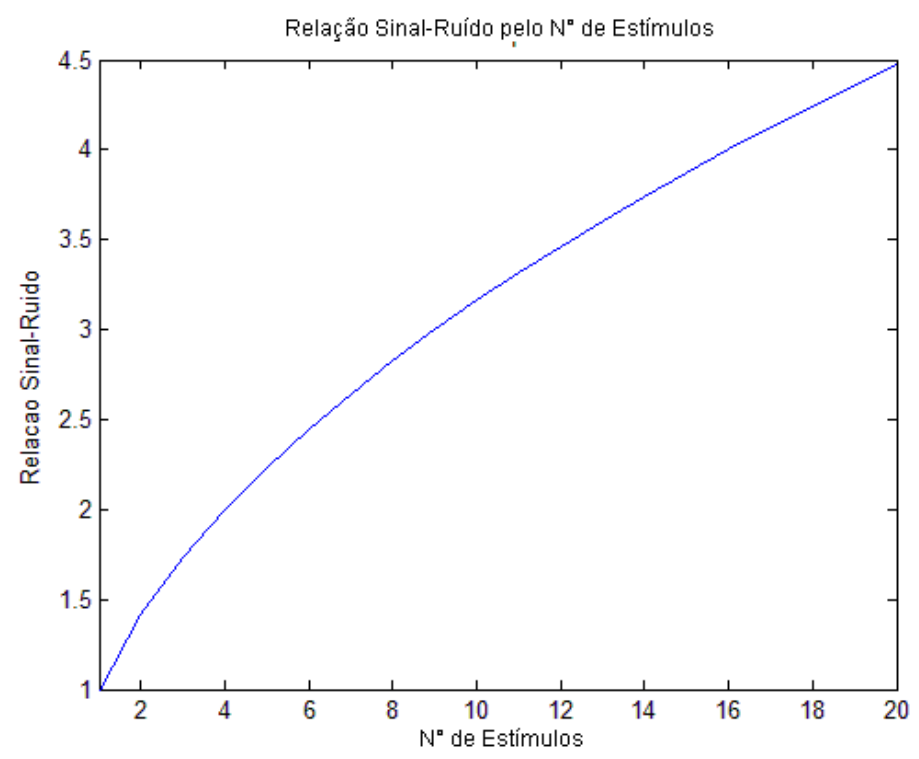

Figura 5.4 - Relação sinal-ruído em função do número de estímulos usados na média coerente

Apesar de a média coerente ter influenciado as relações sinal-ruído dos sinais de EEG de maneiras diferentes da mostrada pela figura 5.4 e não ter aumentado seus valores em 4,5 vezes (após 20 estímulos), visto que as condições simplificadoras ideais não estavam presentes, a média coerente trouxe um aumento significativo do desempenho médio dos oito sujeitos, que, segundo mostra a tabela 5.4 , partiu de $23,95 \%$ (após $2,4 \mathrm{~s}$ ) para $80,73 \%$ (após $48 \mathrm{~s}$ ).

Tabela 5.4 - Precisão do algoritmo (em porcentagem) para os oito sujeitos, aplicando-se a média coerente, após os períodos de 2,4 e 48s.

\begin{tabular}{llllllllll}
\hline$\underline{\text { Sujeito }}$ & $\underline{\text { S1 }}$ & $\underline{\text { S2 }}$ & $\underline{S 3}$ & $\underline{S 4}$ & $\underline{S 6}$ & $\underline{S 7}$ & $\underline{S 8}$ & $\underline{S 9}$ & Média \\
Tempo & & & & & & & & & \\
\hline $2,4 \mathrm{~s}$ & 4,2 & 8,3 & 8,3 & 4,2 & 33,3 & 45,8 & 54,2 & 33,3 & 23,95 \\
\hline $48 \mathrm{~s}$ & 75 & 83,3 & 91,7 & 50 & 70,8 & 100 & 95,8 & 79,2 & 80,73 \\
\hline
\end{tabular}

Admitindo que o reconhecimento do potencial evocado P300 pelo algoritmo classificador seja um fenômeno probabilístico, cuja freqüência de ocorrência pode ser aproximada pela razão entre o número de vezes em que o algoritmo classificador reconheceu o potencial evocado P300, isto é, identificou qual dos 6 
objetos foi escolhido, e o número de classificações realizadas, no caso, 6 rodadas $\mathrm{x}$ 4 sessões $=24$ classificações. Pode-se afirmar que os valores da tabela 5.4 referentes aos desempenhos dos classificadores refletem a probabilidade da BMI funcionar corretamente e, associar o objeto escolhido à presença do potencial evocado P300. As sucessivas apresentações de estímulos a cada 2,4s e respectivas classificações, embora pareçam proporcionar mais informações que permitiriam identificar o objeto escolhido, uma vez que dizem respeito à mesma escolha realizada sucessivas vezes, não podem promover um aumento efetivo do desempenho (probabilidade de acerto) ao longo do tempo porque são eventos probabilísticos independentes e o fato de ter acertado ou errado na classificação anterior não altera a probabilidade de acertar na classificação seguinte.

O aparente resultado paradoxal por efeito do acúmulo de resultados de classificações feitas sobre a mesma escolha acarreta flutuações das probabilidades de acerto. Entretanto ao longo do tempo o desempenho médio não deve variar e a razão entre o número de acertos e de classificações realizadas deve permanecer constante.

Assim, por exemplo, sendo a probabilidade de acerto do algoritmo classificador igual a $60 \%$ ( $\mathrm{P}$ (certo)=0,6 ) e tendo sido observados dois resultados idênticos de classificações, tais como "janela" na primeira e "janela" na segunda classificação, a probabilidade de que "janela" tenha sido o objeto escolhido $P(2$ certos | 2iguais) é dada por:

$$
P(2 \text { certos } \mid 2 \text { iguais })=\frac{P(2 \text { certos } \cap 2 \text { iguais })}{P(2 \text { iguais })}
$$

onde, $P(2$ certos $\cap 2$ iguais $)$ é a probabilidade de se obterem dois resultados corretos iguais, isto é, $0,6^{2}=0,36$.

e $P$ (2iguais) é a probabilidade de se obterem dois resultados iguais dos classificadores ("televisão e televisão", “janela e janela", "porta e porta", "rádio e rádio", "telefone e telefone" ou "lâmpada e lâmpada"). 
Sendo os possíveis resultados da primeira classificação dados pelos objetos do conjunto $\{A 1, A 2, A 3, A 4, A 5, A 6\}$ e os resultados da segunda classificação dados por $\{B 1, B 2, B 3, B 4, B 5, B 6\}$. Então, a probabilidade de se obterem objetos iguais dos dois classificadores $\mathrm{P}$ (iguais) é dada por:

$$
P(\text { iguais })=P(A 1 B 1 \cup A 2 B 2 \cup A 3 B 3 \cup A 4 B 4 \cup A 5 B 5 \cup A 6 B 6)
$$

considerando igual a $1 / 6$ a probabilidade de ter sido escolhido qualquer um dos seis objetos, vem:

$$
\begin{aligned}
& P(\text { iguais })=P(A 1 B 1 \cup A 2 B 2 \cup A 3 B 3 \cup A 4 B 4 \cup A 5 B 5 \cup A 6 B 6)=0,392 \\
& P(2 \text { certos } \mid 2 \text { iguais })=\frac{P(2 \text { certos } \cap 2 \text { iguais })}{P(2 \text { iguais })}=\frac{0,36}{0,392} \approx 91,84 \%
\end{aligned}
$$

Assim, embora a probabilidade de acerto do classificador seja de $60 \%$, caso sejam observados dois resultados idênticos, a probabilidade de que estejam certos é de aproximadamente $91,84 \%$. O fato da probabilidade de acerto do classificador ser de $60 \%$ implica que ao serem realizadas $\mathrm{N}$ classificações, observar-se-ão acertos em aproximadamente $60 \%$ das $\mathrm{N}$ vezes.

Desta forma, é justo atribuir à aplicação da média coerente os aumentos consecutivos da probabilidade de acerto dos algoritmos classificadores, ilustrados nos gráficos da figura 5.1. Pois não é possível estabelecer estratégia, com base nos resultados das ocorrências anteriores e na probabilidade de acerto do classificador, que promova um efetivo aumento ao longo do tempo da probabilidade de determinar corretamente qual objeto foi escolhido.

A média coerente promoveu aumentos dos desempenhos do classificador, que ocorreram de maneiras desiguais, mais acentuados nos casos dos indivíduos deficientes (S1 a S4), cuja probabilidade de acerto média aumentou 12 vezes, que passou de 6,25\% (após 2,4s) para 75\% (após 48s), e menos acentuados nos casos dos indivíduos saudáveis (S6 a S9), os quais tiveram uma melhora da probabilidade de acerto média de aproximadamente 2 vezes, que passou de 41,65\% (após 2,4s) para $86,45 \%$ (após 48s). 
Não obstante formas mais sofisticadas de média coerente, que levam em consideração as variações das latências dos potenciais evocados, tenham sido propostas na literatura (PICTON et al., 1988; WANG; BEGLEITER; PORJESZ, 2001; WOODY, 1967), são escassos os trabalhos em que estas técnicas são empregadas em BMIs. O trabalho de Liang e Bougrain (2008) compara os resultados de algoritmos de classificação de P300 usando três tipos de classificadores baseados em média coerente: média coerente convencional, média coerente precedida de correlação cruzada e média coerente precedida da técnica denominada Dynamic Time Warping. Contudo, no trabalho de Liang e Bougrain (2008) não são usadas estas médias coerentes para tornar mais bem definido o potencial evocado que será classificado por uma rede neural artificial ou máquina de vetor de suporte, como na experiência descrita nesta dissertação. Assim, não é possível fazer uma comparação direta dos desempenhos de classificadores do tipo empregado nesta dissertação para o uso de diferentes formas de médias coerentes. 


\section{Conclusões e propostas para futuros trabalhos}

\subsection{Sugestões para futuros trabalhos}

Este trabalho pretende ser ilustrativo sem ambicionar a concepção de um algoritmo capaz de rivalizar com o estado da arte no desempenho de classificadores. Trabalhos como, por exemplo, o de Costagliola, Dal Seno e Matteucci (2009), que emprega transformada Wavelet na extração de características e a técnica estatística de análise discriminante quadrática na classificação, atingem $100 \%$ de acerto na classificação do P300 usando apenas quatro repetições de estímulos no cálculo da média coerente. Diversos ajustes, deixados aqui como sugestões para trabalhos futuros, poderiam ser realizados a fim de obter desempenhos superiores no reconhecimento do potencial evocado P300:

- A escolha de eletrodos, diferente da realizada aqui, que considerou apenas oito (Fz, Cz, Oz, Pz, P3, P4, P7 e P8) dos 32 disponíveis nas amostras dos oito sujeitos, presentes no banco de dados;

- A aplicação de filtro espacial, que leve em consideração a distribuição topográfica dos eletrodos para atribuir diferentes pesos a cada um deles. Ou, de maneira análoga, a escolha dos respectivos pesos a serem aplicados às saídas das SVMs, para que o módulo de decisão Rx (ver figura 4.9) calcule uma média ponderada ao invés de uma média aritmética, observando as importâncias de cada um dos eletrodos para a detecção do P300;

- A escolha de diferentes freqüências de corte para o filtro passa-banda, que no caso eram de 1 e $12 \mathrm{~Hz}$ respectivamente. Ou a substituição deste filtro fixo por um filtro a posteriori, como o de Wiener, que se adapta às variações do espectro do EEG que ocorrem entre diferentes indivíduos e condições experimentais, e poderia eventualmente promover uma melhor separação dos sinais;

- A alteração do tipo de núcleo usado nas máquinas de vetor de suporte, que no caso foi o linear, e a determinação dos respectivos hiper-parâmetros por meio de validação cruzada poderia produzir uma melhor separação das 
classes e aumento na capacidade de reconhecimento do potencial evocado P300;

- O intervalo de tempo analisado pelas SVMs, que aqui foi demarcado entre 150 e 350ms após cada flash poderia ser ampliado, uma vez que o P300 pode aparecer em qualquer momento entre 250 e $900 \mathrm{~ms}$ após a apresentação do estímulo (DONCHIN et al., 1986).

É importante mencionar que o emprego da média coerente ou de suas variantes em uma BMI requer a apresentação de múltiplos estímulos, e além de acarretar perda de informação da dinâmica cortical, reduz da taxa efetiva de transmissão de informação. Por isso, despontou recentemente a tendência de desenvolvimento de BMls, que prescindem do uso da média coerente ou de suas variantes (BLANKERTZ; CURIO; MULLER, 2002; MULLER et al., 2008; PARRA et al., 2002; TOMIOKA; AIHARA; MULLER, 2006). O trabalho de Li et al. (2009) apresenta uma BMI que permite ao usuário digitar mentalmente um caractere, usando um teclado virtual e identifica o caractere escolhido por meio da detecção do potencial evocado P300, atinge um desempenho de $76,67 \%$ de acerto e dispensa 0 uso da média coerente. Assim, a concepção de um tipo diferente de classificador que dispense o emprego da média coerente e atinja um razoável desempenho na detecção do potencial evocado P300 justificaria a elaboração de um trabalho de nível de doutorado.

\subsection{Conclusões}

Esta dissertação logrou os objetivos definidos no primeiro capítulo. Revisou importantes contribuições para o desenvolvimento de interfaces cérebro-máquina, relacionou as correspondentes técnicas de pré-processamento, extração de características e classificação. Ilustrou, de maneira singela, através de técnicas de processamento de sinais implementadas em Matlab e usando amostras de sinais de EEG provenientes de um banco de dados externo, o funcionamento de uma BMI que permite ao usuário transmitir sua escolha mental a um computador. 
A experiência descrita neste trabalho demonstrou o uso de uma técnica moderna de classificação, a máquina de vetor de suporte, empregada com o propósito de reconhecer o potencial cerebral evocado P300. Foi evidenciado o papel crucial da média coerente para a melhora da relação sinal-ruído e viabilização do funcionamento da BMI. O experimento abdicou do emprego de técnicas mais refinadas de extração de características, como filtros espaciais, em favor de exemplificar de forma singela os fundamentos de uma BMI, não obstante sugestões de aperfeiçoamento do modelo tenham sido oferecidas na seção 6.1.

A pesquisa e o desenvolvimento de BMls exigem um esforço multidisciplinar, que envolve neurologistas, matemáticos, cientistas da computação, psicólogos e profissionais de reabilitação clínica. Apesar da maior parte da literatura publicada sobre BMI até hoje estar relacionada à engenharia e ao aperfeiçoamento de técnicas de processamento de sinais, a aproximação de engenheiros aos profissionais citados é essencial para o desenvolvimento de melhores interfaces cérebro-máquina (WOLPAW; BIRBAUMER, 2006).

Como campo de pesquisa e aplicação tecnológica o projeto de BMls encontra-se na sua infância e são prolíferos os esforços nas pesquisas em diversas áreas associadas às BMls, tais como: investigação de fenômenos cerebrais, técnicas de aquisição de sinais, métodos de extração de características, estratégias de adequação de curto e longo prazo do usuário à interface, validação clínica e suporte ao usuário. 


\section{REFERENCIAS}

ABE, K. et al. Cognitive function in amyotropic lateral sclerosis. J. Neurol. Sci., v. 148, p. 95-100, 1997.

ALLISON, B. et al. Towards an independent brain-computer interface using steady state visual evoked potentials. Clin. Neurophysiol., v. 119, p. 399-408, 2008.

ANDERSON, C.W.; SIJERCIC, Z. Classication of EEG signals from four subjects during five mental tasks. In: SOLVING ENGINEERING PROBLEMS WITH NEURAL NETWORKS. PROCEEDINGS OF THE INTERNATIONAL CONFERENCE ON ENGINEERING APPLICATIONS OF NEURAL NETWORKS, Turku, 1996.

ANDERSON, C.W.; STOLZ, E.A.; SHAMSUNDER, S. Multivariate autoregressive models for classification of spontaneous electroencephalographic signals during mental tasks. IEEE Transactions on Biomedical Engineering, v. 45, p. 277-286, 1998.

BAILLET, S.; MOSHER, J.; LEAHY, R. Electromagnetic brain mapping. IEEE Signal. Proc. Mag., v. 18, p. 14-30, 2001.

BARRETO, G.A.; FROTA, R.A.; DE MEDEIROS, F.N.S. On the classification of mental tasks: a performance comparison of neural and statistical approaches. In: PROCEEDINGS OF THE $14^{\text {TH }}$ IEEE WORKSHOP ON MACHINE LEARNING FOR SIGNAL PROCESSING, p. 529-538, 2004.

BASHASHATI, A. et al. A survey of signal processing algorithms in brain-computer interfaces based on electrical brain signals. J. Neural Eng., v. 4, p. 32-57, 2007.

BERGER, H. Über das Elektrenkephalogramm des Menschen. Archiv für Psychiatrie und Nervenkrankheiten, v. 87, p. 527-570, 1929.

BIRBAUMER, N. et al. A spelling device for the paralysed. Nature, v. 398, p. 297298, 1999.

BIRBAUMER, N. et al. The thought translation device (TTD) for completely paralyzed patients. IEEE Transactions on Rehabilitation Engineering, v. 8, p. 190-193, 2000. 
BIRBAUMER, N. Brain-computer-interface research: coming of age. Clin. Neurophysiol., v. 117 , p. 479-483, 2006a.

BIRBAUMER, N. Breaking the silence: Brain-computer interfaces (BCl) for communication and motor control. Psychophysiology, v. 43, p. 517-532, 2006b.

BIRBAUMER, N.; COHEN, L. Brain-computer interfaces: communication and restoration of movement in paralysis. J. Physiol., v. 579, p. 621-636, 2007.

BISHOP, C.M. Neural Networks for Pattern Recognition. Oxford University Press, 1996.

BLANKERTZ, B.; CURIO, G.; MÜLLER, K.R. Classifying single trial EEG: Towards brain computer interfacing. Advances in Neural Information Processing

Systems, v. 14, p. 157-164, 2002.

BLANKERTZ, B. et al. The Berlin brain-computer interface: EEG-based communication without subject training. IEEE Trans. Neural Sys. Rehab. Eng., v. 14, p. 147-152, 2006.

BLANKERTZ, B. et al. The non-invasive Berlin brain-computer interface: Fast acquisition of effective performance in untrained subjects. Neurolmage, v. 37, p. 539-550, 2007.

BOOSTANI, R. et al. A comparison approach toward finding the best feature and classifier in cue-based $\mathrm{BCl}$. Medical and Biological Engineering and Computing, v. 45, p. 403-412, 2007.

BOSTANOV, V. BCl competition 2003-data sets lb and Ilb: feature extraction from event-related brain potentials with the continuous wavelet transform and the t-value scalogram. IEEE Transactions on Biomedical Engineering, v. 51, p. 1057-1061, 2004.

BRAZIER, M. A. B. Evoked responses recorded from the depths of the human brain. Annals of the New York Academy of Sciences, v. 112, p. 33-59, 1964.

BRODU, N. Multifractal feature vectors for brain-computer interfaces. In: INTERNATIONAL JOINT CONFERENCE ON NEURAL NETWORKS, IJCNN, p. 2883-2890, 2008. 
BRUNNER, C. et al. Online control of a brain-computer interface using phase synchronization. IEEE Trans.Biomed. Eng., v. 53, p. 2501-2506, 2006.

BURKE, D.P. et al. A parametric feature extraction and classification strategy for brain-computer interfacing. IEEE Transactions on Neural Systems and Rehabilitation Engineering, v. 13, p. 12-17, 2005.

CABRERA, A.; DREMSTRUP, K. Auditory and spatial navigation imagery in braincomputer interface using optimized wavelets. J. Neurosci. Methods, v. 174, p. 135146, 2008.

CARIA, A. et al. Regulation of anterior insular cortex activity using real-time fMRI. Neurolmage, v. 35, p. 1238-1246, 2007.

CARMENA, J. et al. Learning to control a brain-machine interface for reaching and grasping by primates. PLoS Biol., v. 1, p. 1-16, 2003.

CARPENTER, G.A. et al. Fuzzy ARTMAP: A neural network architecture for incremental supervised learning of analog multidimensional maps. IEEE Transactions on Neural Networks, v. 3, p. 698-713, 1992.

CARUANA, R. Multitask learning: a knowledge-based source of inductive bias. In: PROC. 10TH INT. CONF. ON MACHINE LEARNING, University of Massachusetts, Amherst, p. 41-48, 1993.

CHANG, C.C.; LIN, C.J. Libsvm: a library for support vector machine. 2001. Software disponível em:

$<$ http://www.csie.ntu.edu.tw/ cjlin/libsvm>.

Acesso em: 02 dez. 2009.

CHATTERJEE, A. et al. A brain-computer interface with vibrotactile biofeedback for haptic information. J. Neuroeng. Rehabil., v. 4, p. 40, 2007.

CHENG, M. et al. Design and implementation of a brain-computer interface with high transfer rates. IEEE Transactions on Biomedical Engineering, v. 49, p. 11811186, 2002.

$\mathrm{CHOCHON}, \mathrm{F}$. et al. Differential contributions of the left and right inferior parietal lobules to number processing. J. Cogn. Neurosci., v. 11, p. 617-630, 1999. 
CONGEDO, M.; LOTTE, F.; LÉCUYER, A. Classification of movement intention by spatially filtered electromagnetic inverse solutions. Physics in Medicine and Biology, v. 51, p. 1971-1989, 2006.

COSTAGLIOLA, S.; DAL SENO, B.; MATTEUCCI, M. Recognition and classification of P300s EEG signals by means of feature extraction using wavelet decomposition. In: INTERNATIONAL JOINT CONFERENCE ON NEURAL NETWORKS, Atlanta, Georgia, 2009, p. 597-603, 2009.

COYLE, D.; PRASAD, G.; MCGINNITY, T.M. A time-frequency approach to feature extraction for a brain-computer interface with a comparative analysis of performance measures. EURASIP J. Appl. Signal Process., v. 2005, p. 3141-3151, 2005.

CURRAN, E. et al. Cognitive tasks for driving a brain-computer interfacing system: A pilot study. IEEE Trans. Neural Syst. Rehab. Eng., v. 12, p. 48-54, 2003.

CURRAN, E.; STOKES, M. Learning to control brain activity: A review of the production and control of EEG components for driving brain-computer interface $(\mathrm{BCl})$ systems. Brain Cogn., v. 51, p. 326-36, 2003.

De KRUIF, B.; SCHAEFER, R.; DESAIN, P. Classification of imagined beats for use in a brain-computer interface. In: PROC. 29TH ANN. INT. CONF. IEEE EMBS, LYON, FRANCE, p. 678-681, 2007.

DECHARMS, C. Applications of real-time fMRI. Nat. Rev. Neurosci., v. 9, p. 720729, 2008.

DELORME, A.; MAKEIG, S. EEGLAB: an open source toolbox for analysis of singletrial EEG dynamics. Journal of Neuroscience Methods, v. 134, p. 9-21, 2004.

DESAIN, $P$. et al. Detecting spread spectrum pseudo random noise tags in EEG/MEG using a structure-based decomposition.In: 4TH INT. BCI WORKSHOP AND TRAINING COURSE , Austria, 2008.

DIX, A. et al. Human-Computer Interaction. 3rd ed., Prentice-Hall, 2004.

DONCHIN, E. et al. Event related brain potentials in the study of consciousness. Consciousness and Self-Regulation, v. 3, Plenum, New York, p. 81-121, 1983. 
DORNHEGE, G. et al. Boosting bit rates in non-invasive EEG single-trial classifications by feature combination and multi-class paradigms. IEEE Transactions on Biomedical Engineering, v. 51, p. 993-1002, 2004.

DORNHEGE, G. et al. Combined optimization of spatial and temporal filters for improving brain-computer interfacing. IEEE Trans. Biomed. Eng., v. 53, p. 22742281, 2006.

DORNHEGE, G. et al. Oward Brain-Computer Interfacing. 1st ed., The MIT Press, 2007.

EBRAHIMI, T. Recent advances in brain-computer interfaces. In: $9^{\text {TH }}$ IEEE WORKSHOP ON MULTIMEDIA SIGNAL PROCESSING, p. 17-17, 2007.

FARWELL, L.; DONCHIN, E. Talking off the top of your head: toward a mental prosthesis utilizing event-related brain potentials. Electroencephalogr. Clin. Neurophysiol., v. 70, p. 510-523, 1988.

FELTON, E. et al. Neural signal based control of the dasher writing system. In: 3RD INT. IEEE/EMBS CONF. ON NEURAL ENGINEERING, p. 366-370, 2007.

FELZER, T.; FREISIEBEN, B. Analyzing EEG signals using the probability estimating guarded neural classifier. IEEE Transactions on Neural Systems and Rehabilitation Engineering, v. 11, p. 361-371, 2003.

FETZ, E. Operant conditioning of cortical unit activity. Science, v. 163, p. 955-958, 1969.

FORMISANO, E. et al. 'who' is saying 'what'? Brain-based decoding of human voice and speech. Science, v. 322, p. 970-973, 2008.

$\mathrm{GAO}, \mathrm{X}$ et al. A BCl-based environmental controller for the motion-disabled. IEEE Transactions on Neural Systems and Rehabilitation Engineering, v. 11, p. 137140, 2003.

GARCIA, G.N.; EBRAHIMI, T.; VESIN, J.M. Joint time-frequency-space classification of EEG in a brain-computer interface application. EURASIP J. Appl. Signal Process., v. 2003, p. 713-729, 2003. 
GARRETT, D. et al. Comparison of linear, nonlinear, and feature selection methods for EEG signal classification. IEEE Transactions on Neural System and Rehabilitation Engineering, v. 11, p. 141-144, 2003.

GAZZANIGA, M. The Cognitive Neurosciences III. $3^{\text {rd }}$ ed., MIT Press, 2004.

GERVEN et al. The brain-computer interface cycle. J. Neural Eng., v. 6, n. 4, 2009.

GERVEN, M.; JENSEN, O. Attention modulations of posterior alpha as a control signal for two-dimensional brain-computer interfaces. Journal of Neuroscience Methods, v. 179, Issue 1, p. 78-84, 2009.

GOUY-PAILLER, $\mathrm{C}$ et al. Topographical dynamics of brain connections for the design of asynchronous brain-computer interfaces. In: PROC. INT. CONF. IEEE ENGINEERING IN MEDICINE AND BIOLOGY SOCIETY (IEEE EMBC), p. 25202523, 2007.

GUGER, C. et al. Prosthetic control by an EEG-based brain-computer interface $(\mathrm{BCl})$. In: PROC. AAATE $5^{\mathrm{TH}}$ EUROPEAN CONFERENCE FOR THE ADVANCEMENT OF ASSISTIVE TECHNOLOGY, 1999.

GUGER, C. et al. How many people are able to control a P300-based brain-computer interface (BCl)? Neurosci Lett. , v. 462, n. 1, p. 94-98, 2009.

GYSELS, E.; CELKA, P. Phase synchronization for the recognition of mental tasks in a brain-computer interface. IEEE Transactions on Neural Systems and Rehabilitation Engineering, v. 12, p. 406-415, 2004.

HAMMON, P.S.; DE AS, V.R. Preprocessing and meta-classification for braincomputer interfaces. IEEE Transactions on Biomedical Engineering, v. 54, p. 518-525, 2007.

HASELSTEINER, E.; PFURTSCHELLER, G. Using time-dependant neural networks for EEG classification. IEEE transactions on rehabilitation engineering, v. 8, p. $457-463,2000$.

HAYKIN, S. Neural Networks: Comprehensive Foundation. I.E.E.E.Press; 2 Sub edition , 1999. 
HERMAN, P.; PRASAD, G.; MCGINNITY, T.M. Investigation of the type-2 fuzzy logic approach to classification in an EEG-based brain-computer interface. In: 27TH ANNUAL INTERNATIONAL CONFERENCE OF THE ENGINEERING IN MEDICINE AND BIOLOGY SOCIETY, 2005. IEEE-EMBS 2005, p. 5354- 5357, 2005.

HINTERBERGER, T. et al. Neuronal mechanisms underlying control of a braincomputer interface. Eur. J. Neurosci., v. 21, p. 3169-3181, 2005.

HJELM, S. The making of Brainball. Interactions, v. 10, p. 26-34, 2003.

HJORTH, B. An on-line transformation of EEG scalp potentials into orthogonal source derivations. Electroencephalogr. Clin. Neurophysiol., v. 39, p. 526-530, 1975.

HOCHBERG, L. et al. Neuronal ensemble control of prosthetic devices by a human with tetraplegia. Nature, v. 442, p. 164-171, 2006.

HOYA, T. et al. Classification of single trial EEG signals by a combined principal + independent component analysis and probabilistic neural network approach. In: PROCEEDINGS ICA 2003, p. 197-202, 2003.

HUAN, N.J.; PALANIAPPAN, R. Classification of mental tasks using fixed and adaptive autoregressive models of EEG signals. In: IEMBS '04. 26TH ANNUAL INTERNATIONAL CONFERENCE OF THE IEEE ENGINEERING IN MEDICINE AND BIOLOGY SOCIETY, p. 1-5, 2004.

HYVÄRINEN, A.; OJA, E. Independent component analysis: Algorithms and applications. Neural Networks, v. 13, p. 411-430, 2000.

JUTTEN, C.; HERAULT, J. Blind separation of sources, part I: An adaptive algorithm based on neuromimetic architecture. Signal Processing, v. 24, p.1-10, 1991.

KAUHANEN, L. et al. EEG and MEG brain-computer interface for tetraplegic patients. IEEE Transactions on Neural Systems and Rehabilitation Engineering, v. 14, p. 190-193, 2006.

KEIRN, Z.; AUNON, J. A new mode of communication between man and his surroundings. IEEE Trans. Biomed. Eng., v. 37, p. 1209-1214, 1990. 
KOHONEN, T. The self-organizing map. Proceedings of the IEEE, v. 78, p. 14641480, 1990.

KOLES, Z. The quantitative extraction and topographic mapping of the abnormal components in the clinical EEG. Electroencephalogr. Clin. Neurophysiol., v. 79, p. 440-447, 1991.

KÖNIG, P.; VERCHURE, P. F. M. J. Neuroscience: Neurons in action. Science, v. 296, p. 1817-1818, 2002.

KOSTOV, A.; POLAK, M. Parallel man-machine training in development of EEGbased cursor control. IEEE Transactions on Rehabilitation Engineering, v. 8, p. 203-205, 2000.

KRAULEDAT, M. et al. Improving speed and accuracy of brain-computer interfaces using readiness potential. Conf. Proc. IEEE Eng. Med. Biol. Soc., v. 6, p. 45114515, 2004.

KREPKI, R. et al. The Berlin brain-computer interface (BBCl)-towards a new communication channel for online control in gaming applications. Multimed. Tools. Appl., v. 33, p. 73-90, 2007.

KRUSIENSKI, D. et al. A comparison of classification techniques for the P300 speller. Journal of Neural Engineering, v. 3, p. 299-305, 2006.

KÜBLER, A.; BIRBAUMER, N. Brain-computer interfaces and communication in paralysis: extinction of goal directed thinking in completely paralysed patients? Clin. Neurophysiol., v. 119, p. 2658-2666, 2008.

KÜBLER, A. et al. Patients with ALS can use sensorimotor rhythms to operate a brain-computer interface. Neurology, v. 64, p. 1775-1777, 2005.

KÜBLER, A. et al. BCl meeting 2005-workshop on clinical issues and applications. IEEE Transactions on Neural Systems and Rehabilitation Engineering, v. 14, p. 131-134, 2006.

KUTAS, M.; MCCARTHY, G.; DONCHIN, E. Augmenting mental chronometry: The P300 as a measure of stimulus evaluation time. Science, v. 197, p. 292-295, 1977. 
$L A L, T$. et al. A brain-computer interface with online feedback based on magnetoencephalography. Proceedings of the International Conference on Machine Learning, p. 465-472, 2005.

LALOR, E. et al. Steady-state VEP-based brain-computer interface control in an immersive 3-D gaming environment. EURASIP journal on applied signal processing, v. 2005, p. 3156-3164, 2005.

LEEB, R. et al. Self-paced (asynchronous) $\mathrm{BCl}$ control of a wheelchair in virtual environments: a case study with a tetraplegic. Comput. Intell. Neurosci., v. 2007, ID 79642, 2007.

LEINS, U. et al. Neurofeedback for children with ADHD: a comparison of SCP and theta/beta protocols. Appl. Psychophysiol. Biofeedback, v. 32, p. 73-88, 2007.

LEMM, S. et al. Spatio-spectral filters for improving the classification of single trial EEG. IEEE Trans. BioMed.. Eng., v. 52, p. 1541-1548, 2005.

LEMM, S.; SCHAFER, C.; CURIO, G. BCI competition 2003-data set III: probabilistic modeling of sensorimotor mu rhythms for classification of imaginary hand movements. IEEE Transactions on Biomedical Engineering, v. 51, p. 1077-1080, 2004.

LEUTHARDT, E. et al. A brain-computer interface using electrocorticographic signals in humans. J. Neural. Eng., v. 1, p. 63-71, 2004.

LI, K. et al. Single Trial Independent Component Analysis for P300 BCl System. Conf. Proc. IEEE Eng. Biol. Soc., p. 4035-4038, v. 1, 2009.

LIANG, N.; BOUGRAIN, L. Averaging techniques for single-trial analysis of oddball event-related potentials. In: 4TH INTERNATIONAL BRAIN-COMPUTER INTERFACE WORKSHOP, Autriche Graz, 2008.

LOGOTHEIS, N. What we can do and what we cannot do with fMRI. Nature, v. 453, p. 869-878, 2008.

LOTTE, F. et al. A review of classification algorithms for EEG-based brain-computer interfaces. Journal of Neural Engineering, v. 4, p. 1-13, 2007. 
LOTTE, F.; LÉCUYER, A.; ARNALDI, B. FuRIA: A novel feature extraction algorithm for brain-computer interfaces using inverse models and fuzzy region of interest. In: PROC. OF THE $3^{\text {RD }}$ IEEE-EMBS INTERNATIONAL CONFERENCE ON NEURAL ENGINEERING, p. 175-178, 2007.

MACKAY, D.J.C. Information Theory, Inference, and Learning Algorithms. Cambridge University Press, 2003.

MARPLE, S.L. Digital Spectral Analysis. Prentice Hall, 1987.

MARTIN, J. Principles of neural science: The collective electrical behavior of cortical neurons: The electroencephalogram and the mechanisms of epilepsy.In: KANDEL, E.; SCHWARTZ, J.; JESSELL, T. Principles of Neural Science, Prentice Hall International, London, p. 777-790, 1991.

MARTINEZ, P.; BAKARDJIAN, H.; CICHOCKI, A. Fully online multicommand braincomputer interface with visual neurofeedback using SSVEP paradigm. Comput. Intell. Neuroscience, v. 2007, ID 94561, 2007.

MASON, S.; BIRCH, G. A general framework for brain-computer interface design. IEEE Transactions on Neural Systems and Rehabilitation Engineering, v. 11, p. 70-85, 2003.

MASON, S. et al. A comprehensive survey of brain interface technology designs. Ann. Biomed. Eng., v. 35, p. 137-169, 2007.

MCFARLAND, D. J. et al. Spatial filter selection for EEG-based communication. Electroencephalographic Clinical Neurophysiology, v. 103, p. 386-394, 1997.

MCFARLAND, D. J.; WOLPAW, J. R. EEG-based communication and control: speed-accuracy relationships. Appl. Psychophysiol. Biofeedback, v. 28, p. 217231, 2003.

MCFARLAND, D. J.; WOLPAW, J. R. Sensorimotor rhythm-based brain-computer interface $(\mathrm{BCl})$ : feature selection by regression improves performance. IEEE Trans. Neural Syst. Rehab. Eng., v. 13, p. 372-379, 2005.

MCMILLAN, G. et al. Direct brain interface utilizing self-regulation of steadystate visual evoked response. Proceedings of RESNA, p. 693-695, 1995. 
MICHEL, C.M. et al. EEG source imaging. Clin Neurophysiol., v. 115, p. 2195-2222, 2004.

MIDDENDORF, M. et al. Brain-computer interfaces based on the steady-state visualevoked response. IEEE Transactions on Rehabilitation Engineering, v. 8, p.211$214,2000$.

MILLÁN, J. R. et al. Local neural classifier for EEG-based recognition of mental tasks. In: IEEE-INNS-ENNS INTERNATIONAL JOINT CONFERENCE ON NEURAL NETWORKS, 2000.

MILLÁN, J. R. et al. Noninvasive brain-actuated control of a mobile robot by human EEG. IEEE Trans. Biomed. Eng., v. 51, p. 1026-1033, 2004.

MILLER, K. et al. Real-time functional brain mapping using electrocorticography. Neurolmage, v. 37, p. 504-507, 2007.

MINER, L.; McFarland, D.; Wolpaw, J. Answering questions with an electroencephalogram-based brain-computer interface. Arch. Phys. Med. Rehabil. v. 79 , p. $1029-1033,1998$.

MONTI et al. Willful Modulation of Brain Activity in Disorders of Consciousness. New England Journal of Medicine, v. 362, p. 579-589, 2010.

MORITZ, C.; PERLMUTER, S.; FETZ, E. Direct control of paralysed muscles by cortical neurons. Nature, v. 456, p. 639-642, 2008.

MORMANN, F. et al. On the predictability of epileptic seizures. Clin. Neurophysiol., v. 116, p. 569-587, 2005.

MÜLLER, K. et al. Machine learning techniques for brain-computer interfaces. Biomed. Tech., v. 49, p. 11-22, 2004.

MÜLLER, K. et al. Machine learning for real-time single-trial EEG analysis: From brain-computer interfacing to mental state monitoring. Journal of Neuroscience Methods, v. 167, p. 82-90, 2008. 
MÜLLER-PUTZ, G et al. Steady-state somatosensory evoked potentials: suitable brain signals for brain-computer interfaces. IEEE transactions on neural systems and rehabilitation engineering, v. 14, p. 30-37, 2006.

MÜLLER-PUTZ, G.; PFURTSCHELLER, G. Control of an electrical prosthesis with an SSVEP-based BCI. IEEE Transactions on Biomedical Engineering, v. 55, p. 361-364, 2008.

MÜNTE, T. Alteration of early components of the visual evoked potential in amyotrophic lateral sclerosis. J. Neurol., v. 245, p. 206-210, 1998.

MUSALLAM, S. et al. Cognitive control signals for neural prosthetics. Science, v. 305, p. 258-262, 2004.

National Institute of Biomedical Imaging and Bioengineering: Picture Gallery.

Disponível em:

$<$ http://www.nibib.nih.gov/publicPage.cfm?section=gallery\&action=desc\&page=5\&ph oto $=1>$

Acesso em 26 mar. 2010.

NICOLELIS, M. Actions from thoughts. Nature, v. 409, p. 403-407, 2001.

NICOLELIS, M. Brain-machine interfaces to restore motor function and probe neural circuits. Nat. Rev. Neurosci., v. 4, p. 417-422, 2003.

NICOLELIS, M.; CHAPIN, J. Controlling robots with the mind. Sci. Am., v. 287, p. 24-31, 2002.

NICOLELIS, M. et al. Chronic, multisite, multielectrode recordings in macaque monkeys. Proceedings of the National Academy of Sciences (PNAS), v. 100, p. 11041-11046, 2003.

NIEDERMEYER, E.; DA SILVA, F. Electroencephalography: Basic Principles, Clinical Applications, and Related Fields. Lippincott Williams \& Wilkins, 2004

NIELSEN, K.; CABRERA, A.; NASCIMENTO, O. EEG based BCI towards a better control. brain-computer interface research at aalborg university. IEEE Transactions on Neural Systems and Rehabilitation Engineering, v. 14, p. 202-204, 2006. 
NIJBOER, F. et al. An auditory brain-computer interface (BCl). J. Neurosci. Methods, v. 167, p. 43-50, 2007.

NOIRHOMME, Q.; KITNEY, R.I.; MACQ, B. Single trial EEG source reconstruction for brain-computer interface. IEEE Transactions on Biomedical Engineering, v. 55, p. 1592-1601, 2008.

OBERMEIER, B. et al. Hidden Markov models for online classification of single trial EEG. Patt. Recogn. Lett., v. 22, p. 1299-1309, 2001.

PARINI, S. et al. A Robust and Self-Paced BCI System Based on a Four Class SSVEP Paradigm: Algorithms and Protocols for a High-Transfer-Rate Direct Brain Communication. Comput Intell Neurosci., v. 2009, ID 864564, 2009.

PARRA, L. et al. Linear spatial integration for single-trial detection in encephalography. Neurolmage, v. 17, p. 223-230, 2002.

PENNY, W.D. et al. EEG-based communication: a pattern recognition approach. IEEE Transactions on Rehabilitation Engineering, v. 8, p. 214-215, 2000.

PERELMOUTER, J.; BIRBAUMER, N. A binary spelling interface with random errors. IEEE Trans. Neural Syst. Rehabil. Eng., v. 8, p. 227-232, 2000.

PETERSEN, S. et al. Positron emission tomographic studies of the cortical anatomy of single-word processing. Nature, v. 331, p. 585-589, 1988.

PICCIONE, F. et al. P300-based brain-computer interface: Reliability and performance in healthy and paralysed participants. Clin. Neurophysiol., v. 117, p. 531-537, 2006.

PICTON, T.W. et al. Evaluation of brainstem auditory evoked potentials using dynamic time warping, Electroen. Clin. Neuro., v. 71, p. 212-225, 1988.

PINEDA, J. et al. Learning to Control Brain Rhythms: Making a Brain-Computer Interface Possible. IEEE Transactions On Neural Systems and Rehabilitation Engineering, v. 11, n.2, p. 181-184, 2003. 
PFURTSCHELLER, G. et al. EEG-based discrimination between imagination of right and left hand movement. Electroencephalography and Clinical Neurophysiology, v. 103, p. 642-651, 1997.

PFURTSCHELLER, G. et al. Separability of EEG signals recorded during right and left motor imagery using adaptive autoregressive parameters. IEEE Transactions on Rehabilitation Engineering., v. 6, p. 316-325, 1998.

PFURTSCHELLER, G. EEG event-related desynchronization (ERD) and eventrelated synchronization (ERS). In: Niedermeyer, E.; Lopes da Silva, F. Electroencephalography: Basic Principles, Clinical Applications and Related Fields, Lippincott Williams \& Wilkins, 4th ed., p. 958-967, 1999.

PFURTSCHELLER, G. et al. Current trends in Graz brain-computer interface (BCl) research. IEEE Transactions on Rehabilitation Engineering, v. 8, p. 216-219, 2000.

PFURTSCHELLER, G. et al. Graz-BCl: state of the art and clinical applications. IEEE Transactions on Neural Systems and Rehabilitation Engineering, v. 11, p. 1-4, 2003.

PFURTSCHELLER, G. et al. Mu rhythm (de)synchronization and EEG single-trial classification of different motor imagery tasks. Neurolmage, v. 31, p. 153-159, 2006.

PFURTSCHELLER, G.; FLOTZINGER, D.; KALCHER, J. Brain-computer interface: a new communication device for handicapped persons. Journal of microcomputer application, v. 16, p. 293-299, 1993.

PFURTSCHELLER, G.; GRAIMANN, B.; NEUPER, C. Wiley Encyclopedia of Biomedical Engineering: EEG-Based Brain-Computer Interface System. John Wiley \& Sons, Inc., 2006.

PFURTSCHELLER, G.; LOPES DA SILVA, F. Event-related EEGMEG synchronization and desynchronization: basic principles. Clin. Neurophysiol., v. 110 , p. 1842-1857, 1999.

PFURTSCHELLER, G.; NEUPER, C. Motor imagery and direct brain-computer communication. Proceedings of the IEEE, v. 89, p. 1123-1134, 2001. 
POPESCU, F. et al. Single trial classification of motor imagination using 6 dry EEG electrodes. PLoS ONE, v. 2, p. 637, 2007.

QIN, J.; LI, Y.; CICHOCKI, A. ICA and committee machine-based algorithm for cursor control in a $\mathrm{BCl}$ system. Lecture notes in computer science, p. 973-978, 2005.

RABINER, R.L. A tutorial on hidden markov models and selected applications in speech recognition. Proceedings of the IEEE, v. 77, p. 257-286, 1989.

RAINA, R.; NG, A.; KOLLER, D. Constructing informative priors using transfer learning. In: PROC. 23RD INT. CONF. ON MACHINE LEARNING, p. 713-720, 2006.

RAMOSER, H.; MULLER-GERKING, J.; PFURTSCHELLER, G. Optimal spatial filtering of single trial EEG during imagined hand movement. IEEE Transactions on Rehabilitation Engineering, v. 8, p. 441-446, 2000.

RAMSEY, $\mathrm{N}$. et al. Towards human $\mathrm{BCl}$ applications based on cognitive brain systems: an investigation of neural signals recorded from the dorsolateral prefrontal cortex. IEEE Trans. Neural Syst. Rehabil. Eng., v. 14, p. 214-217, 2006.

REGAN, D. Steady-state evoked potentials. J. Opt. Soc. Am., v. 11, p. 1475-1489, 1977.

REZEK, I.; ROBERTS, S.; CONRADT, R. Increasing the depth of anesthesia assessment. IEEE Eng. Med. Biol. Mag., v. 26, p. 64-73, 2007.

RIPPON, G. et al. An observational study of cognitive impairment in amyotrophic lateral sclerosis. Arch. Neurol., v. 63, p. 345-352, 2006.

RIVET, B.; SOULOUMIAC, A. Subspace estimation approach to P300 detection and application to brain-computer interface. In: PROC. INT. CONF. IEEE ENGINEERING IN MEDICINE AND BIOLOGY SOCIETY (IEEE EMBC), p. 5071-5074, 2007.

ROCKSTROH, B. et al. Slow Cortical Potentials and Behavior. $2^{\text {nd }}$ ed., Urban \& Schwarzenberg, 1989.

SAMAR, V.J. et al. Wavelet analysis of neuroelectric waveforms: A conceptual tutorial. Brain and Language, v. 66, p. 7-60, 1999. 
SANEI, S.; CHAMBERS, J.A. EEG Signal processing, John Wiley \& Sons, 2007.

SCHAEFER, R. et al. Detecting imagined music from EEG. In: $10^{\mathrm{TH}}$ PROC. INT. CONF. OF MUSIC PERCEPTION AND COGNITION, 2008.

SCHALK, G. et al. EEG-based communication: presence of an error potential. Clin. Neurophysiol., v. 111, p. 2138-2144, 2000.

SCHALK, G. Two-dimensional movement control using electrocorticographic signals in humans. J. Neural Eng., v. 5, p. 75-84, 2008.

SCHERER, R. et al. An asynchronously controlled EEG-based virtual keyboard: Improvement of the spelling rate. IEEE Transactions on Biomedical Engineering, v. 51, p. 979-984, 2004.

SCHERER, R. et al. The self-paced Graz brain-computer interface: methods and applications. Comput. Intell. Neurosci., v. 2007, ID 79826, 2007.

SCHWARTZ, A. Cortical neural prostheses. Ann. Rev. Neurosci., v. 27, p. 487-507, 2004.

SCHWARTZ, A. et al. Brain-controlled interfaces: Movement restoration with neural prosthetics. Neuron., v. 52, p. 205-220, 2006.

SEPULVEDA, F. et al. A comparison of mental task combinations for asynchronous EEG-based BCl's. In: PROC. OF THE IEEE EMBS, France, p. 5055-5058, 2007.

SELLERS, E.; DONCHIN, E. A P300-based brain-computer interface: initial tests by ALS patients. Clin. Neurophysiol., v. 117, p. 538-548, 2006.

SHENOY, P; RAO, R. Dynamic Bayesian networks for brain-computer interfaces. Advances in Neural Information Processing Systems, v. 17, p. 1265-1272, 2005.

SITARAM, R. et al. Temporal classification of multichannel near-infrared spectroscopy signals of motor imagery for developing a brain-computer interface. Neurolmage, v. 34, p. 1416-1427, 2007. 
SMITH, S.W. The Scientist \& Engineer's Guide to Digital Signal Processing. ISBN 0-9660176-3-3, 1997.

SOLIS-ESCALANTE, T.; GENTILETTI, G.; YANEZ-SUAREZ, O. Detection of steadystate visual evoked potentials based on the multisignal classification algorithm. In: 3RD INTERNATIONAL IEEE/EMBS CONFERENCE ON NEURAL ENGINEERING CNE '07, p. 184-187, 2007.

SPENCER, K.M.; POLICH, J. Poststimulus EEG spectral analysis and P300: Attention, task, and probability. Psychophysiology, v. 36, p. 220-232, 1999.

STAM, C. Nonlinear dynamical analysis of EEG and MEG: review of an emerging field. Clin. Neurophysiol., v. 116, p. 2266-2301, 2005.

STONE, J.V. The Encyclopedia of Statistics in Behavioral Science: Independent Component Analysis. Wiley, 2005.

SYKACEK, P.; ROBERTS, S.; STOKES, M. Adaptive $\mathrm{BCl}$ based on variational Bayesian Kalman filtering: an empirical evaluation. IEEE Trans. Biomed. Eng., v. 51, p. 719-729, 2004.

TALLON-BAUDRY, C.; BERTRAND, O. Oscillatory gamma activity in humans and its role in object representation. Trends in Cognitive Sciences, v. 3, p. 151-162, 1999.

TOMIOKA, R.; AIHARA, K.; MULLER, K. Logistic regression for single trial EEG classification. Advances in Neural Inf. Proc. Systems, v. 19, p. 1377-1384, 2006.

TORO, C. et al. Event-related desynchronization and movement-related cortical potentials on the ECoG and EEG. Electroencephalogr. Clin. Neurophysiol., v. 93, p. 380-389, 1994.

TOUYAMA, H.; HIROSE, M. Steady-state VEPs in CAVE for walking around the virtual world. HCI, v. 6, p. 715-717, 2007.

TREJO, L.; ROSIPAL, R.; MATTHHEWS, B. Brain-computer interfaces for 1-D and 2$D$ cursor control: designs using volitional control of the EEG spectrum or steady-state visual evoked potentials. IEEE Transactions on Neural Systems and Rehabilitation Engineering, v. 14, p. 225-229, 2006. 
VAN GERVEN, M. et al. Interpreting single trial data using groupwise regularization. Neuroimage, v. 46, p. 665-676, 2009.

VAN GERVEN, M.; JENSEN, O. Attention modulations of posterior alpha as a control signal for two-dimensional brain-computer interfaces. J. Neurosci. Methods, v. 179 p. 78-84, 2009.

VANACKER, G. et al. Context-based filtering for assisted brain-actuated wheelchair driving. Comput. Intell. Neurosci., v. 2007, ID 25130, 2007.

VAUGHAN, $\mathrm{T}$. et al. The Wadsworth $\mathrm{BCl}$ research and development program: at home with $\mathrm{BCl}$. IEEE Transactions on Neural Systems and Rehabilitation Engineering, v. 14, p. 229-233, 2006.

VELLISTE, M. et al. Cortical control of a prosthetic arm for self-feeding. Nature, v. 453, p. 1098-1101, 2008.

VIDAL, J. Real-time detection of brain events in EEG. Proc. IEEE, v. 65, p. 633-641, 1977.

VIDAURRE, C. et al. A fully on-line adaptive BCI. IEEE Trans. Biomed. Eng., v. 53, p. 1214-1219, 2006.

WANG, K.; BEGLEITER, H.; PORJESZ, B. Warp-averaging event-related potentials. Clinical Neurophysiology, v. 112, p. 1917-1924, 2001.

WEISKOPF, N. et al. Self-regulation of local brain activity using real-time functional magnetic resonance imaging (fMRI). J. Physiol., v. 98, p. 357-73, 2004.

WOLPAW, J. R. Brain-computer interfaces as new brain output pathways. J. Physiol., v. 579, p. 613-619, 2007.

WOLPAW, J. R. et al. An EEG based brain-computer interface for cursor control. Electroencephalography and clinical neurophysiology, v. 78, p. 252-259, 1991.

WOLPAW, J. R. et al. Brain-computer interfaces for communication and control. Clinical Neurophysiology, Ireland: Elsevier. v. 113, p. 767-791, 2002. 
WOLPAW, J. R. et al. BCl meeting 2005-workshop on signals and recording methods. IEEE Transaction on Neural Systems and Rehabilitation Engineering., v. 14, p. $138-141,2006$.

WOLPAW, J. R.; MCFARLAND, D. Control of a two-dimensional movement signal by a noninvasive brain-computer interface in humans. Proc. Natl. Acad. Sci., v. 101, p. 17849-17854, 2004.

WONG, D. et al. Quantifying inter-subject agreement in brain-imaging analyses. Neuroimage, v. 39, p. 1051-1063, 2008.

WOODY, C. D. Characterization of an adaptive filter for the analysis of variable latency neuroelectric signals. Med. Biol. Eng., v. 5, p. 539-553, 1967.

WOON, W.; CICHOKI, A. Novel features for brain-computer interfaces. Comput. Intell. Neurosci., v. 2007, 82827-1--82827-7, 2007.

WU, W.; GAO, X.; GAO, S. One-versus-the-rest (OVR) algorithm: An extension of common spatial patterns(CSP) algorithm to multi-class case. In: 27TH ANNUAL INTERNATIONAL CONFERENCE OF THE ENGINEERING IN MEDICINE AND BIOLOGY SOCIETY IEEE-EMBS 2005, p. 2387- 2390, 2005.

ZHANG, D. et al. An independent brain-computer interface using covert non-spatial visual selective attention. J Neural Eng., v. 7, ID 16010, 2010. 


\section{APÊNDICE A - Demonstração do efeito da média coerente}

A técnica da média coerente, conhecida na literatura estrangeira por averaging, é uma operação no domínio do tempo muito usada em processamento de sinais de EEG para facilitar a observação de componentes de sinais que estão escondidos em ruídos. Esta técnica assume que:

- A componente do sinal que deseja observar e o ruído não estão correlacionados;

- É conhecido o momento em que a componente tem início;

- Ao realizar-se repetidas medidas podem-se encontrar as mesmas componentes;

- O ruído é aleatório e tem média igual à zero.

No mundo real as condições acima podem não ser todas verdadeiras, contudo a técnica tem se mostrado robusta e sob condições aproximadas tem apresentado resultados satisfatórios.

A média coerente, usada para intensificar componentes do sinal em meio a ruídos, pode ser representada por:

$$
x_{j}=s_{j}+n_{j}
$$

onde, $x$ consiste no sinal medido, $s$ na componente e $n$ no ruído, das $j$-ésimas amostras digitalizadas. Supõe-se possível realizar as medidas $N$ vezes consecutivas. $O$ valor $r m s$ de $s$ pode ser várias ordens de magnitude menor que 0 valor $r m s$ de $n$, o que significa que o componente $s$ pode ser praticamente invisível dentro do sinal $x$. A média coerente de $x$, para $N$ medidas é dada pela eq.(2):

$$
\dot{x}=\frac{1}{N} \cdot \sum_{j=1}^{N}\left[s_{j}+n_{j}\right]
$$

Supondo que o ruído $n$ da eq.(2) tenha média igual à zero, temos:

$\langle x(k)\rangle=\langle s(k)>+0$, onde $<. .>$ indica o valor real da variável, isto é, aquele que seria obtido fazendo-se a média de um número $N$ muito grande de amostras $(N \rightarrow \infty)$.

Desta forma, o benefício da média coerente é reduzir o ruído $n(n \rightarrow \infty)$ para valores grandes de $N$. Isto é, a média coerente faz com que $x_{N} \rightarrow \infty s_{N}$. Entretanto, dado que no mundo real $N<<\infty$, a situação ideal não é alcançada e $x$ não se torna 
igual à $s$, e existe uma diferença residual caracterizada pela variância de $\dot{x}$, isto é, $\operatorname{Var}\left(\dot{x}_{N}\right)$ que é igual ao quadrado do desvio padrão de $\dot{x}$.

O segundo momento central de uma distribuição aleatória é igual à variância da distribuição. Isto é:

$$
E\left\{(x-<x>)^{2}\right\}=\operatorname{Var}(x)
$$

onde, $E$ é esperança matemática. Substituindo $x$ por $\dot{x}$, tem-se:

$$
\operatorname{Var}(\dot{x})=E\left\{(\dot{x}-<x>)^{2}\right\}=E\left\{\dot{x}^{2}-2 \cdot \dot{x} \cdot<x>+<x>^{2}\right\}
$$

Sabendo que $<x>$ representa o valor real de $x$, tem-se $E\{<x>\}=<x>$ e $\left.E\{<x\rangle^{2}\right\}=\langle x\rangle^{2}$. Logo,

$$
E\left\{\dot{x}^{2}-2 \cdot \dot{x} \cdot<x>+<x>^{2}\right\}=E\left\{\dot{x}^{2}\right\}-2 \cdot<x>\cdot E\{\dot{x}\}+<x>^{2}
$$

Como a esperança de $\dot{x}$ é igual $a<x>$, isto é, $E\{\dot{x}\}=\langle x>$ vem:

$$
\operatorname{Var}(\dot{x})=E\left\{\dot{x}^{2}\right\}-<x>^{2}
$$

Combinando as eq.(2) e eq.(6) vem:

$$
\begin{aligned}
& \operatorname{Var}(\dot{x})=E\left\{\left[\frac{1}{N} \cdot \sum_{i=1}^{N} x_{i}\right]^{2}\right\}-<x>^{2}=E\left\{\left[\frac{1}{N} \cdot \sum_{j=1}^{N} x_{j}\right] \cdot\left[\frac{1}{N} \cdot \sum_{i=1}^{N} x_{i}\right]\right\}-<x>^{2}= \\
& =\frac{1}{N^{2}} \cdot \sum_{j=1}^{N} \sum_{i=1}^{N} E\left\{x_{j} \cdot x_{i}\right\}-<x>^{2}
\end{aligned}
$$

Os dois somatórios da eq.(7) envolvem todas as combinações de $i$ e $j$ de zero a $\mathrm{N}$, o que implica em $\mathrm{N}^{2}$ combinações. Estas combinações podem ser separadas em dois conjuntos: um com $\mathrm{N}$ termos, tais que $i=j$, e outro com $\mathrm{N}^{2}-\mathrm{N}$ termos, tais que $i \neq j$. Assim, tem-se:

$$
\begin{gathered}
\operatorname{Var}(\dot{x})=\frac{1}{N^{2}} \sum_{j=1}^{N} E\left\{x_{j}^{2}\right\}+\frac{1}{N^{2}} \sum_{j=1}^{N} \sum_{i=1}^{N} E\left\{x_{j} \cdot x_{i}\right\}-<x>^{2} \\
N \text { termos } i=j \quad N(N-1) \text { termos } i \neq j
\end{gathered}
$$

A partir da eq.(1) e admitindo que $E\left\{2 s_{j} n_{j}\right\}=2 E\left\{s_{j}\right\} E\left\{n_{j}\right\}$, pois o ruído e a componente são independentes, pode-se reescrever o valor do somatório de $N$ termos $i=j$ da eq.(8) acima como:

$$
E\left\{x_{j}^{2}\right\}=E\left\{\left[s_{j}+n_{j}\right]^{2}\right\}=E\left\{s_{j}^{2}\right\}+2 \cdot E\left\{s_{j}\right\} \cdot E\left\{n_{j}\right\}+E\left\{n_{j}^{2}\right\}
$$

Assumindo que o ruído $n_{j}$ tem média nula e variância $\sigma_{\mathrm{n}}{ }^{2}$, isto é, $\mathrm{E}\left\{n_{j}\right\}=0$ e $\mathrm{E}\left\{n_{j}{ }^{2}\right\}=\sigma_{\mathrm{n}}{ }^{2}$ vem:

$$
E\left\{x_{j}^{2}\right\}=E\left\{s_{j}^{2}\right\}+\sigma_{n}^{2}
$$


A variância da componente $\left(\sigma_{n}{ }^{2}\right)$ é dada por $\sigma_{n}{ }^{2}=E\left\{s_{j}^{2}\right\}-\langle s\rangle^{2}$, que substituído na eq.(10) fornece:

$$
E\left\{x_{j}^{2}\right\}=\sigma_{s}^{2}+<s>^{2}+\sigma_{n}^{2}
$$

Combinando as eq.(1) e eq.(8) é possível reescrever a parte com $N(N-1)$ termos da eq.(8) como:

$$
\left.E\left\{x_{j} x_{i}\right\}=E\left\{s_{j}+n_{j}\right] \cdot\left[s_{i}+n_{i}\right]\right\}=E\left\{s_{j} s_{i}\right\}+E\left\{n_{j} n_{i}\right\}+E\left\{s_{j} n_{i}\right\}+E\left\{s_{i} n_{j}\right\}
$$

Assumindo que o ruído e a componente são estatisticamente independentes e que os ruídos e as componentes são independentes entre as medidas realizadas ( $i$ e j), é possível reescrever as esperanças matemáticas combinadas da eq.(12) como produtos de esperanças individuais:

$$
\begin{aligned}
& E\left\{s_{j} s_{i}\right\}=E\left\{s_{j}\right\} E\left\{s_{i}\right\}=<s>\times<s>=<s>^{2} \\
& E\left\{n_{j} n_{i}\right\}=E\left\{n_{j}\right\} E\left\{n_{i}\right\}=0 \times 0=0 \\
& E\left\{s_{j} n_{i}\right\}=E\left\{s_{j}\right\} E\left\{n_{i}\right\}=<s>\times 0=0 \\
& E\left\{s_{i} n_{j}\right\}=E\left\{s_{i}\right\} E\left\{n_{j}\right\}=<s>\times 0=0
\end{aligned}
$$

Substituindo a eq.(11) para os $N$ termos $i=j$ e as eq.(12) e eq.(13) para os $N(N-1)$ termos $i \neq j$ na eq.(8), obtêm-se o seguinte valor para a variância de $\dot{x}$ :

$$
\operatorname{Var}(\dot{x})=\frac{1}{N^{2}} \cdot\left[N\left(\sigma_{s}^{2}+<s>^{2}+\sigma_{n}^{2}\right)+\left(N^{2}-N\right) \cdot<s>^{2}\right]-<x>^{2}
$$

Considerando $<n>=0$ e que o valor verdadeiro da medida $x$ é igual à média da componente $s$, isto é, $\langle x\rangle=\langle s\rangle$. É possível escrever:

$$
\operatorname{Var}(\dot{x})=\frac{1}{N^{2}} \cdot\left[N\left(\sigma_{s}^{2}+<s>^{2}+\sigma_{n}^{2}\right)+\left(N^{2}-N\right) \cdot<s>^{2}\right]-<s>^{2}
$$

A eq.(15) equivale à:

$$
\operatorname{Var}(\dot{x})=\frac{\sigma_{s}^{2}+\sigma_{n}^{2}}{N}
$$

A eq.(16) acima fornece o valor da variância da média $(\dot{x})$, e revela que a estimativa do valor médio aumenta com o número de repetições das medidas $N$. No caso, as variâncias $\sigma_{\mathrm{s}}{ }^{2}$ e $\sigma_{\mathrm{n}}{ }^{2}$ são provenientes de duas fontes independentes. Assim, o efeito composto das duas fontes é dado pela soma das variâncias. A raiz quadrada da eq.(16) fornece o desvio padrão da média. Deste modo, conclui-se que a estimativa da componente $s$ melhora com $\frac{1}{\sqrt{N}}$. 